Juan Enrique Faya Castillo

\title{
ANÁLISE ESTRUTURAL DE SÍTIOS DE FOSFORILAÇÃO EM PROTEÍNAS
}


Juan Enrique Faya Castillo

\title{
ANÁLISE ESTRUTURAL DE SÍTIOS DE FOSFORILAÇÃO EM PROTEÍNAS
}

\author{
Dissertação de mestrado. Requisito para a \\ obtenção do título de Mestre em Ciências \\ no programa de Bioinformática. \\ Universidade de São Paulo - USP \\ Instituto de Matemática e Estatística - IME \\ Programa de Pós-Graduação Interunidades em Bioinformática
}

Orientador: Paulo Sérgio Lopes de Oliveira

Brasil

2019 


\section{DEDICATÓRIA}

Aos meus pais, Margarita Castillo Severino e Enrique Faya Guerrero, por seu apoio incondicional e esforço diário que me permitiu cumprir o prometido, suas palavras sempre eram as indicadas para seguir de pé ao longo deste caminho escolhido. À minha família, por ser sempre um exemplo para mim. A Aracelly L. Gómez Ojeda por todo o apoio moral neste tempo e por escutar pacientemente por longas horas meus problemas e comemorar meus logros como se fossem próprios.

\section{DEDICATORIA}

A mis padres, Margarita Castillo Severino y Enrique Faya Guerrero, por su apoyo incondicional y esfuerzo diario que me permitió salir adelante, sus palabras siempre fueron las indicadas para seguir de pie a lo largo de este camino elegido. A mi familia, por ser siempre un ejemplo para mi. A Aracelly L. Gómez Ojeda por todo el apoyo moral durante todo este tiempo y por escucharme pacientemente por escuchar mis problemas por largas horas y por celebrar mis logros como si fueran propios. 


\section{AGRADECIMENTOS}

Ao meu orientador, Dr. Paulo Sergio Lopes de Oliveira, por me permitir ser parte deste projeto e ser parte de seu grupo de trabalho. Estarei sempre agradecido a você pela oportunidade de aprender coisas novas e abrir meus horizontes, e pelo seu tempo dedicado ao progresso do trabalho.

Aos meus amigos do Laboratório de Biologia Computacional, José Carvalho, João Guerra, María Negret, Leandro Bortot, Rodrigo Honorato que foi do grupo, e especialmente a Helder Veras Filho, por se comportar como um co-orientador ao longo do projeto mesmo tendo muito trabalho por fazer, e Mariana Grizante por todo seu apoio na correção da redação do texto, sem a sua ajuda tudo teria sido mais complicado. Todos vocês fizeram com que cada dia fosse diferente, suas dicas e conselhos sempre foram bem recebidos.

A Guillermo Uceda, Edgar Llontop e Edwin Neciosup, meus amigos, com quem compartilhei momentos agradáveis.

Finalmente, agradeço a Pós-Graduação do Instituto de Matemática e Estatística, aos membros do Programa de Bioinformática, ao Laboratório Nacional de Biociências, ao Centro Nacional de Pesquisa em Energia e Materiais, e à Coordenação de Aperfeiçoamento de Pessoal de Nível Superior - CAPES, por terem viabilizado este trabalho. 


\section{RESUMO}

A fosforilação de proteínas realizada pelas Proteínas-Quinases (PKs) é uma das modificações pós-transducional mais comuns envolvidas em muitos processos fisiológicos e patológicos. Um dos passos mais importantes na reação catalítica das PKs com o substrato é o posicionamento correto do resíduo alvo (serina, treonina ou tirosina), o sítio-P, no sítio ativo. Este processo é mediado por regiões encontradas no sítio de ligação do substrato, uma fenda pouco profunda que tem sub-bolsões críticos especialmente formados para ancorar aminoácidos distantes do sítio-P do substrato, aqui denominados âncoras. Nesse contexto, um mecanismo tem sido constantemente descrito e aceito como essencial para a coordenação de quinases e proteína-substrato o chamado consenso linear de fosforilação, isto é, aminoácidos conservados em posições específicas na estrutura primária da proteína ao redor do sítio-P (P-2 e P-3), que ajudam a ancorar a proteína-substrato nas PKs. Neste trabalho, foi testada e corroborada a hipótese de que, para que os aminoácidos nas posições P-2 ou P-3 cumpram um papel de âncoras lineares e o sítio de fosforilação seja fosforilado, mudanças estruturais locais devem ocorrer antes da fosforilação. Para essa avaliação, utilizando substratos de Quinases (PKA e PKC), foi constatado que as $\alpha$-hélice são um bom alvo de estudo por apresentarem sítios P com maior disposição para a fosforilação do que outras estruturas secundárias dentro de nosso conjunto de dados. Para confirmar que neste tipo de estrutura secundária, relativamente rígida e bem definida espacialmente, ocorrem rearranjos estruturais préfosforilação, foram usadas ferramentas de biologia computacional estrutural como modelagem por homologia, dinâmicas Coarse Grained e All Atom, e Docking Molecular. Os resultados revelam que os rearranjos conformacionais que permitem que P-2 e P-3 sejam possíveis âncoras são mais ou menos substanciais dependendo da posição do sítio $\mathrm{P}$ dentro da $\alpha$-hélice. Se o sítio P se encontrar na região $\mathrm{N}$-terminal (nas duas primeiras voltas ou perto delas), a $\alpha$-hélice não sofrerá mudanças conformacionais substanciais, diferente de quando ele se encontra em outra posição dentro da $\alpha$-hélice. Neste trabalho buscamos entender como préeventos de processos de modificação pós-traducional são dependentes da estrutura local de proteínas, e como esses eventos podem levar a alterações temporárias nestas estruturas, contribuindo para aprofundar os conhecimentos gerais na área de fosforilação.

Palavras Chaves: Proteinas - Quinases (Pks), a-hélice, Fosforilação, Consenso linear de Fosforilação, Biologia Computacional, Ferramentas de Biologia Computacional. 


\begin{abstract}
Protein phosphorylation performed by Protein Kinases (PKs) is one of the most common post-translational modifications involved in many physiological and pathological processes. One of the most important steps in the catalytic reaction of the PKs with the substrate is the correct positioning of the target residue (serine, threonine or tyrosine), the Psite, in the active site. This process is mediated by regions found at the substrate binding site, a shallow slit having critical sub-pockets specially formed to anchor amino acids distant from the P-site of the substrate, herein referred to as anchors. In this context, a mechanism has been constantly described and accepted as essential for the coordination of kinases and proteinsubstrate, so-called linear consensus of phosphorylation, that are amino acids conserved at specific positions in the primary structure of the protein around the P-site ( $\mathrm{P}-2$ and $\mathrm{P}-3)$, which help anchoring protein-substrate in PKs. In this work, we tested and corroborated the hypothesis that, for those amino acids at the P-2 or P-3 positions to play a role as linear anchors allowing the phosphorylation site to be phosphorylated, local structural changes must occur prior to phosphorylation. For this evaluation, using kinases (PKA and PKC) substrates, it was found that $\alpha$-helices are a good target of study because they present P-sites with more disposition for phosphorylation than other secondary structures within our data set. To confirm that in this secondary structure, which is relatively rigid and spatially defined, structural pre-phosphorylation rearrangements do occur, we used structural computational biology tools such as homology modeling, Coarse Grained and All Atom dynamics, and Molecular Docking. Results show that the conformational rearrangements that allow P-2 and P-3 to be possible anchors are more or less substantial depending on the position of the P-site within the $\alpha$-helix. If the $\mathrm{P}$-site is in the $\mathrm{N}$-terminal region (or near the first two turns), the $\alpha$ helix will not undergo substantial conformational changes, unlike when it is found in other positions within the $\alpha$-helix. In this work we aimed to understand how pre-events of posttranslational modification processes are dependent on the local structure of proteins, and how these events may lead to temporary changes in these structures, contributing to deepen general knowledge in the field of phosphorylation.
\end{abstract}

Keywords: Protein Kinases (Pks), $\alpha$-helice, Phosphorylation, Linear Consensus of Phosphorylation, Computational Biology, Computational Biology Tools 


\section{RESUMEN}

La fosforilación de proteínas realizada por las Proteínas-Quinases (PKs) es una de las modificaciones post-transduccionales más comunes envueltas en muchos procesos fisiológicos e patológicos. Uno de los pasos más importantes en la reacción catalítica de las PKs con el substrato es el posicionamiento correcto del resíduo alvo (serina, treonina o tirosina), sítio-P, en el sitio activo. Este proceso es mediado por regiones encontradas en el sitio de ligación del substrato, una hendidura poco profunda que tiene sub-hendiduras especialmente formados para anclar aminoácidos distantes del sitio-P del substrato, aqui denominados anclas. En este contexto, un mecanismo ha sido constantemente descrito y aceptado como esencial para la coordenación de quinases y proteína-substrato, llamado consenso linear de fosforilação, esto es, aminoácidos conservados en posiciones específicas en la estructura primária de la proteína alrededor del sitio-P (P-2 e P-3), que ayudan a anclar la proteína-substrato de las PKs. En este trabajo, fue testado y corroborado la hipótesis de que, para que los aminoácidos en las posiciones P-2 o P-3 cumplan un papel de anclas lineares y el sitio de fosforilación sea fosforilado, cambios estructurales locales deben ocurrir antes de la fosforilación. Para esa evaluación, utilizando substratos de Quinasas (PKA e PKC), fue constatado que las $\alpha$-hélices son un buen alvo de estudio por presentar sitios-P con mayor disposición para la fosforilación de que otras estructuras secundárias dentro de nuestro conjunto de datos. Para confirmar que este tipo de estructura secundária, relativamente rígida e bien definida espacialmente, ocurren rearreglos estructurales pré-fosforilación, fueron usadas herramientas de biologia computacional estructural como modelaje por homologia, dinámicas Coarse Grained e All Atom, e Docking Molecular. Los resultados revelan que los rearreglos conformacionales que permiten que P-2 e P-3 sean posibles anclas son más o menos substanciales dependiendo de la posición del sitio-P dentro de la $\alpha$-hélice. Se el sitio-P se encuentra em la región $\mathrm{N}$-terminal (las dos primeras vueltas o cerca de ellas), la $\alpha$-hélice no sufrirá cambios conformacionales substanciales, diferente de cuando el se encuentra en otra posición dentro de la $\alpha$-hélice. En este trabajo buscamos entender como pré-eventos de procesos de modificaciones pós-traducionales son dependientes de la estrutura local de proteínas, y como esos eventos pueden llevar a alteraciones temporales em estas estructuras, para profundizar los conocimientos generales en el área de fosforilación.

Palabras Claves: Proteinas - Quinasas (Pks), a-hélice, Fosforilación, Consenso linear de Fosforilación, Biologia Computacional, Herramientas de Biologia Computacional. 


\section{LISTA DE ILUSTRAÇÕES}

Figura 1: Subunidade catalítica de Proteína Quinase A (PDB: 1FMO). O lóbulo Nterminal é mostrado em vermelho, o C-terminal em azul e a proteína-substrato (PKI) em roxo, encaixando na fenda catalítica (SBS).

Figura 2: Representação dos locais de ligação da cadeia de aminoácidos do substrato (dentro do círculo vermelho); P-3, P-2, P-1, P0, P1, P2 e P3 com o aminoácidos aos quais estão ligados na Proteína Quinase; S -3, S-2, S-1, S0, S1, S2, S3 (imagem extraída de Kobe, 2005)

Figura 3: Consulta de substratos PKCA na base de dados PhosphoSitePlus. As colunas indicam o nome do gene, a proteína-substrato, o organismo, o peso molecular, o resíduo fosforilado, identificador PubMed, a sequência do sítio e o tipo de experimento usado na identificação do sítio. ...

Figura 4: Fluxograma de resultados. Os códigos UNIPROT representam as seguintes proteínas: SERT (P31645), CHAT iso 3 (P28329), TREK-2 (Q9JIS4), CD4 (P01730), SRF (P11831), PLM (O00168), CDK1 (P13863), PLN (P26678)....

Figura 5: A) Fluxograma da seleção de sequências de substratos de $P K$ com sítio-P verdadeiro., B) Distribuição de sítio-P verdadeiros divididos em aqueles que apresentaram consenso linear de fosforilação (com âncoras) e aqueles que não apresentaram consenso linear de fosforilação (sem âncoras). ...

Figura 6: Disposição de sítios $\mathrm{P}$ em estruturas secundárias de $\mathrm{PKs}$ (A), mostrando exemplos do sítio P (em verde e nomeados) e suas respetivas âncoras dentro das estruturas secundárias do tipo folha $\beta(\mathbf{B}), \alpha$-hélice $(\mathbf{C})$ e loops $(\mathbf{D})$

Figura 7: Comparação entre os comprimentos das pontes de Hidrogênio nos sítios $\mathrm{P}$ conhecidos e não conhecidos (qualquer Ser, Thr ou Tyr dentro da hélice) com os aminoácidos i-4, i+4 respectivos, onde i é a posição do Sítio P, ou os aminoácidos Ser, Thr ou Tyr, na sequência primária de aminoácidos.

Figura 8: A) Distâncias entre os Ca do sítio-P Ala-21 (P0) e suas âncoras lineares Arg19 (P-2) e Arg 18 (P-3) do peptídeo PKI (PDB 1FMO), peptídeo inibidor de fosforilação de PKA., B) Segmento da proteína HESl (Cod. UNIPROT Q14469), mostrando distâncias entre os $\mathrm{C} \alpha$ do sítio-P Ser-38 (P0) e suas possíveis âncoras lineares Lys-36 (P-2) e Arg-35 (P-3

Figura 9: Exemplo do arquivo .inp utilizado para a proteína 14-3-3 protein zeta/delta (Cod UNIPROT P63104); filenames: Define o diretório onde os dados de saída são 
salvos; job_cntl: Configuração de controle de trabalho; unit_and_state: leia a informação da sequência; initial_struct: Estrutura inicial., energy_function: Energias locais e não locais; aicg: como construir parâmetros AICG; md_information: Informação para na Dinâmica Molecular; flexible_local: Forçar constantes para potencial

local

flexível.

Figura 10: Distâncias entre os C $\alpha$ do Sítio P Ala-21 (P0) e suas âncoras lineares Arg19 (P-2) e Arg 18 (P-3) do peptídeo PKI (PDB 1FMO), mostrando as distâncias entre seus átomos

Figura 11: Segmento da Proteína Sodium-dependent serotonin transporter, que contém o sítio P (ponto vermelho), mostrando a distância entre os Ca P0 (Ser-277, vermelho) e P-2 (Lys-275, amarelo).

Figura 12: Segmento da Proteína Choline O-acetyltransferase, que contém o sítio $\mathrm{P}$ (ponto vermelho), mostrando a distância entre os C $\alpha$ P0 (Thr-255, vermelho) e P-3 (Lys-252, amarelo).

Figura 13: Segmento da proteína Potassium channel subfamily $K$ member 10, que contém o sítio P (ponto vermelho), mostrando a distância entre os Ca de P0 (Ser-326, vermelho) e P-3 (Arg-323, amarelo) em diferentes estados conformacionais da $\alpha$-hélice ao longo da dinâmica Coarse Grained., A) Frame inicial da dinâmica, com distância de

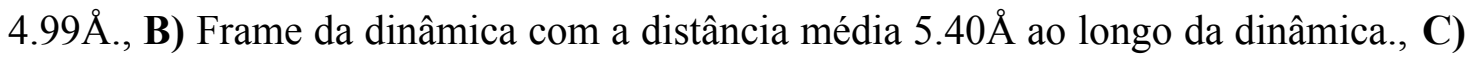
Frame da dinâmica mostrando a flexibilidade da $\alpha$-hélice cuja distância máxima foi $9.10 \AA$.

Figura 14: Segmento da Proteína T-cell surface glycoprotein CD4, que contém o sítio P (ponto vermelho), mostrando a distância entre os C $\alpha$ de P0 (Ser-440, vermelho) e P-3 (Arg-437, amarelo) em diferentes estados conformacionais da $\alpha$-hélice ao longo da dinâmica Coarse Grained. A) Frame inicial da dinâmica com distância de 4.97Å, B)

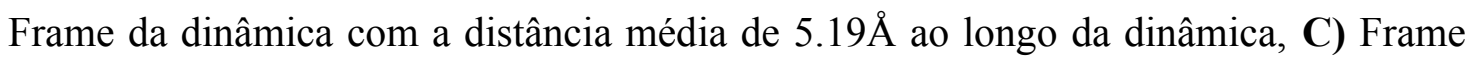
da dinâmica mostrando a distância máxima $8.99 \AA ̊$, que implica no desenovelamento da estrutura secundária.

Figura 15: Segmento da proteína Serum response factor, que contém o sítio P (ponto vermelho), mostrando a distância entre os C $\alpha$ de P0 (Thr-159, vermelho) e P-3 (Arg156, amarelo) em diferentes estados conformacionais da $\alpha$-hélice ao longo da dinâmica Coarse Grained. A) Frame inicial da dinâmica com uma distância de 5.01Å, B) Frame 
da dinâmica com a distância média de $5.49 \AA$ ao longo da dinâmica, C) Frame da dinâmica mostrando a distância máxima de $8.51 \AA$, que implica em pouco desenovelamento na região $\mathrm{N}$-terminal enquanto o restante da hélice mantém sua estrutura

Figura 16: Proteína Fosfolemman, mostrando em "sticks" os aminoácidos Ser 83 e Ser 88, que são os possíveis pontos de fosforilação dentro da hélice. A imagem também mostra a âncora P-2 Arg-81, que é âncora de Ser 83, e os aminoácidos Arg-85 e Arg-86 que são âncoras P-3 e P-2 de Ser-88, respectivamente. Arg-81 se encontra na posição P-7 em relação à Ser-88.

Figura 17: Distribuição de distâncias ao longo dos frames da dinâmica. Notar que entre os frames 2500 e 5000, as distâncias diminuem em A (P-2 - P0) e aumentam em B (P-3 - P0), voltando a ser constantes depois em ambos os casos. A distância máxima é mostrada com uma linha vermelha.

Figura 18: Distribuição de distâncias ao longo dos frames da dinâmica. A) Distância entre Ser-83 (P-0) e Arg-81 (P-2) que mostra um comprimento constante durante a dinâmica, diferente de (B) que mostra uma diminuição da distância entre Ser - 88 e Arg - 86 nos frames $2500 \quad-5000$.

Figura 19: A) A distância da ponte de hidrogênio entre Phe-80 e Ile-84, aumenta a partir do frame 2500 (250 ns) até o frame 6000 (600 ns). No caso de (B) a ponte de hidrogênio só apresenta um pequeno aumento entre os frames 6000 e 7000 (600 ns 700 ns). Finalmente em (C) vemos a superposição das distâncias A e B, mostrando também em "cartoon" o desenovelamento da hélice ao longo da dinâmica....

Figura 20: A) Segmento do frame 5006 da proteína PLM, mostrando o aminoácido Ser-88 em C-terminal da $\alpha$-hélice e as âncoras Arg-85, Arg-86. B) Em amarelo os aminoácidos Ala-21 e as âncoras deste Arg-18 Arg-19 de PKI. C) Superposição das possíveis âncoras de PLM (verde e nomeados) com as âncoras de PKI (amarelo)

Figura 21: A) Proteína CDK1, B) mostrando em "sticks" o aminoácido Ser 277, sítio de fosforilação na região N-terminal, e as possíveis âncoras na posição Lys-274 e Arg275 (P-3 e P-2 respectivamente).

Figura 22: Distribuição de distâncias ao longo dos frames da dinâmica. Notar que as distâncias são quase constantes durante a dinâmica toda, e que os valores máximos de las (linha vermelha), são próximos das distâncias entre os $\mathrm{C} \alpha$ do sítio P de PKI e suas 
âncoras.

Figura 23: A) Sítio P do frame 504, mostrando o aminoácido Ser-277 perto de Nterminal e as âncoras Lys-275, Arg-274. B) Em amarelo os aminoácidos Ala-21 e as âncoras deste Arg-18 Arg-19 de PKI. C) Superposição das possíveis âncoras de CDK1 (verde) com as âncoras de PKI (amarelo).

Figura 24: A) Proteína PLN, mostrando dentro do círculo a hélice que contém o sítio $\mathrm{P}$ e as possíveis âncoras. B) Em "sticks" o sítio P Ser-16 (laranja) e suas possíveis âncoras Arg-13 e Arg-14 (azul).

Figura 25: A) Segmento $\alpha$-hélice do primeiro frame, mostrando o aminoácido Ser-16 na região C-terminal e as âncoras Arg-13, Arg-14. B) PKI em cartoon mostrando em amarelo os aminoácidos Ala-21 e as âncoras deste Arg-18 Arg-19 de PKI. C) Superposição das possíveis âncoras de PLN (verde) com as âncoras de PKI (amarelo).

Figura 26: Resultados do Docking Molecular. A) Acoplamento entre PLM, representada em cartoon verde (Cod. Uniprot O00168) e PKCA, representada em surface rosa Dentro do PLM, encontram-se os aminoácidos Ser-88(P0), Arg-86(P-2), Arg-85(P-3) e Arg-81(P-7) representados em sticks. A PKCA mostra duas regiões de aminoácidos com carga negativa que interagem com Arg-86 e Arg-81. A região hidrofóbica (amarelo) têm interação com Arg-85. B) Interações das possíveis âncoras P-2, P-3 e P-7 (marcadas com setas vermelhas) com aminoácidos ao redor delas. Dentro do círculo se encontra o sítio P, Ser-88, a uma distância de $3.8 \AA$ de Asp148

Figura 27: Resultado do Docking Molecular realizado em HADDOCK, mostrando em stick o aminoácido Ser-277 de CDK1 que se encontrar a uma distância de $8.9 \AA$ em relação a Asp-148 (surface vermelho) na fenda catalítica de PKCA.

Figura 28: Resultados do refinamento do Docking Molecular feito com YASARA, em complexo CDK1-PKCA. A) Sítio P em stick Ser-277 de CDK1 que se encontra a uma distância de 4.2 com relação a Asp-148 de PKCA (surface vermelho), além mostra as possíveis âncoras em sticks Lys-274 e Arg-275 nos bolsões da fenda catalítica de PKCA interagindo com aminoácidos de carga negativa (surface vermelho); B) Superposição de Ser-277 (verde) de CDK1 com Ala-21 (amarelo) de PKI (1FMO), 
além de suas respectivas âncoras lineares.

Figura 29: Interações das possíveis âncoras (setas vermelhas) com aminoácidos de carga negativa Asp-109 e Asp-152 (Arg-275) e Glu-215 e Asp-188 (Lys-274).

Figura 30: A) Acoplamento de PLN (verde) com PKA (roxo). B) Segmento $\alpha$-hélice de PLN (verde, ribbon), mostrando em sticks o sítio P (Ser-16) e suas âncoras interagindo nos bolsões de PKA (surface vermelho), PLN e sobreposto com PKI (laranja, ribbon) e as âncoras deste em sticks (amarelo). C) Interações das possíveis âncoras (marcadas com setas vermelhas) com aminoácidos negativos ao redor delas; dentro do círculo se encontra o sítio $\mathrm{P}$, Ser-16, que interage com Asp166.

Figura 31: A) Rianodine RyR2 (verde, cartoon) acoplado a PKA (roxo, surface) e sobreposto a PKI (laranja, cartoon); a linha em azul representa a fenda catalítica onde se encontram o sítio $\mathrm{P}$ e as âncoras. B) Fenda catalítica onde se encontram sobrepostos o sítio P e as âncoras de RyR2 (verde, sticks) com Ala-21 e as âncoras de PKI (amarelo, sticks) 


\section{LISTA DE TABELAS}

Tabela 1: Aumento considerável no uso de dinâmica coarse grained nos últimos anos, demonstrando assim a grande aceitação desta ferramenta (Busca feita no dia 28 de Agosto de 2018, usando as palavras "coarse-grained" e "molecular dynamics")

Tabela 2: Parâmetros fornecidos pelo HADDOCK para os modelos gerados. O modelo escolhido pertence ao cluster 2, que apresenta o menor "Restraints violation energy" e "HADDOCK score" em relação aos outros. 


\section{LISTA DE ABREVIATURAS E SIGLAS}

\begin{tabular}{ll} 
PKs & Protein Kinase \\
ATP & Adenosine Triphosphate \\
PKA & Protein Kinase A \\
cAMP & Cyclic adenosine monophosphate \\
DNA & Deoxyribonucleic acid \\
ePK & eukaryotic Protein Kinase \\
ACG & Protein kinase A, G, and C \\
SBS & Substrate Binding Site (Sítio de ligação do substrato) \\
PDB & Protein Data Bank \\
PKI & Protein kinase inhibitor \\
PKA & Protein kinase A \\
Sítio-P, P0 & Sítio de Fosforilação \\
PKC & Protein kinase C \\
nRTKs & Non-receptor tyrosine kinase (nRTK) \\
Hsp-90 & Heat shock protein 90 \\
AR & Ankyrin-repeat \\
NMR & Nuclear Magnetic Resonance \\
UINPROT & Universal Protein Resource \\
YASARA & Yet Another Scientific Artificial Reality \\
PSI-BLAST & Position-Specific Iterated BLAST \\
PSIPRED & Predict Secondary Structure \\
PSSP & Profiles from Sequence and Structuraly related Proteins \\
CE & Combinatorial Extension \\
FatCat & $\begin{array}{l}\text { Flexible structure AlignmenT by Chaining Aligned fragment pairs } \\
\text { allowing Twists }\end{array}$ \\
SHEBA & Structural Homology by Environ- ment-Based \\
DMCG & AlignmentDinâmicas Moleculares Coarse Grained \\
DMAA & Dinâmicas Moleculares Coarse Grained \\
\hline
\end{tabular}




\begin{tabular}{|c|c|}
\hline RMSD & Root Mean Square Deviation \\
\hline RMSF & Root Mean Square Fluctuation \\
\hline CABS & CA-B and Side group \\
\hline NAMD-CG & Not (just) Anther Molecular Dynamics program - Coarse Grained \\
\hline AICG2_PLUS & Atomic interaction based CG with the flexible local potential \\
\hline FLP & Flexible local potential \\
\hline AMBER & Assisted Model Building with Energy Refinement \\
\hline CHARM & Chemistry at HARvard Macromolecular Mechanics \\
\hline OPLS & Optimized Potentials for Liquid Simulations \\
\hline GROMACS & GROningen MAchine for Chemical Simulations \\
\hline YAMBER & Yet Another Model Building and Energy Refinement Force Field \\
\hline HADDOCK & High Ambiguity Driven protein-protein DOCKing \\
\hline AIR & Ambiguous Interaction Restraints \\
\hline FCC & Fraction of Common Contacts \\
\hline SRT & Sodium-dependent serotonin transporter \\
\hline CHAT iso 3 & Choline O-Acetyltransferase \\
\hline TREK-2 & Potassium channel subfamily K \\
\hline CD4 & T-cell superficie glycoprotein CD4 \\
\hline SRF & Serum response factor \\
\hline PLM & Phospholenman \\
\hline CDK1 & Cyclin dependent kinase 1 \\
\hline BLAST-P & The Basic Local Alignment Search Tool - Protein \\
\hline RCSB & Research Collaboratory for Structural Bioinformatics \\
\hline CSPC & Conjunto de sítios-P cochecidos \\
\hline KCIP-1 & $14-3-3$ protein zeta/delta \\
\hline PLN & Phospholanbam \\
\hline RyR & Ryanodine receptors \\
\hline $3 \mathrm{D}$ & Tridimensional \\
\hline
\end{tabular}




\section{SUMÁRIO}

DEDICATÓRIA 3

AGRADECIMENTOS 4

RESUMO

ABSTRACT

RESUMEN

LISTA DE ILUSTRAÇÕES

LISTA DE TABELAS

LISTA DE ABREVIATURAS E SIGLAS 14

SUMÁRIO 16

1 INTRODUÇÃO___ 18

$1.1 \quad$ História, Fosforilação e Proteínas quinases___ 18

1.2 Interação entre Proteína quinase - Substrato quinase 20

1.3 Consenso de fosforilação___ 21

1.4 Proteínas quinase A e proteínas quinase $C_{2} 22$

1.5 Fosforilação em estruturas secundárias___ 23

1.6 Banco de dados experimentais de fosforilação

2 OBJETIVOS

2.1 Geral 26

2.2 Específicos__ 26

3 JUSTIFICATIVA 27

4 METODOLOGIA___ 28

4.1 Obtenção de dados _ 28

4.1.1 Seleção de sequências __ 28

4.1.2 Modelagem comparativa de substratos para gerar estruturas tridimensionais_ 29

4.1.3 Seleção de substratos

4.2 Dinâmicas Coarse Grained para medir comprimentos entre sítios P e suas âncoras $P-2$ e $P$-3

4.3 Dinâmicas All Atom de substratos selecionados___ 33

4.4 Docking molecular de substratos proteínas quinases e PKs__ 
5.1 Seleção de um conjunto de estruturas de proteínas que são fosforiladas por Pks

5.1.1 Seleção de sequências de susbtratos fosforilados 38

5.1.2 Modelagem por Homologia de substratos de PKs e classificação de Sítios P

5.2 Análise da variabilidade estrutural dos comprimentos entre sítios-P e suas âncoras P-2 e P-3 em $\alpha$-hélice

5.2.1 Dinâmicas Coarse Grained das proteinas de nosso conjunto de dados 43

5.2.1.1 Análises de proteínas fora dos intervalos da média dos valores médios 46

5.2.1.2 Análises de proteínas fora dos intervalos da média dos valores máximos

5.2.2 Dinâmicas All Atom para a análise dos substratos selecionados

5.2.2.1 Sítio-P em N-terminal e C-terminal com ancoras ao início e ao meio da $\alpha$-hélice

5.2.2.2 Sitio-P perto de $N$-terminal e âncoras fora da $\alpha$-hélice

5.2.2.3 Sítio-P em C-terminal e âncoras dentro da $\alpha$-hélice

5.3 Proposta de mecanismo de interação entre PKs e substratos com sítios-P em $\alpha-$ hélice

5.3.1 Interação PKC-Fosfolenman 59

5.3.2 Interação $P K C-C D K 1$ 62

5.3.1 Interação PKA - Fosfolanbam 64

6 CONCLUSÕES 69

7 REFERÊNCIAS 70

ANEXO A: Exemplo de um arquivo .inp de CafeMol 78

ANEXO B: Proteínas selecionadas 79 


\section{INTRODUÇÃO}

\subsection{História, Fosforilação e Proteínas quinases}

A fosforilação de proteínas é o tipo de modificação pós-traducional mais recorrente nas vias de sinalização, e desempenha um papel importante nas células eucarióticas, regulando muitos processos celulares como metabolismo, crescimento, divisão, diferenciação, motilidade, transporte de membrana, contração muscular, imunidade, aprendizado e memória (BRINKWORTH, BREINL, \& KOBE, 2003; HUNTER, 1995; UBERSAX \& FERRELL, 2007) . Uma variedade de aminoácidos podem ser fosforilados nas proteínas; em organismos procariotos, por exemplo, histidina (His, H) e aspartato (Asp, D) têm um papel importante nas vias de sinalização quando fosforiladas (GROBAN, NARAYANAN, \& JACOBSON, 2006), enquanto que em eucariotos, serina (Ser, S), treonina (Thr, T) ou tirosina (Tyr, Y) são os resíduos específicos a serem fosforilados pelas Proteínas quinases (PKs), uma família de enzimas evolutivamente relacionadas pelos seus domínios catalíticos, que transferem grupos fosfatos do ATP para os resíduos mencionados (BIONDI; NEBREDA, 2003).

Os estudos sobre PKs e seu papel na transdução de sinais tiveram início no laboratório de Pesquisa de Câncer Ben May da Universidade de Chicago pelos pesquisadores WilliamsAshman, Kennedy, e Smith. Depois disso na década de 1950, Burnett e Kennedy, caracterizaram pela primeira vez a atividade de uma enzima quinase (BURNETT; KENNEDY, 1954). Duas décadas depois, Hunter e Sefton em 1980, reportaram que o produto do gene transformante do vírus do sarcoma de Rous (v-Src) catalisa a fosforilação da tirosina, o que representa explicitamente o primeiro estudo da atividade da enzima proteína-tirosina quinase (HUNTER; SEFTON, 1980). Em 1995, Fischer e Krebs (FISCHER; KREBS, 1955; KREBS; FISCHER, 1955), e, Sutherland e Wosilait (SUTHERLAND; WOSILAIT, 1955) caracterizaram a primeira proteína quinase específica, que catalisa a fosforilação dependente de ATP. Três anos depois, o grupo de Sutherland descreveu o papel de cAMP como segundo mensageiro, o que permitiu, em 1968, a descoberta da PKA (cyclic AMPdependent protein kinase), uma serina/treonina quinase, por Walsh, Perkins e Krebs. A busca por proteínas quinases ativadas por segundos mensageiros levou à descoberta da proteína quinase G em 1970, e da proteína quinase C em 1977, o que permitiu o início da descoberta 
de muitas outras quinases, agora usando clonagem de DNA como metodologia (ROSKOSKI, 2015).

Em 2002, Manning e colaboradores identificaram dentro do projeto Genoma Humano 518 genes que codificam PKs, dos quais aproximadamente 478 pertencem a uma única superfamília chamada proteínas quinases de eucariotos (ePK) cujos domínios catalíticos estão relacionados em sua sequência primária. De acordo com estes, as ePKs são classificadas em 9 grupos definidos e dois grupos de exceções (MANNING et al., 2002):

- ACG (Contém as famílias PKA, PKG e PKC)

- CAMK (Calcium/calmodulin-dependent protein kinase)

- CK1 (Casein kinase 1)

- CMGC (Contém as famílias CDK, MAPK, GSK3, CLK )

- STE (Homólogos Quinase de levadura Sterile 7, Sterile 11, Sterile 20 kinases)

- TK (Tyrosine kinase)

- TKL (Tyrosine kinase-like)

- RGC ( Receptor Guanylate Cyclases, similar em sequência a TK)

- PKL ( PKL-fold kinases)

- Outros (Algumas quinases exclusivas que são claramente ePKs, mas não se encaixam nos outros grupos Epk)

- Atípicas (Quinases que não têm similaridade de sequência com quinases típicas, mas são conhecidas ou previram ter atividade enzimática)

Todas as quinases compartilham um domínio catalítico similar composto por uma estrutura dividida em dois lóbulos: um lóbulo $\mathrm{N}$-terminal, formado por 5 folhas- $\beta$ e $2 \alpha$ hélices, e um lóbulo C-terminal composto por $6 \alpha$-hélices e 2 folhas- $\beta$ (KOBE et al., 2005); também apresenta uma fenda entre os lóbulos onde o ATP se liga ao substrato, chamada de fenda catalítica ou sítio de ligação do substrato (SBS) (Fig .1). O tamanho em profundidade do SBS varia de acordo com o resíduo a ser fosforilado. Por exemplo, uma quinase que fosforila preferencialmente uma tirosina tem uma fenda mais profunda, diferente de uma quinase com afinidade a fosforilar serina ou treonina, uma vez que a cadeia lateral de tirosina é mais longa do que os outros dois aminoácidos em menção (FERRAZ, 2017). As PKs se diferenciam uma das outras pelo seu modo de regulação e pelo substrato que catalisam. 
A

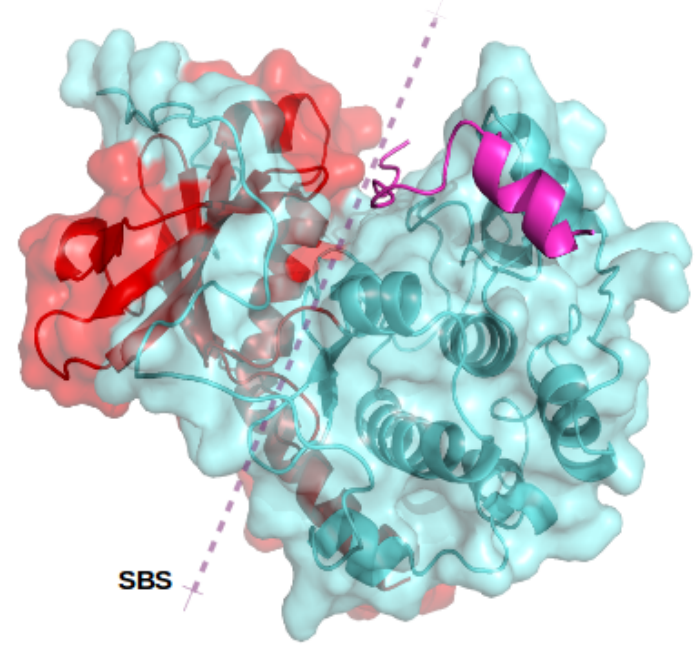

B

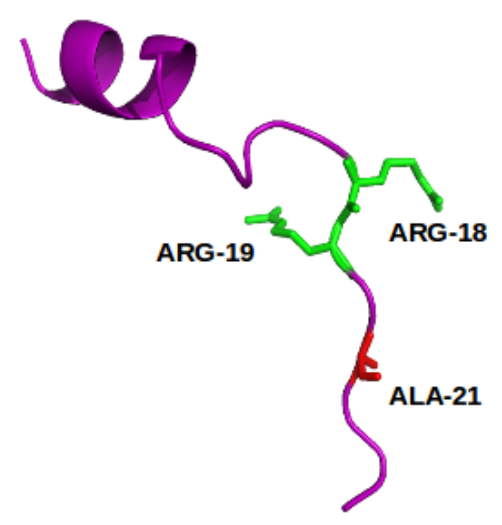

Figura 1. Subunidade catalítica de Proteína Kinase A (PDB: 1FMO). O lóbulo N-terminal é mostrado em vermelho, o C-terminal em azul e a proteína-substrato (PKI) em roxo, encaixando na fenda catalítica (SBS).

\subsection{Interação entre Proteína Quinase - Substrato Quinase}

As PKs representam aproximadamente $2 \%$ das proteínas codificadas por genomas de eucariotos, e isso as torna o terceiro domínio protéico mais comum no genoma humano (BIONDI; NEBREDA, 2003; ENDICOTT; NOBLE; JOHNSON, 2012; MANNING et al., 2002). Estima-se que 30-50 \% do proteoma humano apresenta pelo menos um resíduo alvo de fosforilação (fosfoproteína), ou seja, há uma grande quantidade de sítios (Ser, Thr, Tyr) potenciais de interação entre os substratos e as PKs. Devido ao papel importante da fosforilação como reguladora da sinalização celular, esses sítios de fosforilação não são fosforilados aleatoriamente, porque isso geraria caos na rede de sinalização celular. Portanto, entender a interação de PKs e seu substrato protéico representa um alvo atraente para a compreensão de uma ampla gama de doenças, como leucemias, tumores, doenças cardiovasculares, diabetes mellitus, desordens nos sistema imune, processos inflamatório e câncer (COHEN, 2002; LAHIRY et al., 2010).

Para entender como as PKs fosforilam aminoácidos, é necessário entender como ocorre a interação entre PK e Substrato-quinases. O lóbulo N-terminal da PK se liga ao ATP e o C-terminal se liga ao substrato. As PKs podem se encontrar ao menos em duas 
conformações, estado ativo e inativo, sendo que no primeiro estado encontram-se em sua máxima atividade catalítica. Neste estado ocorre a seguinte reação: é transferido um $\gamma$-fosfato do ATP que se encontra em um bolsão hidrofóbico para o grupo hidroxil do sítio de fosforilação que previamente foi desprotonado por um Asp (Asp-166 para 1FMO) invariável em todas as quinases, permitindo a fosforilação do aminoácido (HUSE; KURIYAN, 2002; ROSKOSKI, 2014). Um fator determinante para a especificidade da interação das PKs com o substrato é o contato com os aminoácidos que flanqueiam o sítio de fosforilação, os quais contribuem com o aumento da energia de interação entre o substrato e a PK. Este mecanismo é longamente descrito e aceito para coordenar a fosforilação de proteínas, sendo que as sequências de aminoácidos (motifs) do substrato que facilitam a especificidade são chamadas de consenso de fosforilação (KEMP et al., 1975).

\subsection{Consenso de fosforilação}

O consenso de fosforilação são resíduos de aminoácidos encontrados na imediação do sítio de fosforilação, importantes para determinar a especificidade da PK aumentando a interação entre o substrato e a PKs. Os consensos de fosforilação podem ser de dois tipos: consensos tradicionais ou lineares de fosforilação, que podem ser preditos inspecionando a sequência primária da proteína substrato, e os consensos estruturais de fosforilação (FERRAZ, 2017), que são resíduos de aminoácidos que na sequência primária não se encontram perto do sítio de fosforilação, mas que por causa do enovelamento da proteína, se encontram em uma distância de $10 \AA ̊$ com relação ao aminoácido fosforilável (DUARTE et al., 2014).

Para PKA, por exemplo, o consenso foi inicialmente determinado como KRXXS ou RRXS (KREBS; BEAVO, 1979) onde "S" é o sítio fosforilável ou sítio-P, "X" é qualquer aminoácido, "K" é lisina e "R" é arginina. Em 2001, Jhon B. Schabb propõe um padrão mais geral, RXR[S/T], $[\mathrm{R} / \mathrm{K}] \mathrm{XX}[\mathrm{S} / \mathrm{T}]$ ou $[\mathrm{R} / \mathrm{K}] \mathrm{X}[\mathrm{S} / \mathrm{T}]$; além de mencionar sítios fisiológicos para PKA que não estão contidos no consenso tradicional de fosforilação (SHABB*, 2001). Outros consensos de fosforilação foram já descritos como se mostra na revisão de Chad J. Miller e Benjamin E. Turk (MILLER; TURK, 2018). A importância dos aminoácidos flanqueadores, especialmente de lisina e arginina, geralmente chamados de "especificidade peptídica" (KOBE et al., 2005), ou âncoras (FERRAZ, 2017), é aumentar a probabilidade de interagir com o SBS por causa do tamanho da cadeia lateral dos aminoácidos flanqueadores, e 
portanto, auxiliar a interação com o PK, dependendo do aminoácido fosforilado e da especificidade do peptídeo, cada PK apresenta uma peculiaridade única.

Para o consenso de fosforilação, pode-se usar a nomenclatura utilizada comumente para proteases (SCHECHTER; BERGER, 1967). Se o resíduo do substrato fosforilado for determinado como P0 (sítio-P), o resíduo adjacente a ele na sua posição N-terminal e/o Cterminal será chamado $\mathrm{P}-1$ e $\mathrm{P}+1$, respectivamente, da mesma forma que denota os resíduos pertencentes à PKs que os nomeia com a letra $\mathrm{S}$, portanto, seria obtido para o resíduo $\mathrm{P}-1$ ligado a S-1, P0 se juntou a S0, P+1 ligado a $\mathrm{S}+1$, e assim por diante (Fig .2), criando interações favoráveis por carga, ligação de hidrogênio ou interações hidrofóbicas. Finalmente, é sabido que eles não são os únicos elementos que determinam a especificidade da fosforilação dentro da célula, uma vez que o recrutamento de substrato desempenha um papel importante na determinação de a preferência do substrato.

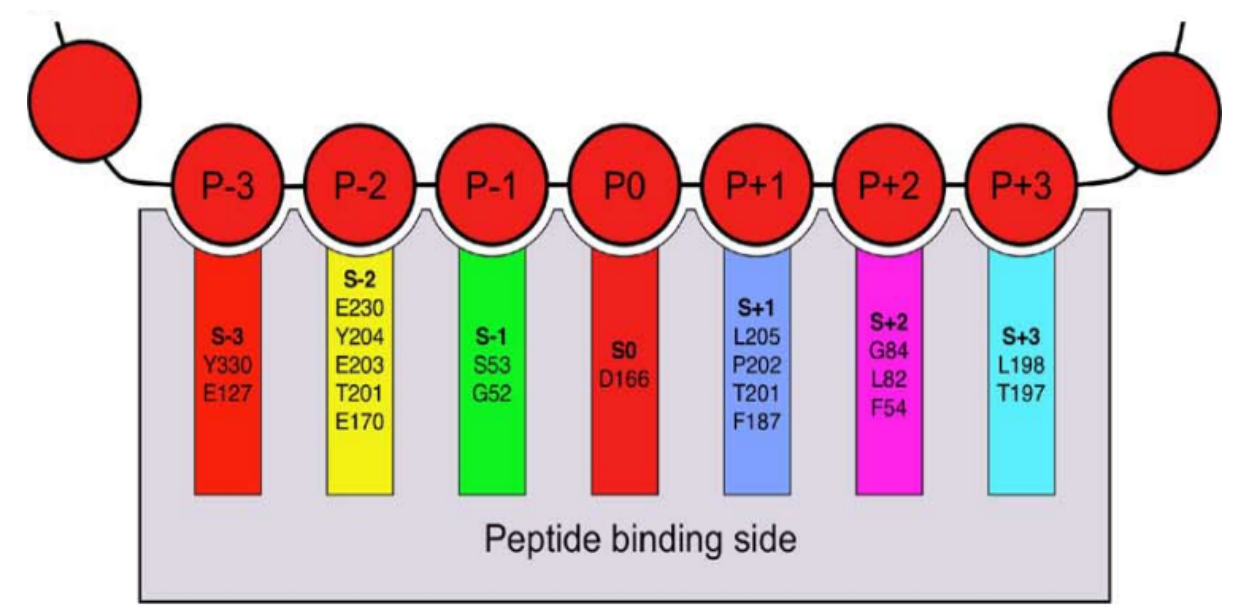

Figura 2. Representação dos locais de ligação da cadeia de aminoácidos do substrato (dentro do círculo vermelho); P-3, P-2, P-1, P0, P1, P2 e P3 com o aminoácidos aos quais estão ligados na Proteína Quinase; S -3, S-2, S-1, S0, S1, S2, S3 (imagem extraída de Kobe, 2005).

\subsection{Proteínas quinase A e proteínas quinase C}

PKA e PKC são duas proteínas que pertencem à mesma família de proteínas-quinases ACG (PEARCE; KOMANDER; ALESSI, 2010). Estas duas PKs homólogas são um modelo de estudo interessante pelo vasto conhecimento disponível a respeito delas. Os sutratos de PKC apresentam um consenso de fosforilação com as mesmas características que os sustratos de PKA, onde P-2 e P-3 contém resíduos básicos como Arg e Lys, aqueles que vão interagir 
com os aminoácidos encontrados nos bolsões carregados negativamente das PKs (WOODGETT; GOULD; HUNTER, 1986).

PKA também foi a primeira quinase a ser resolvida estruturalmente (KNIGHTON et al., 1991a) e para a qual há um cristal resolvido em complexo ao inibidor natural (KNIGHTON et al., 1991b). PKC assim como PKA têm uma validação in vitro que confirma o consenso de fosforilação, na qual um pseudosubstrato de sequência Arg19-Phe-Ala-ArgLys-Gly-Ala25-Leu-Arg-Gln-Lys-Asn-Val-His-Glu-Val-Lys-Asn36, se liga ao sítio catalítico, mantendo ocupada a fenda formada por os dois lóbulos e, portanto, a PK inativa. Isso ocorre por que a Ala-25 ocupa a posição de um sítio-P, e se ela é substituída por uma Ser, a região do substrato se transforma em uma região de alta afinidade e a catálise é feita (FERRAZ, 2017; HOUSE; KEMP, 1987).

\subsection{Fosforilação em estruturas secundárias}

As proteínas substratos são compostas por estruturas secundárias do tipo $\alpha$-hélice, folhas- $\beta$ ou loops, sendo $\alpha$-hélices as estruturas secundárias mais comumente encontradas (ELBAUM; ZONDLO, 2014). Uma $\alpha$-hélice ideal é uma rede de ligações de hidrogênio que se forma entre o oxigênio carbonil de cada resíduo (i) com o hidrogênio do grupo amida do resíduo i +4 , com uma distância ótima de $2.72 \AA$, de tal modo que ocorre uma volta a cada 3,6 aminoácidos (OHEIX; PEACOCK, 2015). De acordo com Pauling e colaboradores, as $\alpha$ hélices são estruturas bem definidas com distâncias constantes entre seus átomos; $\mathrm{N}-\mathrm{C} \alpha=$ $1.47 \AA, \mathrm{C} \alpha-\mathrm{C}=1.53 \AA, \mathrm{C}-\mathrm{N}=1.32 \AA$, ângulos de dobramento fixos; $\mathrm{C} \alpha-\mathrm{C}-\mathrm{N}=117^{\circ}, \mathrm{C}-\mathrm{N}-$ $\mathrm{C} \alpha=120^{\circ}, \mathrm{N}-\mathrm{C} \alpha-\mathrm{C}=110^{\circ}$, ângulo dihedrals $\varphi=-57$ e $\psi=-47$, e um ângulo dihedral planal $\mathrm{C} \alpha-\mathrm{C}-\mathrm{N}-\mathrm{C} \alpha=180^{\circ}$ (HAIMOV; SREBNIK, 2016; PAULING; COREY; BRANSON, 1951).

O segundo tipo de estrutura secundária mais comum encontrado nas proteínas são as folhas- $\beta$, segmentos esticados da cadeia polipeptídica mantidos juntos por uma rede de ligações de hidrogênio. A cadeia polipeptídica que forma as folhas- $\beta$ é chamada de cadeia beta, e os aminoácidos que se encontram dentro dela estão separados do aminoácido adjacente por uma distância aproximada de $3.5 \AA$. As cadeias laterais dos aminoácidos adjacentes apontam em direções opostas, e segundo a direção das cadeias beta, as folhas- $\beta$ podem ser paralelas, antiparalelas ou mistas. Finalmente diferente das $\alpha$-hélice e folhas- $\beta$, os loops são 
estruturas não regulares e periódicas, o que permite mudanças na direção da cadeia polipeptídica fazendo com que a proteína tenha uma estrutura compacta (BERG et al., 2002).

Estudos com relação ao comportamento destas estruturas secundárias que contém sítio-P foram já feitos desde uma visão pós-fosforilação. Por exemplo, sabe-se que a fosforilação do aminoácido Y-298 de Cdc37 resulta em um desenovelamento parcial da hélice $\alpha 1$ tornando-se uma sequência fosfopeptídica exposta, o que facilita seu reconhecimento pelos domínios SH2 de nRTKs, que vai a potenciar a fosforilação de Y-197 de Hsp-90 (BACHMAN et al., 2018). Sabe-se ainda que a dupla fosforilação de Ser-66 e Ser-76, resulta em um desenovelamento local das hélices AR1-3 da proteína P19 ${ }_{\text {IKA }}$ (KUMAR et al., 2018). Resultados similares foram encontrados para a proteína P4.1, na qual a fosforilação de duas serinas (Ser80 e Ser-84) diminui a probabilidade de formação de $\alpha$-hélice (VETTER; LECLERC, 2001). Outros estudos foram realizados para saber se a fosforilação do sítio $\mathrm{P}$ em peptídeos promove a formação de certas estruturas secundárias, e concluíram que a fosforilação de Ser ou Thr no peptídeos modelos AcGGSGGNH2, AcGGTGGNH2, tende a diminuir a propensão de formação de cadeia $\beta$ e promover a conformação helicoidal (HE et al., 2016).

Investigações sobre a estabilidade das $\alpha$-hélices em relação ao posicionamento dos sítios-P foram também já feitos. Trabalhos como os de Doing e colaboradores, De Gado e colaboradores e, Elabum e Zondlo, mostram que a fosforilação do sítio-P têm um efeito nas interações locais e podem ter um efeito na estrutura secundária da $\alpha$-hélice. Os resultados concluem que a hélice é mais estável se a fosforilação ocorre perto da região N-terminal; caso contrário, se a fosforilação ocorre no interior da hélice ou na região C-terminal, ela se torna é instável e o desenovelamento ocorre (ANDREW et al., 2002; ELBAUM; ZONDLO, 2014; SIGNARVIC; DEGRADO, 2003).

Como se pode observar, existem diferentes estudos do comportamento de $\alpha$-hélices na fase de pós-fosforilação o que a torna um bom alvo de estudo. É necessário mencionar que, em comparação com pesquisas sobre o comportamento de folhas- $\beta$ que contém sítios-P, as $\alpha$ hélice e loops estão melhor estudados, mas mesmo assim a análise destas estruturas secundárias é ainda pouca. Se considerarmos o comportamento e disposição estrutural das estruturas secundárias, em especial das $\alpha$-hélices que apresentam um consenso linear na fase de pré-fosforilação, que são o foco deste trabalho, a informação disponível é muito escassa, sendo portanto uma das causas críticas para o início deste projeto. 


\subsection{Banco de dados experimentais de fosforilação}

A grande quantidade de sequências com sítios de fosforilação (P0) encontradas em banco de dados experimentais, como Phosphonet (http://www.phosphonet.ca/), Phospho.ELM (DINKEL et al., 2011), PhosphoGrid (STARK et al., 2010), Phosida (GNAD et al., 2007) e PhosphoSitePlus (HORNBECK et al., 2004) descrito na metodologia, mostram que o impacto das investigações com referência a fosforilação de proteínas é muito grande. Por exemplo, em um estudo prévio de nosso laboratório (FERRAZ, 2017) foram identificados em PhosphositePlus 1106 sítios registrados como alvos da proteína PKA, distribuídos em 625 proteínas diferentes. Analisando as sequências desses sítios, 492 tiveram o motivo canônico em P-2 e P-3 ([R/K][R/K]X[S/T]), 474 tiveram pelo menos as âncoras consideradas na posição P-2 ou P-3. Sendo assim, 966 sítios (87.3\%) apresentam algum resíduo básico nas posições das âncoras, e os restantes (140 sítios), não apresentam resíduo R ou K na posição P2 ou P-3 (FERRAZ, 2017).

Neste contexto, a prospecção de bancos de dados experimentais de fosforilação de proteínas permitem a facilidade de acesso e estudo desses volumosos dados, e portanto, a geração de novos conhecimentos no campo de estudo. Essa prospecção permitirá testar as hipóteses propostas neste trabalho, a saber, que se o sítio-P se encontrar na região N-terminal da $\alpha$-hélice e apresentar âncoras lineares, não ocorrem rearranjos conformacionais substanciais para haver interação com PK e permitir a fosforilação, uma vez que as distâncias entre P0 e suas âncoras serão ótimas (parecidas com o PKI). Caso contrário, isto é, quando sítio-P se encontra em outra posição que não seja N-terminal dentro da $\alpha$-hélice, ocorrerão rearranjos conformacionais para permitir a interação com a PK e consequentemente, a fosforilação. 


\section{OBJETIVOS}

\subsection{Geral}

O principal objetivo do presente trabalho é contribuir para entender o comportamento de reconhecimento de sítios de fosforilação em substrato de proteínas quinases que contém consensos lineares de fosforilação do ponto de vista da biologia estrutural e computacional.

\subsection{Específicos}

Estudar a posição estrutural de sítios de fosforilação e âncoras lineares sequenciais presentes em estruturas secundárias de proteínas substratos experimentalmente determinadas de PKs.

Avaliar se existe uma conformação estrutural pré-estabelecida do resíduo P0 para interagir com PKs.

Avaliar prováveis mudanças conformacionais das $\alpha$-hélices para a ligação dos sítios-Putativos estruturais de fosforilação (P0 e âncoras lineares) em Pks.

Propor um mecanismo teórico de interação entre PKs e regiões de $\alpha$-hélices que contém sítio de fosforilação em consensos lineares. 


\section{JUSTIFICATIVA}

Estudos sobre a disposição dos sítios de fosforilação e âncoras no consenso linear em estruturas secundárias como as $\alpha$-hélices, uma das mais abundantes nas proteínas, não foram encontrados na literatura atual. Tendo em conta a importância da fosforilação de proteínas nas vias de sinalização celular, e que bancos de dados experimentais como PhosphoSitePlus tem permitido observar padrões de aminoácidos em posições específicas ao redor dos sítios-P em substratos de PK da família ACG, isto é, PKA e PKC, é de nosso interesse estudar questões que ainda não foram respondidas, como:

1) Qual é a disposição dos aminoácidos e o comportamento das estruturas secundárias pré-fosforilação, que apresentam P0 e âncoras lineares em sua estrutura? No caso das $\alpha$ hélices, responder esta questão nos permitirá saber se já existe uma predisposição nesta estrutura secundária com sítios-P conhecidos que permita à proteína interagir com o sítio de ligação do substrato da PK, da mesma forma como o complexo inibidor PKI e a quinase PKA.

2) Quais são as modificações estruturais durante o processo de recrutamento de substrato que devem ter as estruturas secundárias para interagir com o SBS da PK, e permitir que o consenso linear de fosforilação participe para formar o complexo enzima-substrato e, assim, ocorra a fosforilação?

Para avançar nesse conhecimento, torna-se essencial uma revisão do tema e uma reanálise utilizando dados cada vez mais disponíveis graças ao desenvolvimento de novas tecnologias para o estudo da proteômica. O uso desses dados de fosfoproteômica combinados com técnicas de biologia computacional pode auxiliar a entender o processo de fosforilação entre PKs e substratos bem definidos, o que é relevante para o entendimento de processos fisiopatológicos. Neste sentido, dado o papel central de proteínas quinases, entendemos que explorar as nuances de interação proteína-proteína neste grupo pode auxiliar na criação de sondas biológicas para auxiliar pesquisadores de bancada na modulação de vias mediadas por PK, gerando novos conhecimentos nesta área de estudo. 


\section{METODOLOGIA}

\subsection{Obtenção de dados}

\subsubsection{Seleção de sequências}

Inicialmente, foi preciso classificar substratos que apresentam pontos de fosforilação na sequência primária de aminoácidos. Utilizamos o banco de dados PhosphoSitePlus (HORNBECK et al., 2004, 2015), que armazena dados de modificações pós traducionais sobre sítios de fosforilação. Os dados armazenados neste banco de dados são curados mensalmente e atualizados diariamente, sendo possível baixar todo o banco de dados ou realizar uma busca sistemática. Esta última opção foi a escolhida para baixar todos os substratos armazenados para as quinases PKA e PKC, pertencentes à família ACG, já que PhosphoSitePlus também permite fazer consultas por sítios associados a uma determinada quinase.

Os substratos selecionados do banco de dados foram aqueles que apresentaram na sequência não só o sítio-P e as âncoras lineares nas posições P-2 e P-3, mas também cuja sequência fornecida por PhosphoSitePlus fosse parte de ao menos uma estrutura cristalográfica ou resolvida por Ressonância Magnética Nuclear (NMR). Assim, teremos informações experimentais de sítios de fosforilação contidos no cristal ou dados de NMR. Para a obtenção das estruturas proteicas que contém as sequências de fosforilação, foi necessário usar o formato FASTA das proteínas, os quais foram obtidos com os códigos UNIPROT (APWEILER et al., 2004) fornecidos por PhosphoSitePlus. Se a sequência está presente em uma proteína completa no $\mathrm{PDB}$, a etapa de modelagem molecular não será feita, mas se só é encontrada a sequência ou parte dela é um cristal, tendo em conta que a sequência de aminoácidos tem um maior comprimento que a sequência fornecida por o banco de dados, a modelagem comparativa será feita para obter as outras partes da estrutura proteica que não estejam na estrutura experimental.

Além dos códigos UNIPROT, PhosphoSitePlus também retorna as seguintes informações: símbolo do gene que codifica a proteína, nome da proteína, organismo de estudo, peso molecular, resíduo fosforilado, identificador do artigo no PubMed (ROBERTS, 
2001), sequência de entorno +/-7 aminoácidos ao redor do sítio-P e o método experimental utilizado para identificar o sítio-P, ou seja, in vivo ou in vitro (Fig. 3).

\begin{tabular}{|c|c|c|c|c|c|c|c|}
\hline GENE & PROTEIN & ORGANISM & MW_(DA) & RSD & SITE_GRP_ID & SITE_+1.7AM & METHOD \\
\hline Entabopl & 4E-BP1 & rat & 12,404 & 564 & 447527 & FLMECRNSPVAKT PP & In Viro \\
\hline Aanat & AA-NAT & fat & 23,142 & T29 & 452141 & LGCQRRH LPASEFR & In Vivo \\
\hline ABCB1 & ABCB1 & human & 141,479 & S661 & 456983 & SSNDSRSSLIRKRST & In Viro \\
\hline$A B C B 1$ & ABCB1 & human & 141,479 & S667 & 455363 & SsLIRKRsTRRsVRG & In Vito \\
\hline ABCB1 & ABCB1 & human & 141,479 & s671 & 455365 & RKRSTRRsVROSQAQ & In Vitzo \\
\hline Adcy 2 & ADCY2 & rat & 123,316 & S490 & 25795203 & DGAKMRAs VRMTRYL & In Vivo \\
\hline Addcy 2 & ADCY2 & rat & 123,316 & $\$ 543$ & 25795202 & NRTLRTKSQKKRFEE & In Viva \\
\hline Adcy6 & ADCY6 & rat & 131,846 & s10 & 450817 & LPVARSGSGRSSMSW & In Viro \\
\hline Adcy6 & ADCY 6 & rat & 131,846 & s568 & 455528 & TFLILGASQKRKEEK & In Vizo \\
\hline Addcy6 & ADCY6 & rat & 131,846 & S674 & 455529 & EDLEKKYsRKVDPRF & In Viro \\
\hline Adcy6 & ADCY 6 & rat & 131,046 & T931 & 455530 & HAQQVES TARL DFLU & In Viro \\
\hline
\end{tabular}

Figura 3. Consulta de substratos PKCA na base de dados PhosphoSitePlus. As colunas indicam o nome do gene, a proteína-substrato, o organismo, o peso molecular, o resíduo fosforilado, identificador PubMed, a sequência do sítio e o tipo de experimento usado na identificação do sítio.

\subsubsection{Modelagem comparativa de substratos para gerar estruturas tridimensionais}

A modelagem neste contexto significa fazer uma previsão de como os átomos dos aminoácidos estão dispostos em uma sequência de proteína conhecida (estrutura primária), a fim de observar como os sítios-P e as âncoras estão dispostos na proteína-substrato. É importante modelar a proteína toda para não perder informação que será útil em etapas posteriores. Para começar, os substratos de interesse obtidos pelo PhosphoSitePlus foram compilados por meio do código UNIPROT. Desta forma, as sequências primárias das proteínas, necessárias para modelagem comparativa, são salvas em formato FASTA.

A modelagem comparativa geralmente segue 5 etapas (FISER; ŠALI, 2003):

- $\quad$ Procura de estruturas relacionadas para a sequência alvo (target),

- $\quad$ Seleção de moldes (templates),

- Alinhamento da sequência alvo com um ou mais moldes,

- Construção do modelo,

- $\quad$ Avaliação. 
Aqui, utilizamos o software YASARA (versão 19.1.27), programa cujas funções de energia foram otimizadas, de modo que os modelos de proteína de baixa energia são mais propensos a serem previsões corretas (KRIEGER et al., 2009). A modelagem é explicada a seguir.

As sequências foram submetidas em uma pesquisa PSI-BLAST (Uniref90), que gera uma matriz de valores específicos de posição (position specific site matrix - PSSM), usada para a busca de moldes no banco de dados Protein Data Bank (PDB, http://www.rcsb.org/). Os moldes foram classificados em relação ao seu alinhamento e qualidade. Para avaliar o modelo, foram usados os parâmetros WhatCheck, um tipo de avaliador interno que verifica se um modelo satisfaz ou não as restrições utilizadas para o cálculo (HOOFT et al., 1996). Os arquivos de saída gerados pelo PSI-BLAST também permitem a previsão de estruturas secundárias usando o PSIPRED (MCGUFFIN; BRYSON; JONES, 2000). YASARA usa PSSP (Profiles from Sequence and Structuraly related Proteins), um método que realiza uma pesquisa por moldes relacionados, que estão estruturalmente alinhados usando algoritmos $\mathrm{CE}$ (SHINDYALOV; BOURNE, 1998), FatCat (YE; GODZIK, 2003) e SHEBA (JUNG; LEE, 2000). O melhor modelo foi usado para gerar um alinhamento múltiplo da sequência de alvo contra o molde, usando a matriz de Valores de SSALN (QIU; ELBER, 2005). Em seguida, os modelos gerados passaram por uma minimização de energia, com solvatação implícita utilizando os campos de força YASARA (KRIEGER et al., 2009). O melhor modelo gerado foi usado como modelo final. Os modelos finais gerados foram salvos como arquivo PDB.

\subsubsection{Seleção de substratos}

Tendo já as proteínas substratos das quinases PKA e PKC, foram selecionadas mediante um script em R (https://www.r-project.org/, versão 3.4.4) aquelas proteínas substratos que apresentaram o ponto de fosforilação na estrutura secundária definida $\alpha$-hélice e loops. Este script também classifica as proteína-substratos que apresentam o sítio-P no Nterminal da $\alpha$-hélice (as duas primeiras voltas da $\alpha$-hélice) e proteína-substratos que apresentam o sítio-P em outra posição dentro da $\alpha$-hélice (centro ou C-terminal). Com estas proteínas, foi possível observar como os sítio-P e as âncoras estão dispostos em suas estruturas secundárias. Por isso foi importante modelar a proteína toda para não perder informação do comportamento das outras $\alpha$-hélices que não são fosforiladas e que encontramse na mesma proteína, para observar se existe alguma diferença. Neste processo surge uma 
pergunta, Será que existe uma predisposição estrutural para desenovelamento em $\alpha$ hélices que apresentam aminoácidos Ser, Thr ou Tyr ? Para respondê-la, foi obtido um conjunto de estruturas de proteínas resolvidas por difração de raios-X com resolução menor de $2.5 \AA$, totalizando de 98.668 estruturas. Filtrando-se esse conjunto para que as estruturas tivessem ao menos uma $\alpha$-hélice, não estivessem contidas em nossa base de dados de substratos de PKs e que tivessem resíduos $\mathrm{S} / \mathrm{T} / \mathrm{Y}$ em hélices, reduzimos o conjunto para 5.386 PDBs aqui chamado de conjunto de referência, ao que o parâmetro geométrico do comprimentos das ligações de hidrogênio foi medido. Finalmente, as proteínas substratos de PKs modeladas foram usada nos passos posteriores, como dinâmicas Coarse Grained, dinâmicas All Atom e Docking molecular.

\subsection{Dinâmicas Coarse Grained para medir comprimentos entre sítios P e suas âncoras P-2 e P-3}

Dinâmicas moleculares coarse grained (DMCG) simulam o comportamento de átomos e moléculas por aproximações audaciosas, simplificando os átomos em diferentes níveis de granularidade, diminuindo seu custo computacional (KMIECIK et al., 2019). Nos último anos, as pesquisas com relação a dinâmicas coarse grained de proteínas tiveram um aumento considerável (Tabela 1).

Tendo já os substratos selecionados, as DMCG são o passo seguinte que permite, assim como as dinâmicas moleculares All Atom (DMAA), analisar alterações estruturais que podem ser "root mean square deviation" (RMSD) e "root mean square fluctuation” (RMSF), interações proteína - proteína, adicionar temperatura, pressão, e mais (TAKAHASHI; ODA; NARUSE, 2014).

Neste projeto, DMCG serão usadas para medir distâncias entre o sítio-P e suas possíveis âncoras nas posições P-2 e P-3. DCMG tem diferentes tipos de modelos generalizados como por exemplo: Martini Coarse Grained (MONTICELLI et al., 2008), CABS (KOLINSKI, 2004), NAMD-CG (TAKADA, 2012) e CafeMol (KENZAKI et al., 2011), sendo este último o modelo usado neste trabalho. CafeMol é um software para sistemas biomoleculares que pode ser usado para proteínas, ácidos nucléicos e membranas lipídicas e seus complexos. CafeMol foi usado em diferentes trabalhos para investigar vários sistemas, tendo apresentado um bom desempenho. Além de ser bastante usado, uma comparação de 
CafeMol contra modelos coarse grained, Go e Martini, em relação à dinâmica de Eglin C, uma proteína monomérica pequena de 70 resíduos, mostra que Cafemol é o modelo que têm uma melhor correlação com o modelo All Atom, concluindo que atualmente é o modelo mais preciso e fácil de usar para explorar as dinâmicas de proteína (LU; SALSBURY, 2015).

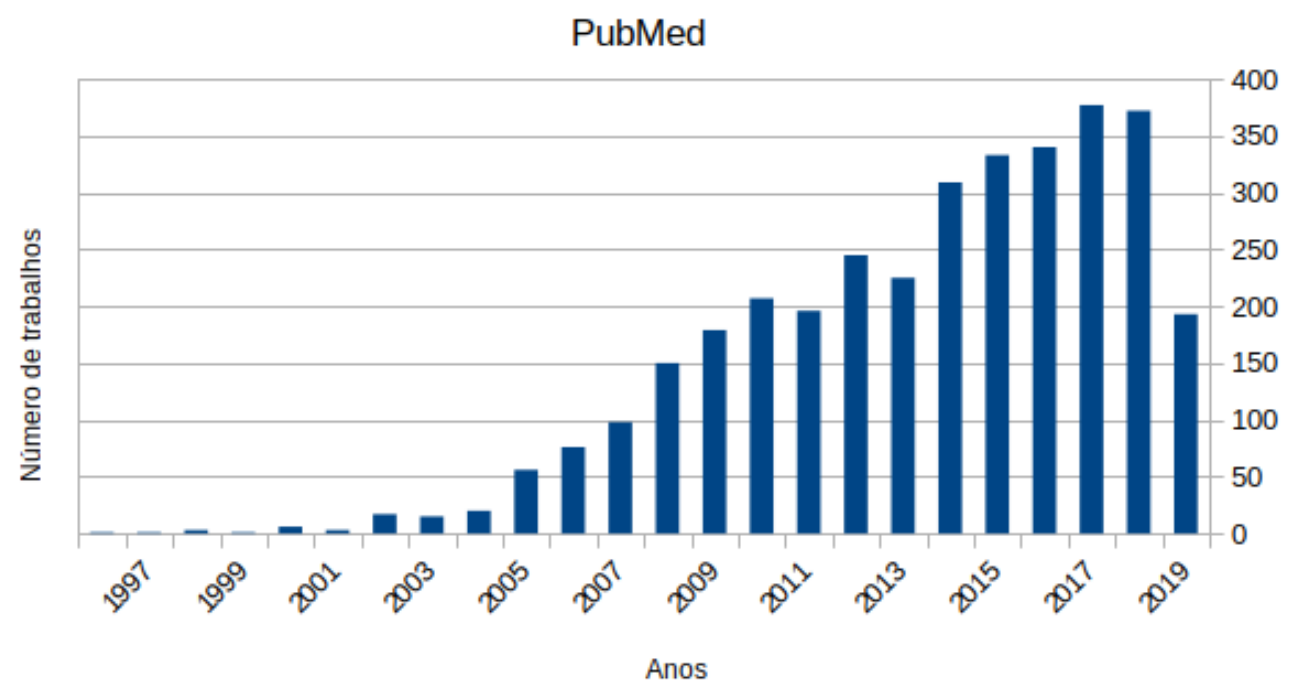

Tabela 1. Aumento considerável no uso de dinâmica coarse grained nos últimos anos, demonstrando assim a grande aceitação desta ferramenta (Busca feita no dia 28 de Agosto de 2018, usando as palavras "coarsegrained" e "molecular dynamics").

Para usar CafeMol, foi necessário o uso do PDB da proteína que foi modelada por homologia em YASARA, além de um arquivo com extensão “.inp” (Anexo. A) que contém as informações necessárias para correr a dinâmica. O resultado fornece vários arquivos, dos quais dois são necessários para a análise da dinâmica: o binário ".dcd”, que contém as trajetórias, e “.psf”, que contém a estrutura da proteína. Com estes arquivos, as distâncias entre os aminoácidos âncoras e os sítio de fosforilação foram medidas, para conhecer a média da distância que eles têm em nestas estruturas secundárias. As simulações Coarse Grained foram do tipo dinâmica Langevin, a uma temperatura de $300 \mathrm{~K}$ durante $1 \mu$ s. As interações não ligadas foram parametrizadas com AICG2_PLUS para não locais e FLP para as locais. O intervalo de integração foi de 0.4 , como recomenda o manual de CAFEMOL quando são usadas somente proteínas (http://www.cafemol.org/documents/CafeMolManual 3.0.pdf). Os átomos $\mathrm{C} \alpha$ foram usados para representar cada aminoácido da proteína, e um total de 20 milhões de passos foram feitos em cada simulação. A informação da estrutura foi salva a cada 10.000 passos, obtendo assim 2.000 Conformações; a lista de vizinhos foi atualizada a cada 100 passos 


\subsection{Dinâmicas All Atom de substratos selecionados}

Desde a primeira dinâmica All Atom (DMAA), publicada no ano 1977 por Karplus e colaboradores (MCCAMMON; GELIN; KARPLUS, 1977) e que permitiu extrair importante informação com relação ao inibidor tripsina pancreática bovina, soube-se também que as proteínas não são corpos rígidos, mas têm um movimento, o qual desempenha um papel muito importante em relação à função da mesma.

As DMAA tiveram grande sucesso em reproduzir características físico químicas das estruturas moleculares, baseando-se na evolução de coordenadas e momento através do tempo. Esta evolução é chamada de trajetória (obtida mediante as equações de Newton), e é muito importante porque permite analisar diferentes características que são dependentes do tempo, respondendo possíveis perguntas de interesse biológico que de maneira experimental não foram ainda respondidas (KARPLUS; MCCAMMON, 2002).

As DMAA são baseadas em campos de força, que são expressões matemáticas que descrevem a energia dos átomos e moléculas que interagem dentro do sistema que está sendo simulado (GONZÁLEZ, 2011; MACKERELL, 2004). Os campos de força evoluíram muito desde o desenvolvimento do primeiro campo de força polarizável na década de 1970, que envolveu os primeiros descritores de propriedades eletrostáticas de átomos e moléculas (APPLEQUIST; CARL; FUNG, 1972), até a atualidade (WARSHEL; KATO; PISLIAKOV, 2007), em que campos de força mais robustos foram disponibilizados dentro do pacotes de dinâmicas como AMBER, CHARM, OPLS ou GROMACS, graças ao progresso de novos métodos teóricos e extensiva parametrização de novas funções potenciais (BAKER, 2015).

As DMAA neste projeto foram feitas usando o programa YASARA, que permite realizar DMAA usando seu próprios campos de força chamado YAMBER (Yet Another Model Building and Energy Refinement Force Field), um campo de força derivado de AMBER. Já que nossas proteínas modeladas por homologia requerem maior precisão em seus campos de força para uma DMAA (LEE et al., 2001), YAMBER é o campo de força para proteínas mais preciso que YASARA nos pode oferecer (KRIEGER et al., 2004).

Dos substratos obtidos, foram selecionadas proteínas modelos para fazer DMAA, as quais permitem estudos mais profundos e não só de distâncias entre P0 e as possíveis âncoras. 
Dentre as análises realizadas com All Atom, foram feitas as análises gerais de RMSD e também análises focadas, como superposição de átomos das cadeias laterais das possíveis âncoras, distâncias entre átomos de P0 e âncoras P-2 e P-3. Foram feitas dinâmicas de $1 \mu \mathrm{s}$ em YASARA, a uma temperatura constante de $298 \mathrm{~K}$. Cada conformação foi salva a 100 ps, gerando dez mil conformações.

\subsection{Docking molecular de substratos proteínas quinases e Pks}

Docking ou acoplamento molecular é uma técnica que pode ser usada para predizer como um ligante pode interagir com o sítio de união de um receptor. O ligante pode ser uma pequena molécula, mas também pode ser uma proteína. As forças de interação, como Van der Waals, Coulombicas, ligações de hidrogênio, e outras, tem um papel importante nessas interações, e a soma de todas elas fornece o "Docking Score", que é o potencial de união entre o ligante e a proteína (PAGADALA; SYED; TUSZYNSKI, 2017). Existe uma grande diversidade de programas de docking, e dentre deles encontram-se os programas ab initio e data-driven. No primeiro tipo, a proteína é fixada no espaço, enquanto no outro tipo, ela é rodada e trasladada no entorno na primeira. Para cada nova configuração, um score é gerado baseado em vários termos, como por exemplo, complementaridade de superfícies, forças Van der Waals, e assim por diante.

Programas como TreeDock (FAHMY; WAGNER, 2002) baseiam-se em pontos de ancoragem que melhoram o docking, e são classificados de acordo com os potenciais Lennard-Jones. Já programas como HADDOCK, pelo contrário, fazem um docking tipo data -driven, ou seja, fazem uso de informação experimental ou predita para o processo de docking (DE VRIES; VAN DIJK; BONVIN, 2010). Como foi já mencionado, HADDOCK é um programa de docking dirigido por informação, que trabalha com 3 etapas sucessivas (RODRIGUES; KARACA; BONVIN, 2015):

- Início do docking com minimização de energia do corpo rígido,

- Refinamentos semi-flexíveis nos ângulos torsionais,

- Refinamento final em solvente explícito.

O modo de união do complexo protéico é feito, em grande medida, na primeira etapa, na qual os melhores complexos são dispostos de acordo com a pontuação HADDOCK (que é uma soma ponderada de forças eletrostáticas, Van der Walls, energias de restrição, área de 
superfície enterrada e termos de dessolvatação empírica), e usados para o refinamento da segunda etapa que permite pequenas ou médias mudanças conformacionais para melhorar a pontuação geral dos complexos proteicos. Finalmente, a terceira etapa é uma curta simulação de dinâmica molecular restringida (KARACA; BONVIN, 2013; RODRIGUES; KARACA; BONVIN, 2015).

O programa faz uso também das interações bioquímicas e biofísicas, e as informações sobre os resíduos que interagem são introduzidas como restrições de interação ambíguas (AIR), um tipo de dado que é derivado de informações experimentais dos resíduos envolvidos na interação intermolecular, os quais podem divididos em duas classes, ativos ou passivos. Os resíduos ativos são aqueles que necessariamente devem estar na interface do complexo e geram violações de restrição; já os resíduos passivos são os que outorgam informação experimental e se encontram próximos ao resíduo ativo, mas não geram violações de restrição. HADDOCK também permite incorporar restrições de distância chamadas de restrições de interação não-ambíguas (RODRIGUES; KARACA; BONVIN, 2015).

Os resultados do docking foram agrupados de acordo com as soluções de contatos comuns usando "FCC clustering", onde a melhor conformação de interação deve-se encontrar em um dos clusters (RODRIGUES et al., 2012). HADDOCK, então se diferencia de outros programas de docking pelo uso de uma grande diversidade de dados experimentais ou de bioinformática para fazer o modelamento (MELQUIOND; BONVIN, 2010).

O abordagem de docking foi feita para responder as seguintes perguntas:

- Qual é a capacidade das estruturas secundárias de fazer um acoplamento com a quinase?

- Qual é a conformação estrutural que as estruturas secundárias que apresentam P0 devem ter para que o gasto de energia seja mínimo e que ocorra acoplamento com a quinase?

Foram selecionados substratos de proteínas quinases gerados pelo programa YASARA, sendo que as proteínas selecionadas contém a sequência de aminoácidos onde se encontram o ponto de fosforilação e as âncoras nas posições P-2 e P-3. Finalmente, foram gerados os parâmetros HADDOCK para o acoplamento correspondente, e as proteínas foram usadas em docking dos tipos rígido e flexível. Sendo HADDOCK um docking de tipo 
dirigido, nos permite fazer restrições de distância para dirigir os substratos-quinases na fenda catalítica. A principal restrição de distância foi feita entre o sítio-P (P0) e ácido aspártico (Asp-166 para PKA e Asp-148 para PKC) com uma distância de $~ 8 \AA ̊$ entre os carbono alpha dos resíduos selecionados. Estas restrições foram usadas tanto para o docking rígido como para o flexível. O chamado docking proteína-proteína permitiu estudar o comportamento que deve ter a estrutura secundária para fazer um acoplamento com a proteínas quinase, bem como das possíveis mudanças conformacionais que devem acontecer nas estruturas secundárias do tipo $\alpha$-hélice para interagir com a PK.

Aqueles complexos fornecidos pelo HADDOCK que, embora sejam o melhor modelo para os casos selecionados, não tiveram um acoplamento que permitiu que o sítio-P da PK interagisse com a SBS do Substrato Quinase, passaram por um refinamento de Docking no programa YASARA para melhorar o acoplamento, levando em conta as mesmas restrições, adicionado molas com comprimentos finais ao redor de 4.0 $\AA$ entre os átomos HG do sítio-P e OD2 do ácido aspártico (Asp-166 para PKA e Asp-148 para PKC) das Pks. As possíveis âncoras foram também dirigidas aos sub-bolsões da fenda catalítica, simulando a interação do complexo PKI-PKA. 


\section{RESULTADO E DISCUSSÃO}

O fluxograma de trabalho planejado ao longo deste trabalho de Mestrado, permitiu mediante técnicas computacionais de biologia estrutural responder questões referente ao comportamento de proteínas pré-fosforiladas por PKs, e conhecer qual é a possível mudança estrutural que deve ocorrer para permitir a fosforilação do sítio-P. As técnicas usadas neste projeto são baseadas em diferentes revisões da literatura para sustentar nossa pesquisa, além da experiência dos pesquisadores e colaboradores de nosso laboratório em temas relacionados à fosforilação de proteínas.

A primeira seção dos resultados, "Seleção de um conjunto de estruturas de proteínas que são fosforiladas por PKs", apresenta o processo feito para a obtenção das proteínas substratos de PKs e a classificação estrutural dos sítios-P. A segunda seção, "Análise da variabilidade estrutural dos comprimentos entre sítios-P e suas âncoras P-2 e P-3 em $\alpha$ hélice", tenta responder se existem conformações dentro das dinâmicas das proteínas que apresentam sítios-P e possíveis âncoras lineares que permitam o encaixe desta na fenda catalítica de PKs ao igual que o complexo PKI-PKA. O problema conformacional é abordado com duas técnicas diferentes (Coarse Grained e All Atom).

Na terceira seção, "Proposta de mecanismo de interação entre PKs e substratos com sítios-P em $\alpha$-hélice", é proposto um modelo de interação entre PK e seus substratos usando âncoras localizadas em sítios-P em consenso lineares. Os resultados apresentados são resumidos na seguinte figura (Figura. 4). Com a finalidade de uma leitura mais fluida, quando se fale de distância entre o sítio-P e P-2 ou distância entre o sítio-P e P-3, será abreviado com d(P0_P-2) e d(P0_P-3), respectivamente. 


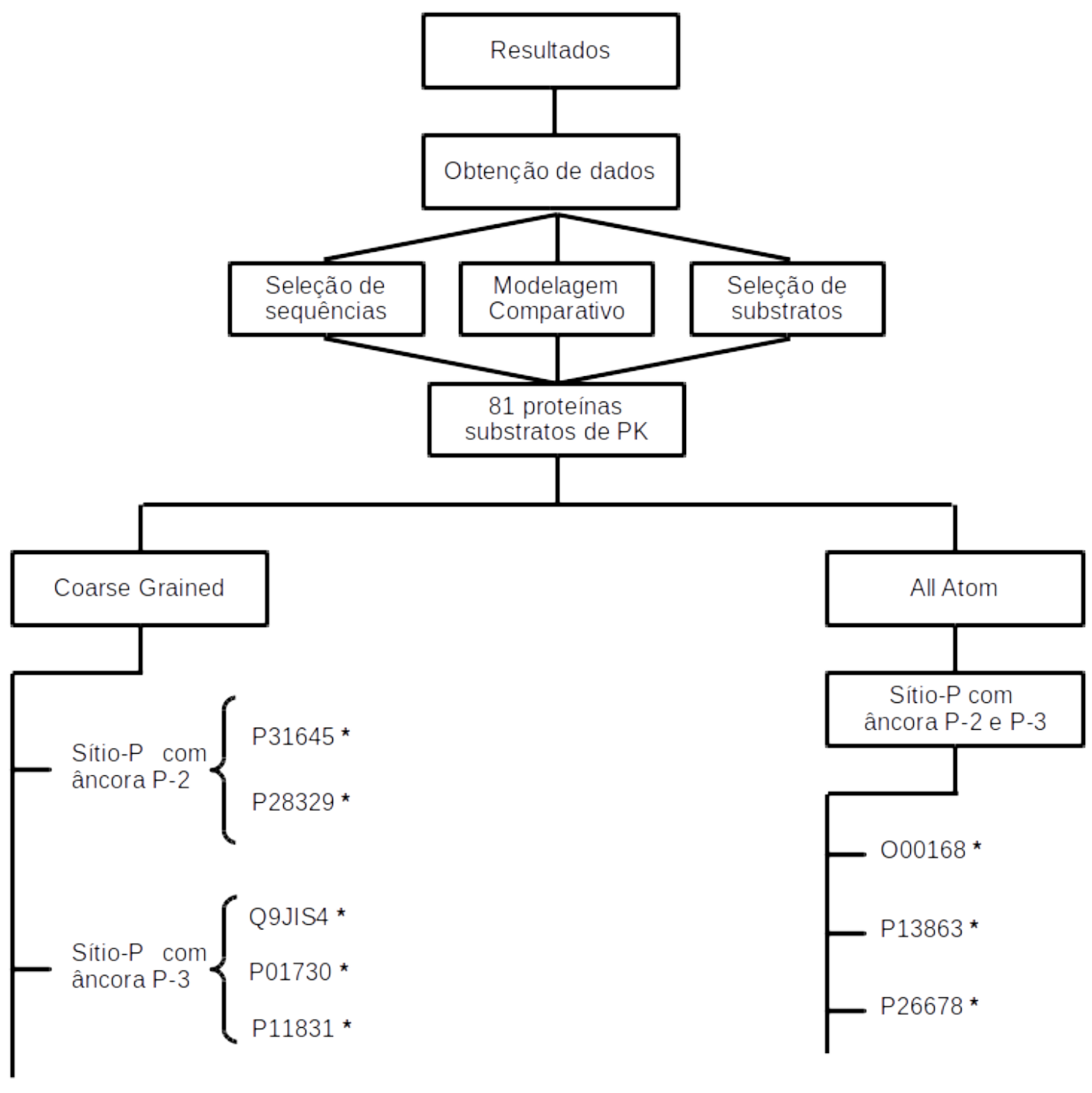

* Cod. UNIPROT

Figura 4. Fluxograma de resultados. Os códigos UNIPROT representam as seguintes proteínas: SERT (P31645), CHAT iso 3 (P28329), TREK-2 (Q9JIS4), CD4 (P01730), SRF (P11831), PLM (O00168), CDK1 (P13863), PLN (P26678).

\subsection{Seleção de um conjunto de estruturas de proteínas que são fosforiladas por Pks}

\subsubsection{Seleção de sequências de susbtratos fosforilados}

$\mathrm{Na}$ procura de proteínas substratos de PK na base de dados experimentais PhosphoSitePlus, foram identificados 987 sequências com sítios registrados para PKC, das quais, 870 pertencem a PKCA e 117 pertencem a PKCB. Destas só foram selecionadas 
mediante um BLAST-P aquelas que apenas tiveram sequência do sítio-P (15 aminoácidos) identificada em uma estrutura no banco de dados RCSB PDB. Desta forma, foram selecionadas 168 sequências substratos de PKC, 150 de PKCA e 18 de PKCB com estruturas 3D determinadas. A estas estruturas foram adicionadas 8 sequências de substratos de PKA que foram obtidas em um trabalho prévio feito no Laboratório (FERRAZ, 2017), fazendo um total de 176 sequências de substratos de PK com estruturas 3D determinadas (Fig. 5A).

Destas 176 sequências, 56\% tiveram o consenso linear de fosforilação $([\mathrm{R} / \mathrm{K}]$ [R/K]X[S/T]), sendo 22 sequências com os resíduos básicos Arg ou Lys na posição P-2 e P-3, 46 sequências com Arg ou Lys na posição P-2 e 31 sequências com Arg ou Lys na posição P3. Os $44 \%$ restantes não tiveram o consenso linear de fosforilação, mas apenas o sítio-P (Fig. 5B).

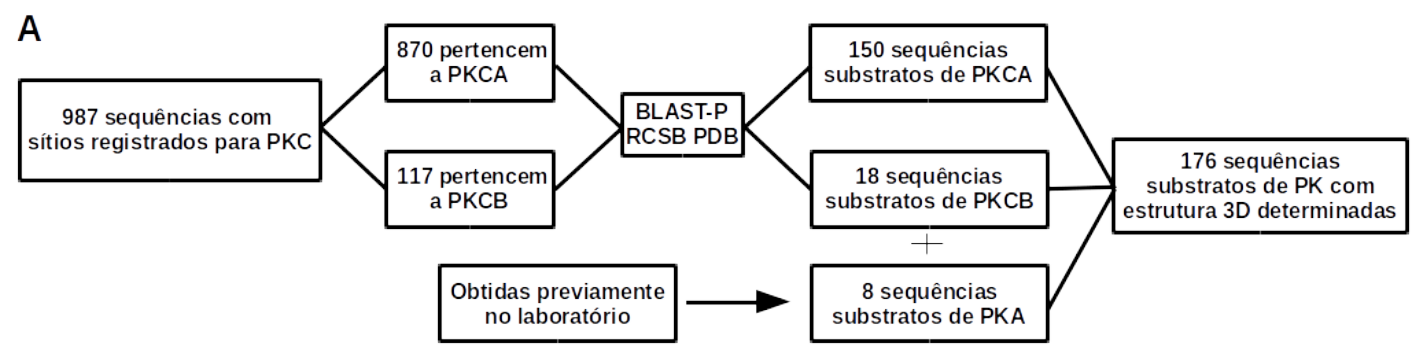

B

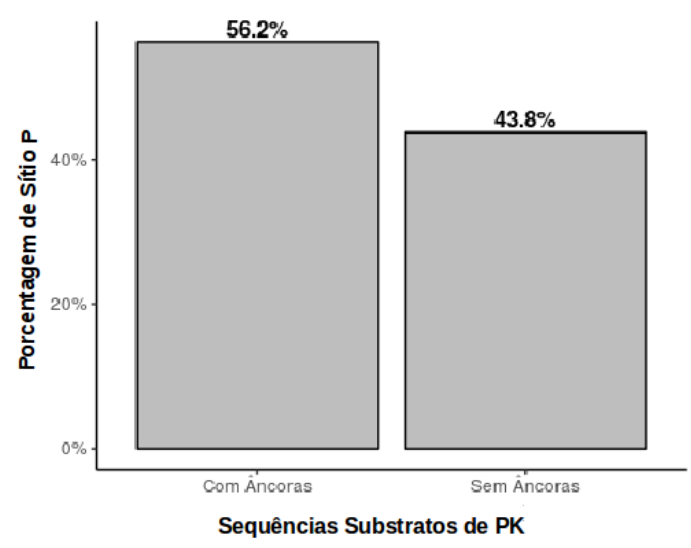

Figura 5. A) Fluxograma da seleção de sequências de substratos de PK com sítio-P verdadeiro, B) Distribuição de sítio-P verdadeiros divididos em aqueles que apresentaram consenso linear de fosforilação (com âncoras) e aqueles que não apresentaram consenso linear de fosforilação (sem âncoras). 


\subsubsection{Modelagem por Homologia de substratos de PKs e classificação de Sítios P}

Dado que um dos focos deste trabalho é observar o comportamento da proteína préfosforilada por PKs, tentou-se obter a estrutura completa da proteína-substrato que contém o consenso linear de fosforilação usando Modelagem por Homologia, mediante o código UNIPROT fornecido por PhosphoSitePlus . A Modelagem por Homologia feita em YASARA, gerou um total de 81 modelos proteicos para 176 sítios-P (Anexo B). Isso ocorre por que, em alguns casos,a mesma proteína contém mais de um sítio-P de PKs, ou ainda a mesma sequência é compartilhada por duas ou mais proteínas. Chamamos este conjunto de dados de “conjunto de sítios-P conhecidos" (CSPC).

Uma das primeiras análises feitas para o conjunto de sítios-P conhecidos foi identificar, em qual tipo de estrutura secundária o sítios-P estão preferencialmente localizados. José Jiménez e colaboradores sugerem que os sítios-P, em especial, Ser e Thr, tendem a estar em maior frequência em segmentos flexíveis, não-estruturados ou conectores entre domínios, seguidos por $\alpha$-hélices e finalmente por folhas- $\beta$ (JIMÉNEZ et al., 2007). Em nossos resultados, as $\alpha$-hélices apresentam uma maior quantidade de sítios-P, cerca de $\sim 50 \%$, seguida por loops, com cerca de $\sim 40 \%$ e finalmente por folhas- $\beta$, com menos de $5 \%$ (Fig. 6). Evidenciada a abundância de sítios-P em $\alpha$-hélices, que é um tipo de estrutura secundária relativamente regular e estável, chamou-nos a atenção como uma estrutura que tem parâmetros de distância relativamente pouco variáveis entre $C A$ vizinhos poderiam se adequar aos parâmetros de distância (P0_-P-2 e P0_P-3) relatados por nosso grupo (FERRAZ, 2017) para a ocorrência de fosforilação em um dado sítio-P. A primeira pergunta que nos surgiu foi: Será que existe uma predisposição estrutural para desenovelamento em $\alpha$ hélices que apresentam aminoácidos Ser, Thr ou Tyr?

Para determinar se a presença de um sítio-P (Ser, Thr ou Tyr) predispõe as $\alpha$-hélices a ter uma conformação diferente em relação àquelas que não apresentam este tipo de evento, nós avaliamos se algum parâmetro geométrico médio era estatisticamente diferente entre os dois conjuntos de dados: o conjunto de sítios-P conhecidos (CSPC, definido acima) e o conjunto de referência (ver seção 4.1.3 dos métodos). Para isso, procedeu-se a medição dos comprimentos das ligações de hidrogênio do conjunto de referência e das estruturas de substratos de proteínas quinase, entre o "O" do resíduo i-4 e o "N" do resíduo i (P0), e o "O" de i com o "N" do resíduo $\mathrm{i}+4$, já que a grande maioria de PDBs não são resolvidos com 
hidrogênios. É importante enfatizar que as duas primeiras e últimas voltas da $\alpha$-hélice não foram levadas em conta nos cálculos.

\section{A}

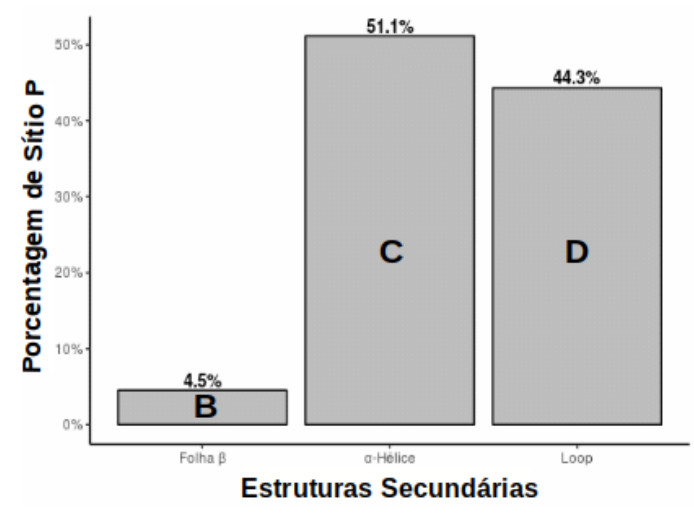

B

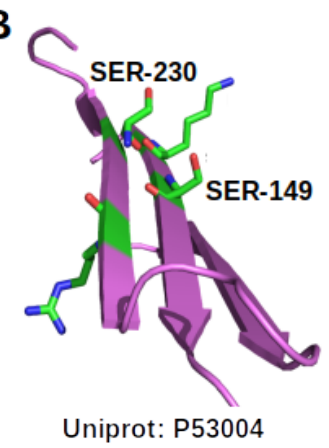

C

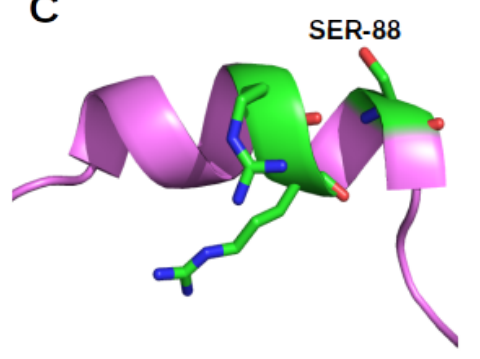

Uniprot: 000168

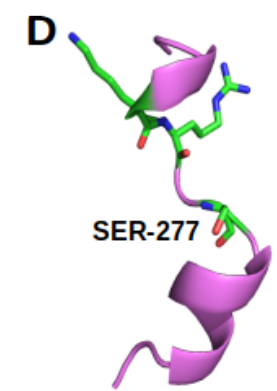

Uniprot: P13863

Figura 6. Disposição de sítios $\mathrm{P}$ em estruturas secundárias de $\mathrm{PKs}$ (A), mostrando exemplos do sítio $\mathrm{P}$ (em verde e nomeados) e seus respetivas âncoras dentro das estruturas secundárias do tipo folha $\beta$ (B), $\alpha$-hélice (C) e loops (D).

O resultado revela, que as médias do comprimento de ligações de hidrogênio em $\alpha$ hélices entre o CSPC e o conjunto de referência, são muito próximas, com 3.003 $(+/-0.18)$ e $3.039 \AA(+/-$ 0.38), respectivamente (Fig. 7). O teste de Mann-Whitney U, revela que a diferença entre os dois grupos analisados não é estatisticamente significativa por ter um $p$ value de 0.6259 .

Apesar de não ser evidente que exista uma diferença entre $\alpha$-hélices com sítios-P e outras $\alpha$-hélices, devemos levar em consideração que estamos analisando somente uma das conformações possíveis para cada um dos substratos. Para o caso de proteínas CSPC, submetemos essas estruturas a um processo de minimização de energia que tende a otimizar distâncias de ligações de hidrogênio. O conjunto de referência tem estruturas que podem estar enviesadas pela força do empacotamento cristalino. Para avaliar um espaço conformacional mais abrangente dos substratos do CSPC, avaliamos dados obtidos experimentalmente através 
de NMR e dados obtidos por simulações de dinâmica molecular com o objetivo de responder a questão: $O$ que deve ocorrer na $\alpha$-hélice para permitir a fosforilação?

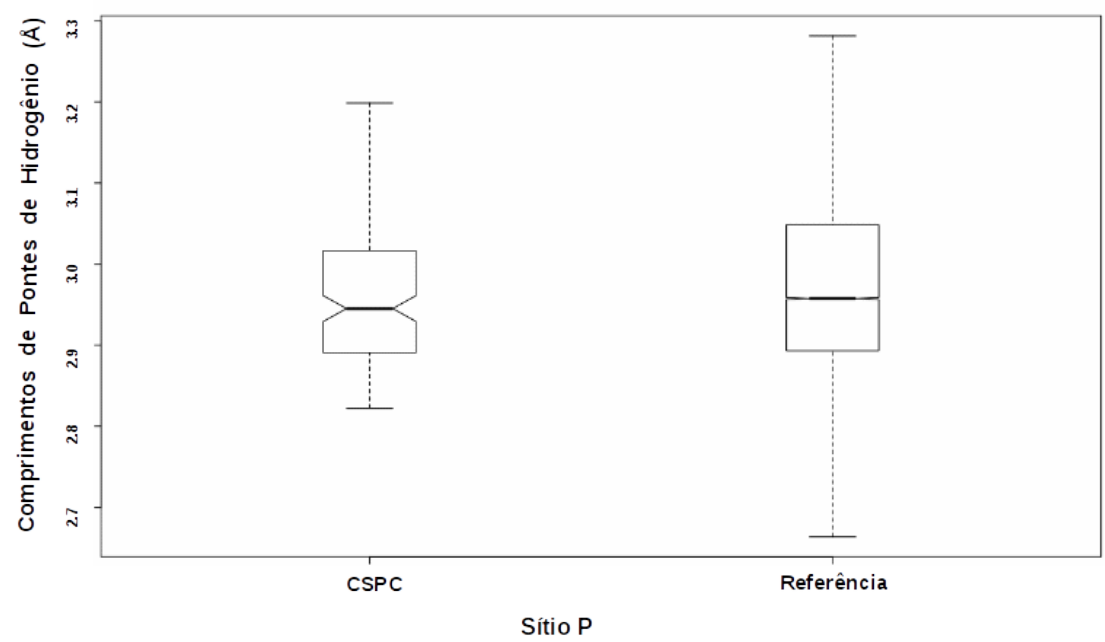

Figura 7. Comparação entre os comprimentos das pontes de Hidrogênio nos sítios $P$ conhecidos e não conhecidos (qualquer Ser, Thr ou Tyr dentro das hélice) com os aminoácidos i-4, i+4 respectivos, onde i é a posição do sítio $\mathrm{P}$, ou os aminoácidos Ser, Thr ou Tyr, na sequência primaria de aminoácidos.

\subsection{Análise da variabilidade estrutural dos comprimentos entre sítios-P e suas âncoras P-2} e P-3 em $\alpha$-hélice

Uma das características dos sítios-P em nosso grupo de proteínas é a presença do consenso linear de fosforilação e, dentro deles, os aminoácidos âncoras nas posições P-2 e P3. Estudos revelaram que, na maioria dos casos, a PK interage não só com o sítio-P na fenda catalítica, mas com até 4 aminoácidos adicionais, os quais podem interagir com porções da PK que estão fora do sítio ativo (KNIGHTON et al., 1991a). Além disso, normalmente estes aminoácidos têm complementaridade de carga, ligações de hidrogênio ou interações hidrofóbicas com os aminoácidos presentes na PK (BROWN et al., 1999; HOLMES; SOLOMON, 2001). Para entender a variabilidade estrutural dos comprimentos entre sítio-P e suas âncoras P-2 e P-3 em $\alpha$-hélices, foram usadas duas técnicas, dinâmicas Coarse Grained e dinâmicas All Atom. 


\subsubsection{Dinâmicas Coarse Grained das proteínas de nosso conjunto de dados.}

Foi realizada uma análise comparativa das distâncias dos $\mathrm{C} \alpha$ entre estes sítios-P (P0) e suas âncoras P-2 e P-3 do conjunto de dados de substrato de PKs com sítios-P em estruturas helicoidais com as distâncias dos $\mathrm{C} \alpha$ nas mesmas posições conhecidos para PKI, um peptídeo inibidor de fosforilação de PKA. Esse peptídeo apresenta as distâncias necessárias para interagir com a quinase (Fig. 8A), sendo que a distância entre Ala-21 (P0) e Arg-19 (P-2) é de

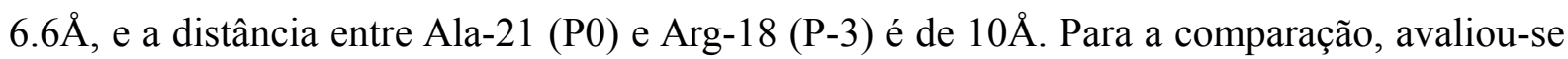
as distâncias em diferentes conformações das hélices nas proteínas-substratos estudadas. Sabidamente, as distâncias encontradas em uma hélice enovelada são bastante distintas das consideradas ideais para a ligação nas PKs (Fig. 8B).

A
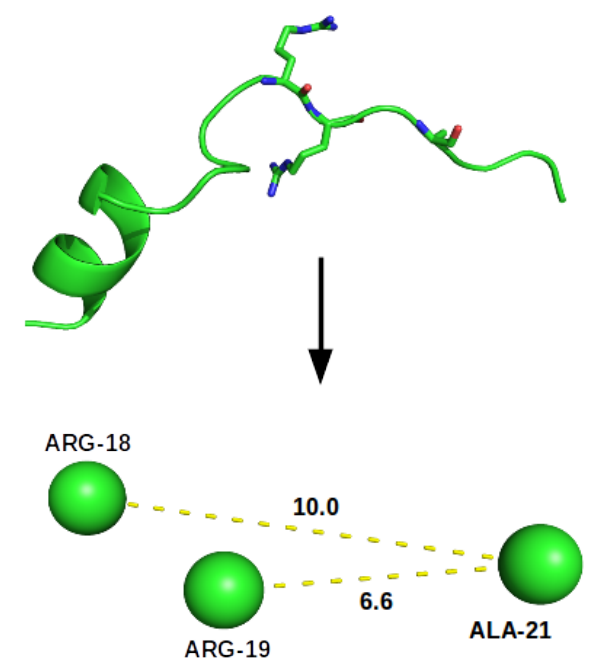

B
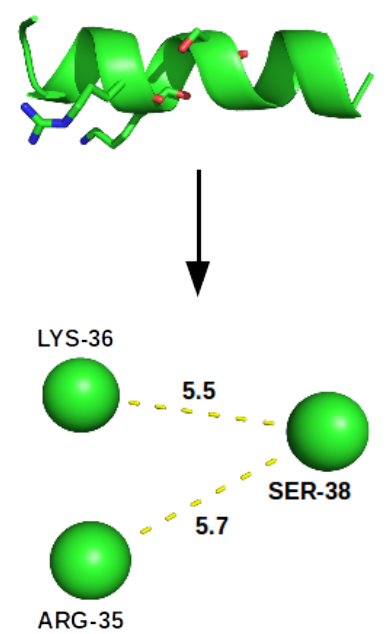

Figura 8. A) Distâncias entre os Ca do sítio-P Ala-21 (P0) e suas âncoras lineares Arg-19 (P-2) e Arg 18 (P-3) do peptídeo PKI (PDB 1FMO), peptídeo inibidor de fosforilação de PKA B) Seguimento da proteína HES1 (Cod. UNIPROT Q14469), mostrando distâncias entre os C $\alpha$ do sítio-P Ser-38 (P0) e seus possíveis âncoras lineares Lys-36 (P-2) e Arg-35 (P-3) .

Neste contexto, a abordagem adotada nas análises foi o uso do programa CafeMol, que permite fazer simulações de dinâmica molecular na escala Coarse Grained. Os parâmetros escolhidos para a proteína $K C I P-1$, são mostrados como exemplo (Fig. 9). É importante destacar o uso de L_FLP e AICG2_PLUS, duas funções de energia, que têm como dependência o ângulo diédrico, o que pode ser manipulado na seção de "flexible_local", a qual contém duas variáveis que são os pesos dos potenciais locais flexíveis para o ângulo diédrico e as ligações virtuais. Normalmente, estes definidos como 1.00 (default), mas neste 
caso usamos 0.2 para permitir maior flexibilidade das variáveis ao longo da dinâmica, já que o valor de 1 pode levar a uma super-estabilização das proteínas, e como já é conhecido que os sítios-P se encontram nas $\alpha$-hélice que geralmente permanecem bem dobradas, um potencial local com uma flexibilidade mais realista é importante (LI et al., 2012).
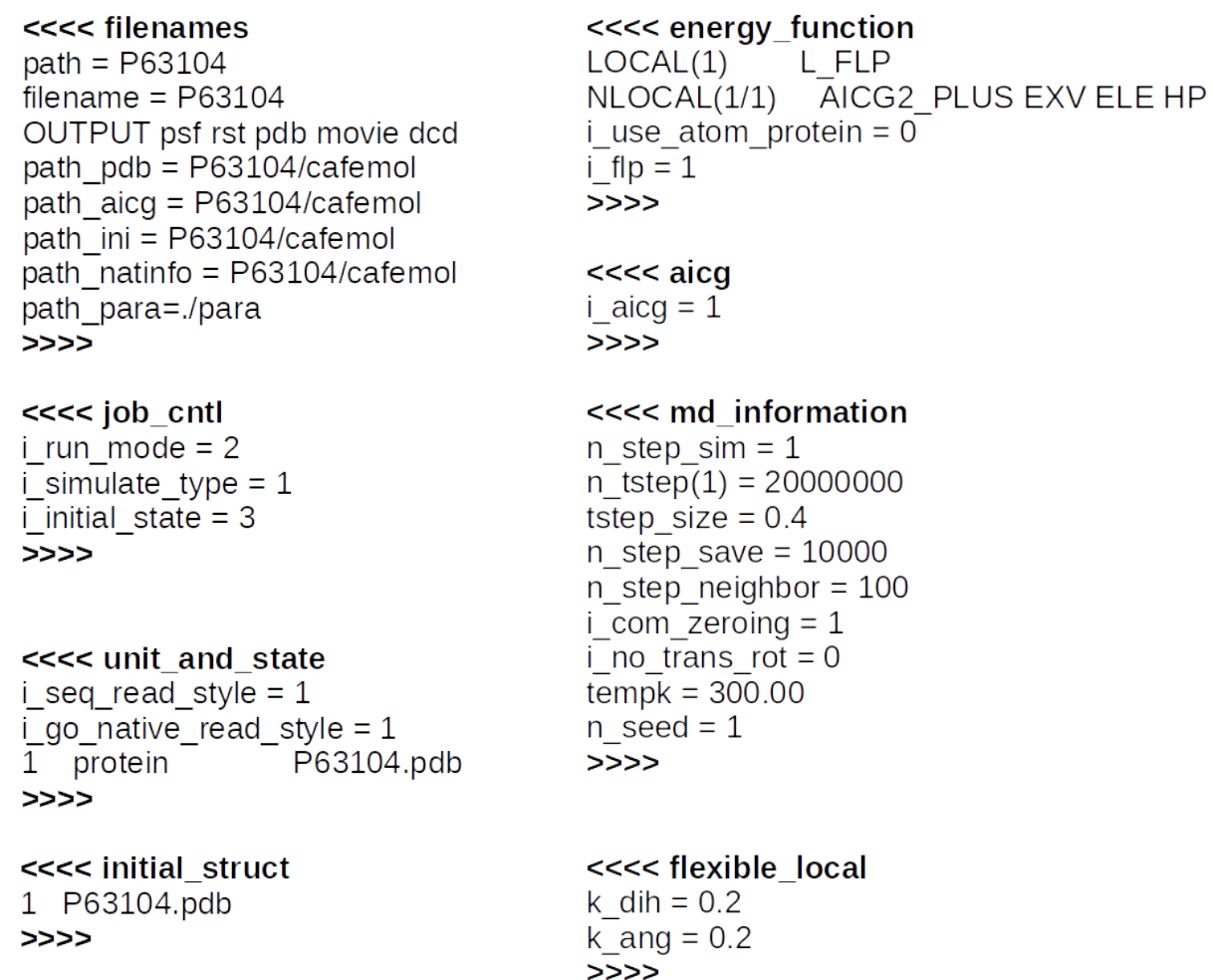

Figura 9. Exemplo do arquivo inp utilizado para a proteína 14-3-3 protein zeta/delta (Cod UNIPROT P63104); filenames: Define o diretório onde a data de saída é salva; job_cntl: Configuração de controle de trabalho; unit_and_state: leia a informação da seqüência; initial_struct: Estrutura inicial., energy_function: Energias locais e não locais; aicg: como construir parâmetros AICG; md_information: Informação para na Dinâmica Molecular; flexible_local: Forçar constantes para potencial local flexível.

Feita a dinâmica Coarse Grained de $1 \mu$ s para todas as 81 proteínas da nossa base de dados, foi obtida a média dos comprimentos das d(P0-P-2) e d(P0_P-3) dos C $\alpha$ para cada sequência substrato de PK durante toda a dinâmica Coarse Grained correspondente. Os resultados revelam que para as $\alpha$-hélice, as médias dos comprimentos das distâncias entre P0

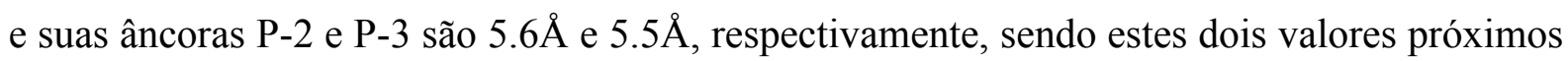
ao comprimento das d(P0_P-2) da PKI. Nenhum dos dois valores médios se aproxima ao valor da d(P0_P-3) da PKI, as distâncias médias obtidas não seriam ótimas se comparadas com as distâncias entre os $\mathrm{C} \alpha$ de $\mathrm{PKI}$, em especial a d(P0_P-3), que não apresenta um comprimento de cerca de $10 \AA$ para interagir como uma âncora linear com a PK respectiva (Fig. 10A). Esta análise permitiu observar que dentro dos boxplot gerados para P-2 e P-3, foram encontrados valores que saíam da média, os quais foram identificados e posteriormente 
analisados (Fig. 11, 12). Também foram medidos o valores máximos dos comprimentos das distâncias entre os C $\alpha$ de P0 - P-2 e P0 - P-3 durante todas as dinâmicas Coarse Grained de cada proteína (Fig. 10B). Esta análise nos permitiu observar quais mudanças conformacionais podem ocorrer nas $\alpha$-hélices que contém um sítio-P em sua estrutura para cumprir com os requisitos de distâncias observadas no modelo de PKI.

A partir destes dados decidimos analisar as estruturas cujas distâncias estavam fora dos intervalos da média tanto para os valores médios da Figura 9A como para os valores máximos da Figura 9B. As proteínas fora da média na Figura 10A para P0-P-2 e P0-P-3 apresentam o sítio-P no N-terminal das $\alpha$-hélices com valores médios de $6.2 \AA$ e $9.1 \AA$, respectivamente, e pertencem à proteína Sodium-dependent serotonin transporter (Cod. UNIPROT P31645) e Choline O-acetyltransferase (Cod. UNIPROT P28329).

A análise dos valores máximos (Fig. 10B) revelou que todas as estruturas secundárias aumentaram suas distâncias ao redor de $1 \AA \AA$, como é esperado para os loops, por serem estruturas que apresentam uma alta flexibilidade, correspondendo muito à regra PKI (Fig. $\mathbf{8 A}$ ), enquanto isto não acontece em média com as distâncias para $\alpha$-hélice e folhas- $\beta$. Porém, existem conformações para estas duas últimas estruturas que poderiam adquirir os valores necessários de distância para se acomodarem na fenda catalítica, no caso de $\alpha$-hélices apresentaram em P0-P-3 um aumento de distância que podem ir até ao redor de $10 \AA \AA$, como é o caso de Choline O-acetyltransferase. Outras proteínas também tiveram grandes variações para P0-P-3 como o casos de Potassium channel subfamily K member 10 (Cod UNIPROT Q9JIS4 ) e T-cell superficie glycoprotein CD4 (Cod UNIPROT P01730), ambas com sítios-P dentro da $\alpha$-hélice, e Serum response factor (Cod UNIPROT P11831), com sítio-P no Nterminal. 

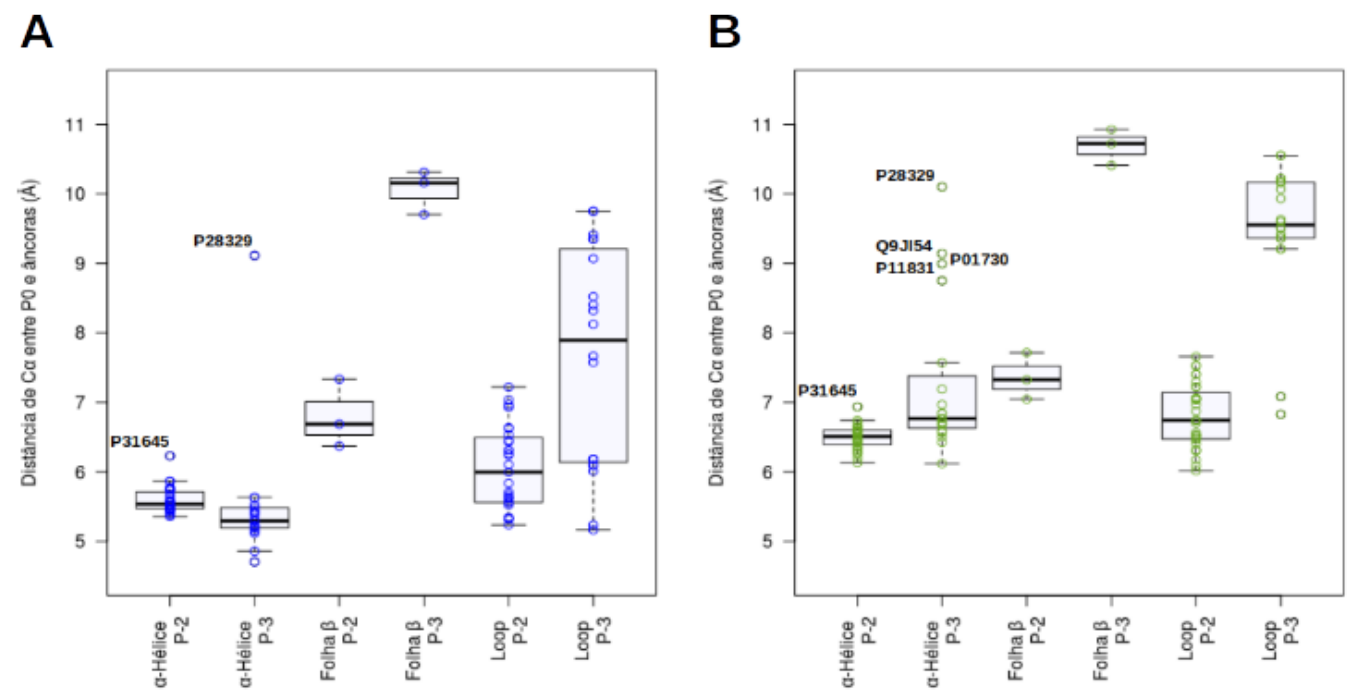

Figura 10. Distâncias entre os C $\alpha$ do sítio-P e suas âncoras lineares P-2 e P-3 para cada proteína, em A está representado o valor médio da distância ao longo da dinâmica e em $\mathbf{B}$ os valores máximo da distância ao longo da dinâmica.

\subsubsection{Análises de proteínas fora dos intervalos da média dos valores médios}

Sodium-dependent serotonin transporter (Fig. 11) têm um sítio-P verdadeiro na posição Ser-277 e apresenta um aminoácido positivo na posição P-2, Lys-275, que pode ser considerado como âncora linear pela d(P0_P-2) que que faz parte de um consenso linear [R/K]X[S/T] (SHABB*, 2001). No caso de Choline O-acetyltransferase (Fig. 12), que têm um sítio-P verdadeiro na posição Thr-255 e apresenta um aminoácido positivo na posição P-3, Lys-252, o valor médio desta proteína (9.1 ̊) é próximo à d(P0_P-3) de PKI. Segundo estudos, a posição Thr-255 no N-terminal da $\alpha$-hélice facilita a fosforilação desta proteína sem requerer rearranjos conformacionais substanciais da hélice que contém o sítio-P (DOBRANSKY et al., 2004). 


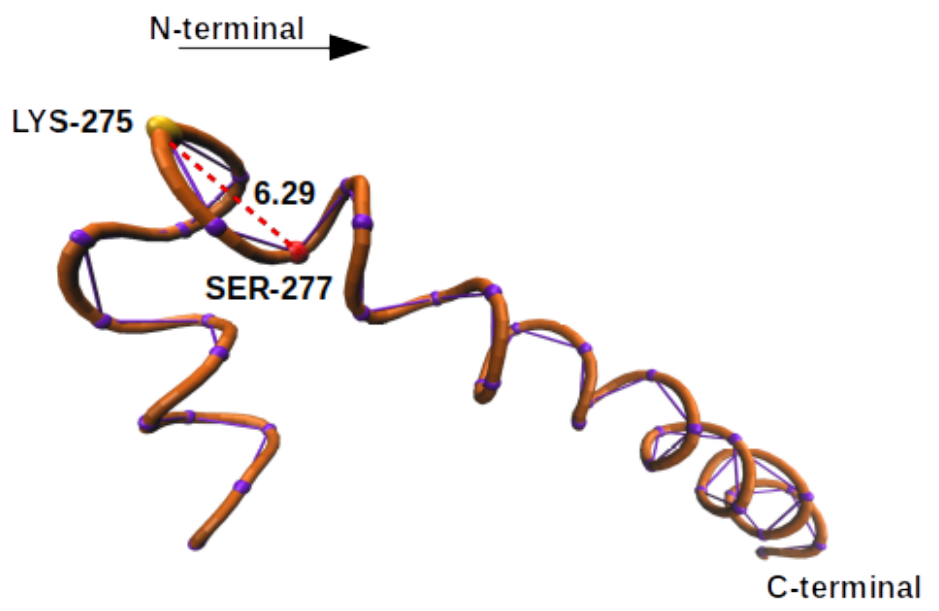

Figura 11. Segmento da proteína Sodium-dependent serotonin transporter, que contém o sítio P (ponto vermelho), mostrando a distância entre os C $\alpha$ P0 (Ser-277, vermelho) e P-2 (Lys-275, amarelo).

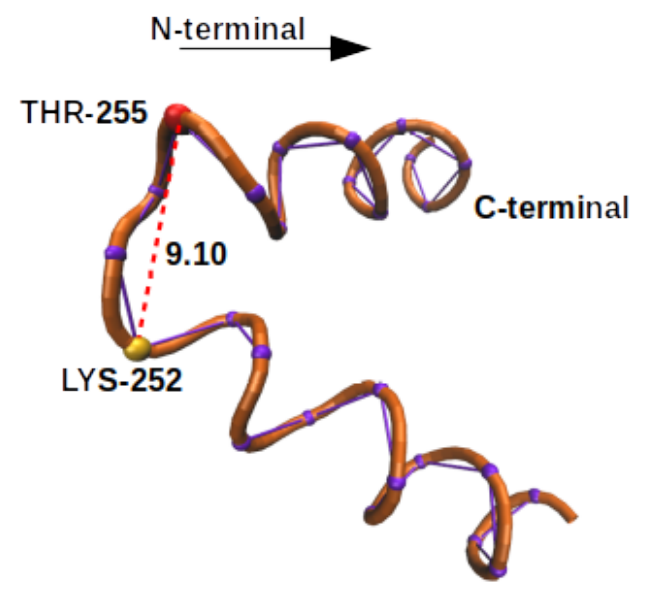

Figura 12. Segmento da proteína Choline O-acetyltransferase, que contém o sítio $\mathrm{P}$ (ponto vermelho), mostrando o comprimento da distância entre os Ca P0 (Thr-255, vermelho) e P-3 (Lys-252, amarelo).

\subsubsection{Análises de proteínas fora dos intervalos da média dos valores máximos}

Na proteína Potassium channel subfamily K member 10 (TREK-2), o sítio-P se encontra no centro da $\alpha$-hélice, portanto sua âncora também se encontra dentro da $\alpha$-hélice. A análise da dinâmica Coarse Grained revela que existe uma mudança conformacional estrutural da $\alpha$-hélice que contém o sítio-P (Fig. 13), e ela ocorre justamente entre o sítio-P (Ser-326) e seu aminoácido na posição linear P-3 (Arg-323). 


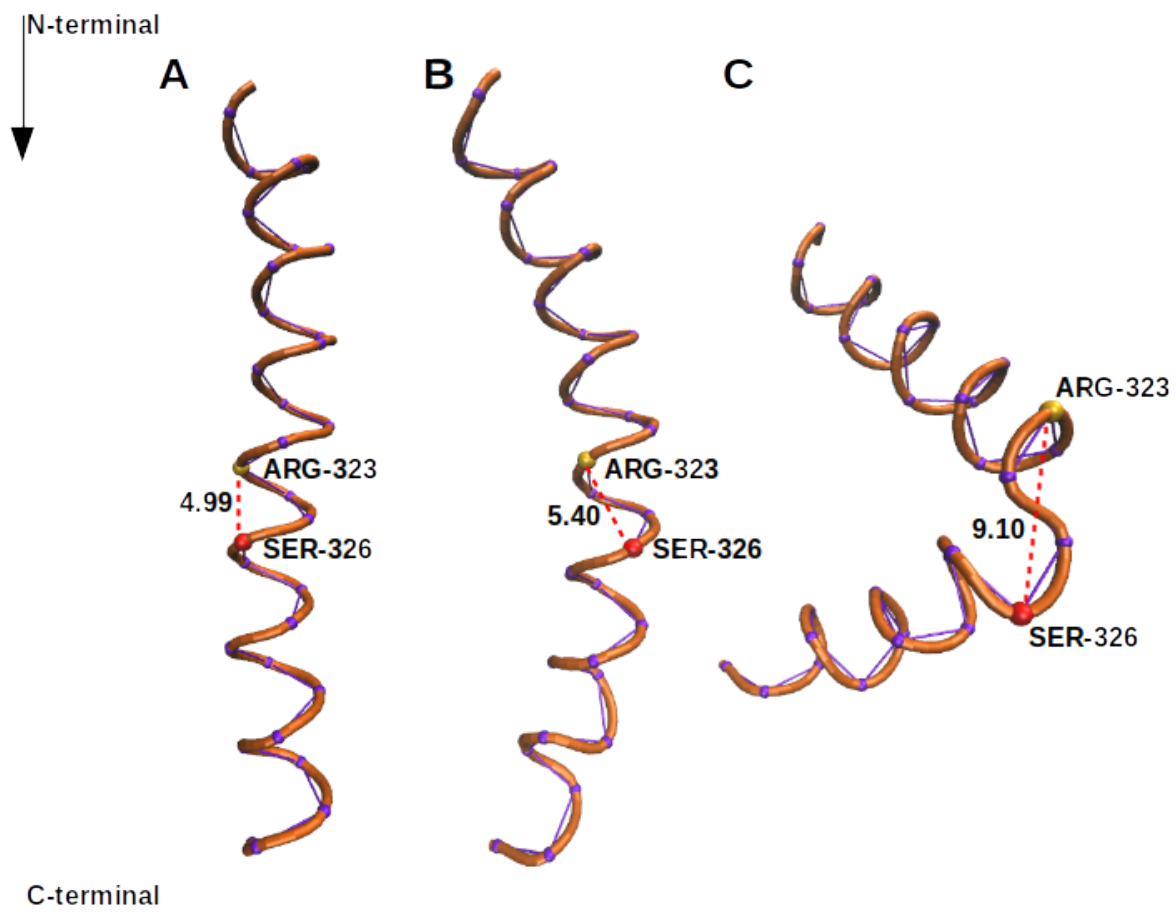

Figura 13. Segmento da proteína Potassium channel subfamily $K$ member 10, que contém o sítio P (ponto vermelho), mostrando a distância entre os C $\alpha$ de P0 (Ser-326, vermelho) e P-3 (Arg-323, amarelo) em diferentes estados conformacionais da $\alpha$-hélice ao longo da dinâmica Coarse Grained. A) Frame inicial da

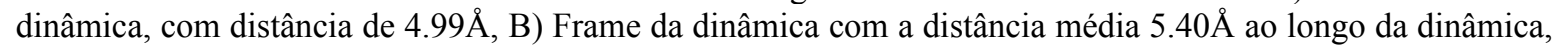
C) Frame da dinâmica mostrando a flexibilidade da $\alpha$-hélice cuja distância máxima foi $9.10 \AA$.

No caso da proteína T-cell surface glycoprotein CD4, o sítio-P se encontra no Cterminal da $\alpha$-hélice, e seu aminoácido correspondente, na posição P-3, se encontra no meio desta estrutura secundária. A análise da dinâmica revela que, assim como na proteína TREK2, ocorre uma mudança conformacional local dentro da $\alpha$-hélice durante a dinâmica (Fig. 14), permitindo uma distância máxima ao redor de $9 \AA$ (Fig. 14C). A proteína Serum response factor contém uma $\alpha$-hélice que apresenta o sítio-P no N-terminal, e diferente das duas proteínas mencionadas anteriormente, aqui não ocorreu uma mudança conformacional substancial da $\alpha$-hélice (Fig. 15). 


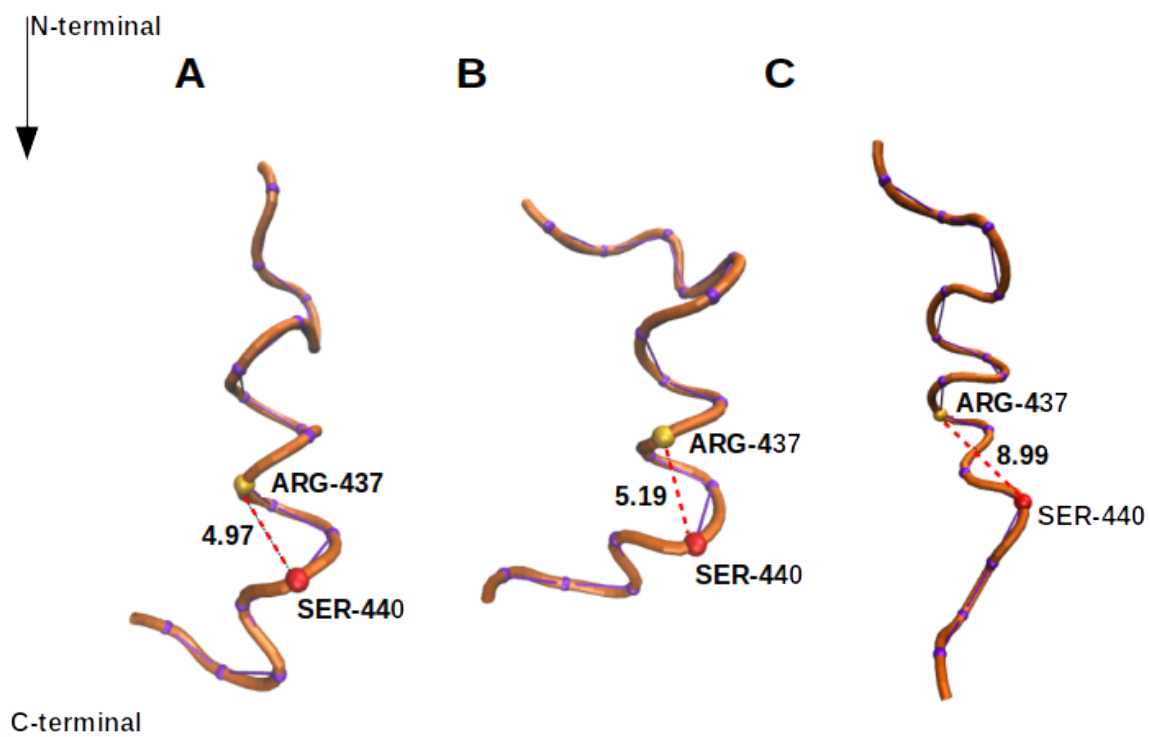

Figura 14. Segmento da Proteina T-cell surface glycoprotein CD4, que contém o sítio P (ponto vermelho), mostrando a distância entre os C $\alpha$ de P0 (Ser-440, vermelho) e P-3 (Arg-437, amarelo) em diferentes estados conformacionais da $\alpha$-hélice ao longo da dinâmica Coarse Grained. A) Frame inicial da dinâmica com distância de 4.97Å, B) Frame da dinâmica com a distância média de 5.19 ̊ ao longo da dinâmica, C) Frame da dinâmica mostrando a distância máxima $8.99 \AA$, que implica no desenovelamento da estrutura secundária.

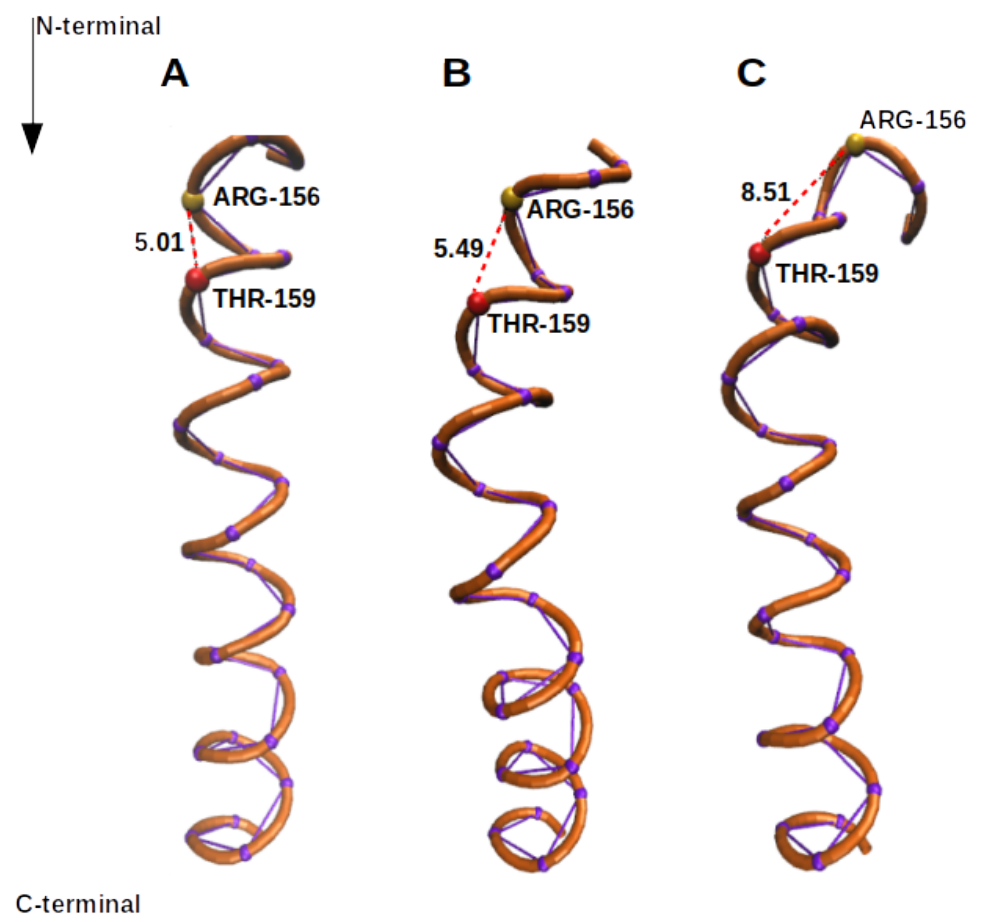

Figura 15. Segmento da proteína Serum response factor, que contém o sítio P (ponto vermelho), mostrando a distância entre os Ca de P0 (Thr-159, vermelho) e P-3 (Arg-156, amarelo) em diferentes estados conformacionais da $\alpha$-hélice ao longo da dinâmica Coarse Grained. A) Frame inicial da dinâmica com uma

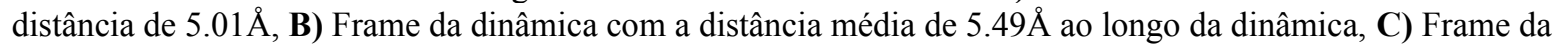
dinâmica mostrando a distância máxima de $8.51 \AA ̊$, que implica em pouco desenovelamento na região $\mathrm{N}$ terminal enquanto o restante da hélice mantém sua estrutura. 
Os resultados das análises destas $\alpha$-hélices com dinâmicas Coarse Grained permitem corroborar as hipóteses levantadas neste trabalho, ou seja, que se o sítio-P apresentar um consenso linear na região N-terminal das $\alpha$-hélices, não ocorrerão mudanças conformacionais substanciais, porque Ser ou Thr são aminoácidos que ocorrem frequentemente em posições Nterminais (WILLIAMS et al., 1987), e as cadeias laterais destes aminoácidos podem adotar rotâmeros favoráveis para se ligar a grupos NH livres da cadeia principal mediante ligações de hidrogênio (ANDREW et al., 2002). Estudos revelam que quando o aminoácido Ser nesta posição é fosforilado, a $\alpha$-hélice se torna mais estável (PULLEN et al., 1995; SMART; MCCAMMON, 1999). Em nosso caso, observamos que mesmo que um sítio-P verdadeiro com consenso linear ainda não esteja fosforilado e se encontrar no N-terminal da $\alpha$-hélice, esta tende a ser mais estável ao longo da dinâmica Coarse Grained, sem sofrer mudanças conformacionais estruturais (Fig. 11., 12., 15). A diferença nos casos onde o sítio-P se encontra no interior da $\alpha$-hélice e a presença de um sítio-P verdadeiro com consenso linear é suficiente para que a $\alpha$-hélice sofra uma mudança conformacional (Fig. 13) ou sofra um desenovelamento (Fig. 14) (ANDREW et al., 2002; SZILÁK et al., 1997).

Como é observado na Figura 10, a proteína TREK-2 tem uma mudança conformacional que ocorre estritamente entre os aminoácidos Arg-323 (P-3) e Ser-326 (P0), enquanto o restante da $\alpha$-hélice não sofre uma mudança conformacional tão visível como ocorre entre os aminoácidos mencionados. As características químicas dos aminoácidos ao redor do sítio-P Arg-323 (P-3), Val-324, Leu-325, Ser-326 (P0), Lys-327, Lys-328, Thr-329, permitem que isto ocorra. Magnus Monné e colaboradores (MONNÉ; HERMANSSON; VON HEIJNE, 1999), em um estudo sobre a predisposição dos aminoácidos em $\alpha$-hélice transmembrana, revelam que os aminoácidos Ser, Trp, Val, Leu não são favoráveis para manter a forma da $\alpha$-hélice, apresentando uma propensão de volta menor ou igual a 0.7 , ao contrário dos aminoácidos que apresentam uma maior propensão de volta, como Arg (1.7) ou Lys (1.6) (BALLESTEROS et al., 2000). Tendo esta referência, os aminoácidos Val-324 e Leu-325 são dos aminoácidos com menor propensão (0.5 e 0.4, respectivamente), permitindo que essa porção da hélice se desenovele, fazendo com que Arg-323 esteja a uma distância de seu C $\alpha$ com relação do sítio-P de ao redor de $\sim 9 \AA$, e assim possa servir de âncora linear de Ser-326 e logo ser fosforilada por PKCA (KANG et al., 2007; KANG; HAN; KIM, 2006).

O caso de T-cell surface glycoprotein CD4 (Fig. 14) têm relação com TREK-2 em relação aos aminoácidos presentes entre a âncora P-3 e o sítio-P porque nesta proteína, que 
também é uma proteína de membrana, e os aminoácidos entre Arg-437 (P-3) e Ser-440 (P0), são Leu-438 e Leu-439, como já foi mencionado. Este aminoácido é um dos que têm a mais baixa propensão de volta (0.4), o que permitiu o desenovelamento da $\alpha$-hélice ao longo da dinâmica até ter uma distância ao redor de $9 \AA \AA$, fazendo com que P-3 adquira uma distância ótima para atuar como âncora e permitir a Ser-440 ser fosforilada. É sabido também que a fosforilação desta Ser-440 pode alterar a conformação da $\alpha$-hélice (JIN et al., 2004).

Conforme demonstrado, as distâncias podem variar no caso P-2 em até $1 \AA$, permitindo que esta possa ser uma âncora linear, sem ter uma mudança conformacional substancial. Mesmo assim esta se encontra no centro ou C-terminal da $\alpha$-hélice. No caso de P3 , como já foi apresentado, as $\alpha$-hélices podem ter grandes mudanças conformacionais que permitem que os aminoácidos nesta posição possam ser uma âncora do sítio-P com distância adequada. Na Figura 9, pode-se observar que os sítios- $\mathrm{P}$ em folhas- $\beta$ cumprem com as distâncias de PKI, os valores médios achados para os P0 e suas âncoras P-2 e P-3 em folhas- $\beta$ foram $6.8 \AA \AA$ e $10.0 \AA$, respectivamente. No caso de loops, que são estruturas secundárias muito flexíveis, a variação de comprimento é muito ampla, o que permite que as âncoras se movimentem adquirindo as distância ideais para a fosforilação.

\subsubsection{Dinâmicas All Atom para a análise dos substratos selecionados}

Apesar de simulações de dinâmica molecular Coarse Grained permitirem simulações mais longas em tempos computacionais bem menores, seu modelo reducionista pode não descrever corretamente os sistemas moleculares como os modelos atomísticos completos. Foram escolhidos 3 exemplos dos substratos obtidos pela técnica de modelagem por homologia para ilustrar o consenso linear de fosforilação. Eles foram usados em dinâmicas All Atom feitas com o programa YASARA, com uma duração de $1 \mu$ s a uma temperatura constante de 298K, gerando 10.000 conformações por dinâmica.

\subsubsection{Sítio-P em N-terminal e C-terminal com âncoras ao início e ao meio da $\alpha$-hélice}

A proteína Fosfolenman (PLM) (código UNIPROT O00168) (Fig. 16) é fosforilada nos resíduos Ser-83 e Ser-88. Estes sítios-P apresentam possíveis âncoras lineares, Arg-81 (P2) no caso da Ser-83, e Arg-86 (P-2), Arg-85 (P-3), no caso da Ser-88. As d(P0_P-2) inicial entre $\mathrm{C} \alpha$ foram $5.4 \AA$ e $5.2 \AA$, para Ser-83 e Ser-88, respetivamente. A d(P0_P-3) inicial entre 
C $\alpha$ foram 5.3Å para Ser-88. A primeira análise feita na dinâmica All Atom foi identificar os aminoácidos menos variáveis quanto ao movimento do $\mathrm{C} \alpha$, o que permitirá alinhar a proteína toda por estes aminoácidos. Para isso, foi usada a função de Bio3d, "core.find”, que devolve os índices dos aminoácidos com menor movimento durante toda a dinâmica molecular.

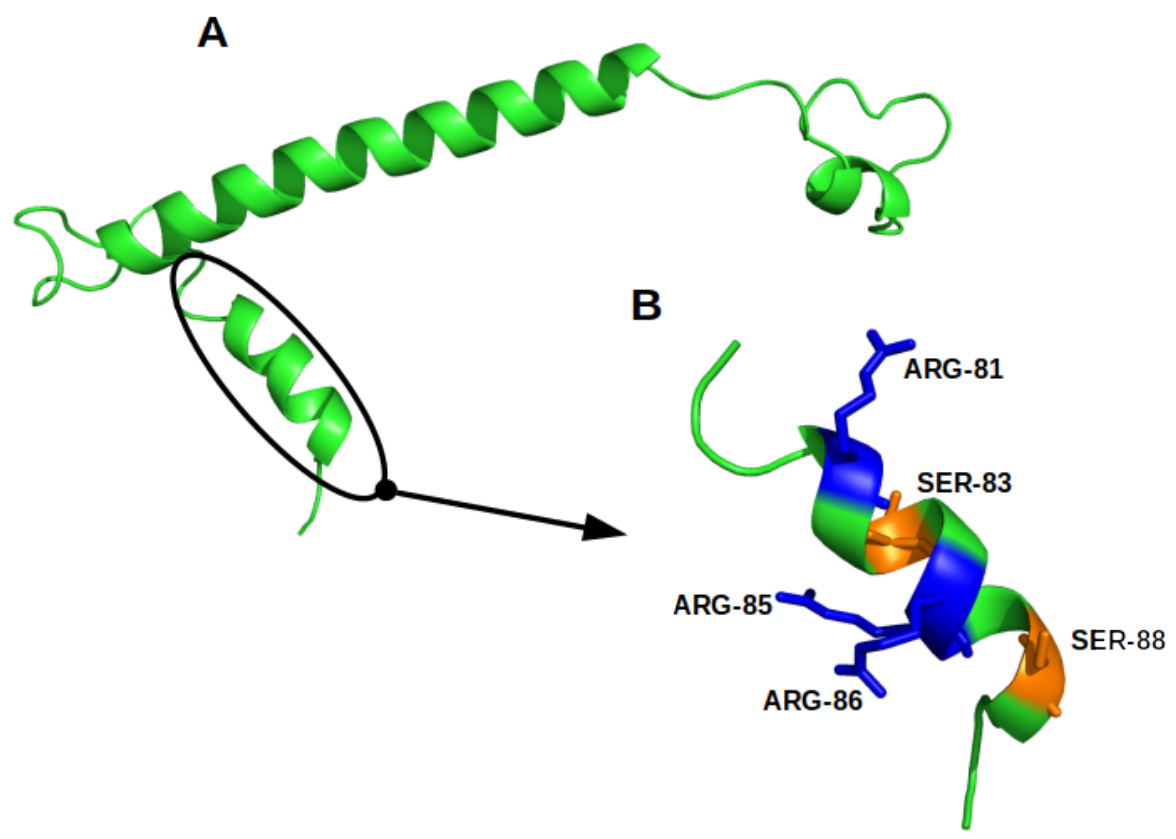

Figura 16. Proteína Fosfolemman, mostrando em "sticks" os aminoácidos Ser 83 e Ser 88, que são os possíveis pontos de fosforilação dentro da hélice. A imagem também mostra a âncora P-2 Arg-81, que é âncora de Ser 83, e os aminoácidos Arg-85 e Arg-86 que são âncoras P-3 e P-2 de Ser-88, respectivamente. Arg-81 se encontra na posição P-7 em relação à Ser-88.

Foram medidas as distâncias entre os C $\alpha$ do sítio P (Ser-88) e suas possíveis âncoras nas posições P-2 (Arg-86) e P-3 (Arg-85), o que permitirá observar as distâncias e a relação que existe entre elas. $\mathrm{O}$ que fica evidente nos resultados é que existe uma relação entre os comprimentos das distâncias (Figs. 17, 18 e 19). Quando entre os frames 2500 e 5000 as distâncias tendem a diminuir entre os $\mathrm{C} \alpha$ de Ser-88 e Arg-86, as distâncias entre os C $\alpha$ de Ser88 e Arg-85 aumentam. O movimento dos aminoácidos de dentro da $\alpha$-hélice não é independente um do outro, pois eles se movimentam em grupo, seguindo um padrão. As distâncias máximas medidas foram de $6.03 \AA ̊$ entre os sítios P0 e P-2, e $6.49 \AA ̊$ entre os sítios $\mathrm{P} 0$ e P-3, distâncias próximas àquelas já conhecidas entre P0 e P-2 de PKI, o que teoricamente torna P-2 uma possível âncora por se encontrar a uma distância ótima. 


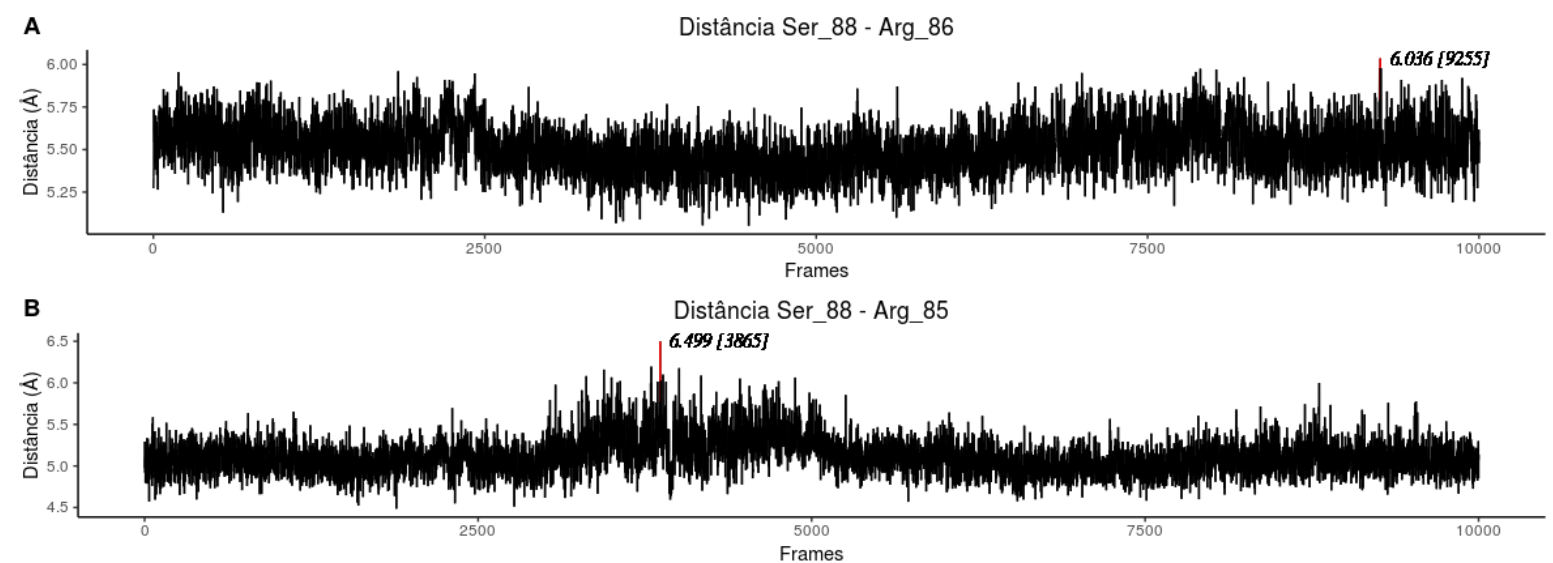

Figura 17. Distribuição de distâncias ao longo dos frames da dinâmica. Notar que entre os frames 2500 e 5000, as distâncias diminuem em A (P-2 - P0) e aumentam em B (P-3 - P0), voltando a ser constantes depois em ambos os casos. A distância máxima é mostrada com uma linha vermelha.

Já que a mesma $\alpha$-hélice apresenta um segundo ponto de fosforilação na posição Ser83, o qual apresenta uma possível âncora na posição Arg-81 (P-2), foi também medida a distância entre os $C \alpha$ destes aminoácidos, sendo o valor máximo obtido de $5.942 \AA ̊$ (Fig. 18).

As distâncias entre os aminoácidos mencionados revelam que esta $\alpha$-hélice de PLM com sítio-P no C-terminal apresenta uma possível âncora linear P-2 dentro da $\alpha$-hélice, já que a distância é semelhante a P-0 - P-2 de PKI. Foi medido o comprimento das ligações de hidrogênio dentro da $\alpha$-hélice para saber se existe outro tipo de mudanças conformacionais dentro da $\alpha$-hélice ao longo da dinâmica.

Os resultados revelam que, ao longo da dinâmica, a $\alpha$-hélice apresenta deformações estruturais por causa do aumento do comprimento das ligações de hidrogênio entre os aminoácidos Phe-80_Ile-84 e Ile-84_Ser-88. Para a primeira ligação de hidrogênio formada entre Phe-80 e Ile-84, ao redor do conformação 2500 (250ns), existe um aumento do comprimento da ligação de hidrogênio que dura até a conformação 6000 (600ns., Fig. 19A). No caso da segunda ligação de hidrogênio medida, Ile-84 - Ser-88, o aumento ocorre entre 600 ns e 700 ns (Fig. 19B). Uma sobreposição destas duas medições revela que estas duas ligações de hidrogênio tendem a se complementar (Fig. 19C). 


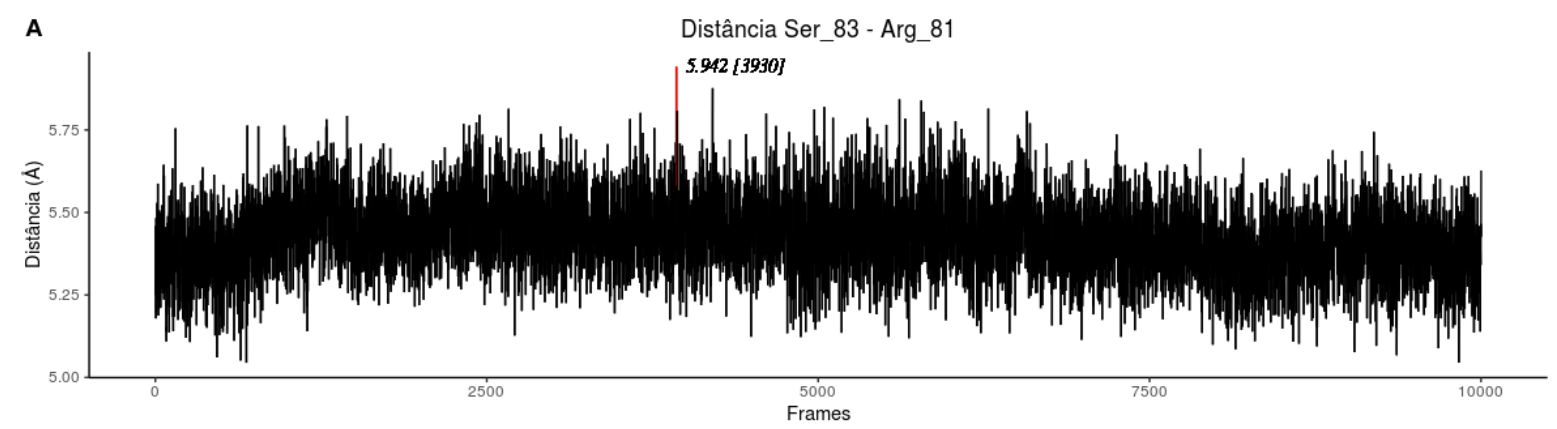

B

Distância Ser_88 - Arg_86

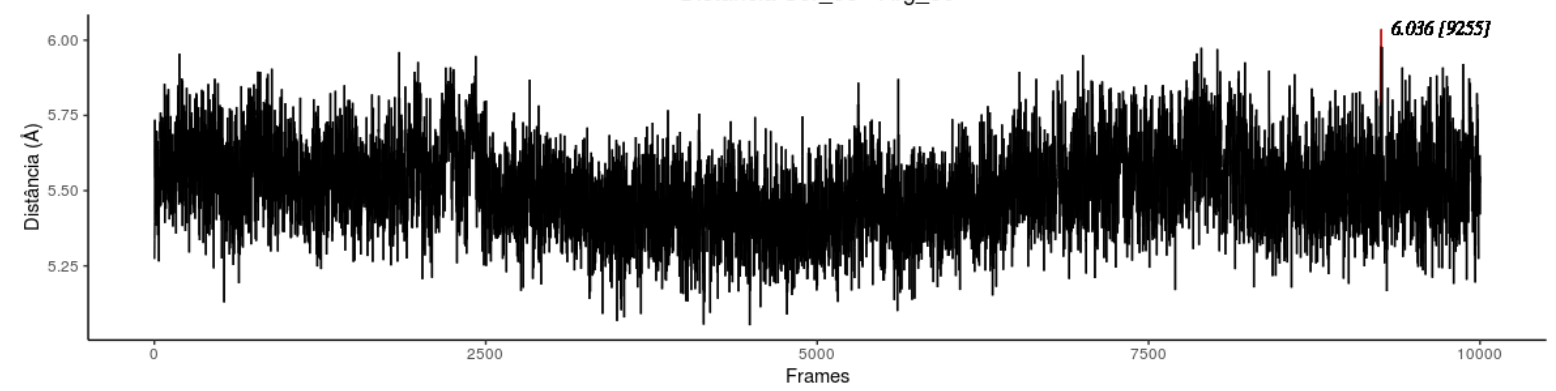

Figura 18. Distribuição de distâncias ao longo dos frames da dinâmica, A) Distância entre Ser-83 (P-0) e Arg-81 (P-2) que mostra um comprimento constante durante a dinâmica, diferente de B) que mostra uma diminuição da distância entre Ser - 88 e Arg - 86 nos frames 2500 - 5000.

Sabendo então que existe uma deformação dentro da $\alpha$-hélice durante um período de tempo, foi criado um script em R com o pacote "Bio3D" que tomamos átomos "CA" ,"CB" ,"NE" e "CZ" das âncoras de PKI para fazer uma sobreposição destes átomos com as âncoras de PLM durante toda a dinâmica. O menor RMSD entre os átomos fixados revelariam a conformação mais próxima, ou seja, a conformação que têm as âncoras com semelhante predisposição tridimensional que servirá para fazer o Docking molecular entre PLM e PKCA. Os resultados fornecidos mostram que a conformação com menor RMSD com respeito aos átomo fixados foi a conformação 5006, com um valor de $1.285 \AA$ (Fig. 20). 


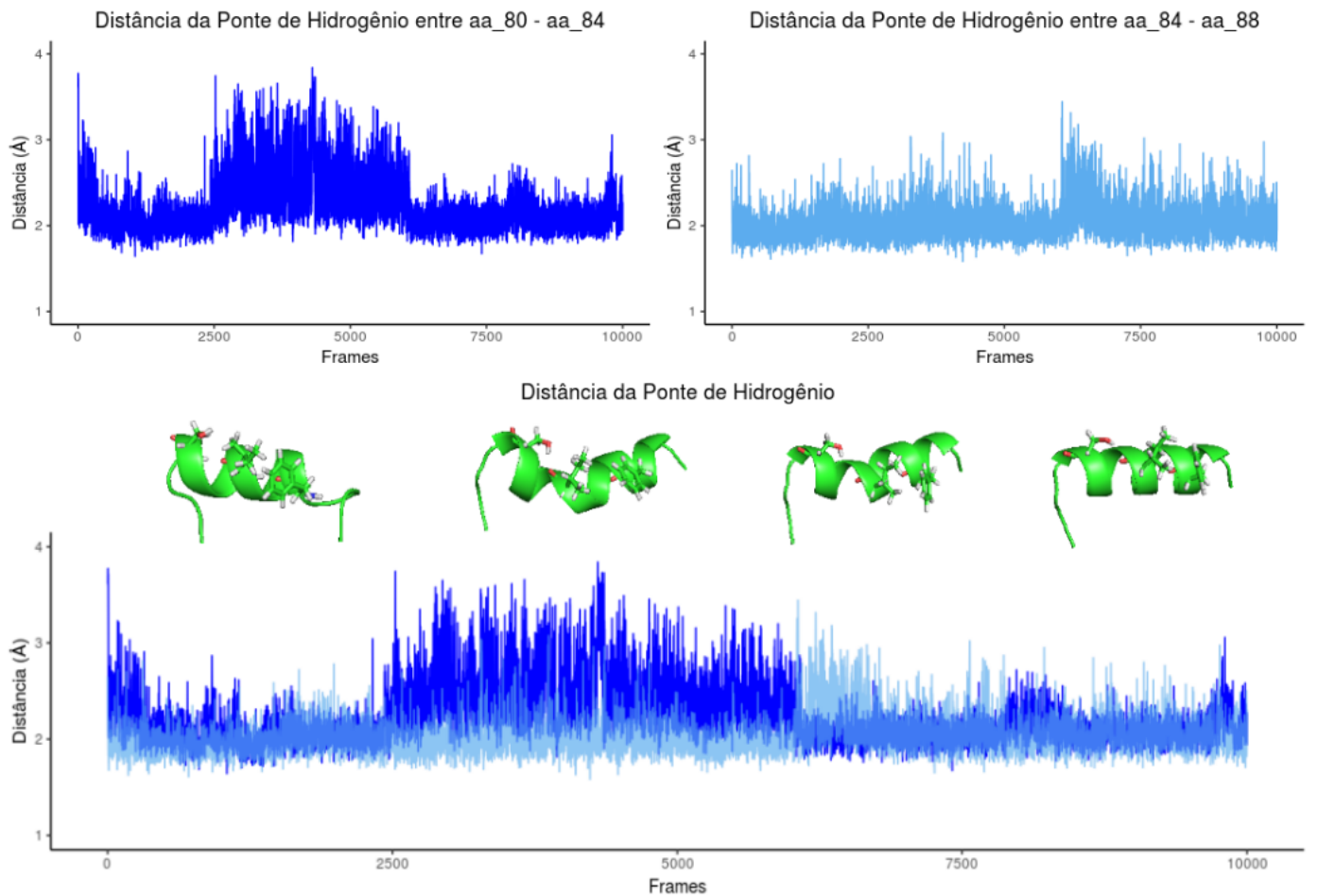

Figura 19. A) A distância da ponte de hidrogênio entre Phe- 80 e Ile- 84 , aumenta a partir do frame 2500 (250 ns) até o frame 6000 (600 ns). O caso de B) a ponte de hidrogênio só apresenta um pequeno aumento entre os frames 6000 e 7000 (600 ns - 700 ns). Finalmente em C) vemos a sobreposição das distâncias A e B, mostrando também em cartoon o desenovelamento da hélice ao longo da dinâmica.

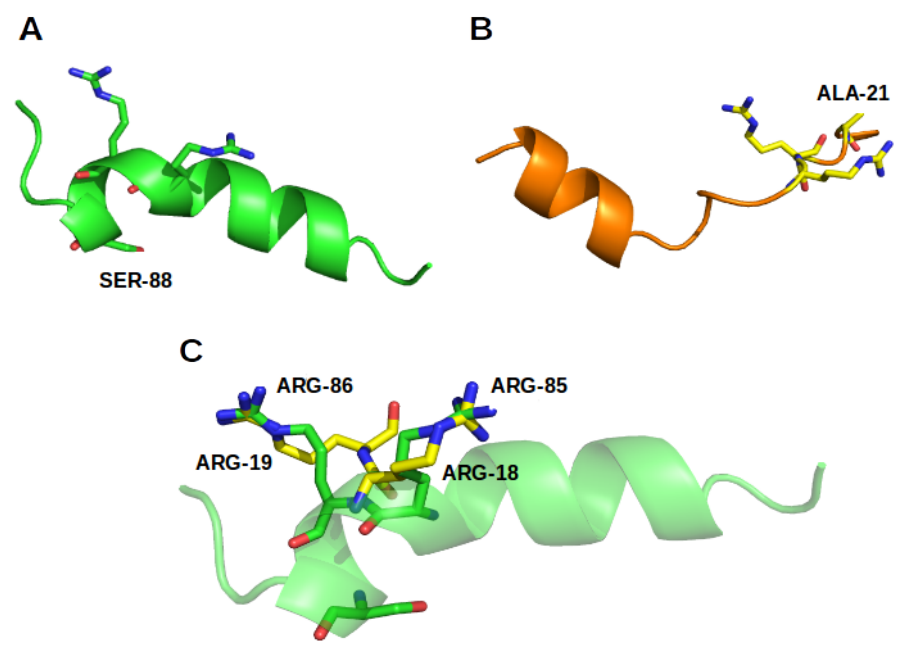

Figura 20. A) Segmento do frame 5006 da proteína PLM, mostrando o aminoácido Ser- 88 em C-terminal da $\alpha$-hélice e as âncoras Arg-85, Arg-86. B) Em amarelo, os aminoácidos Ala-21 e as âncoras deste Arg-18 Arg19 de PKI. C) Sobreposição das possíveis âncoras de PLM (verde e nomeados) com as âncoras de PKI (amarelo). 


\subsubsection{Sítio-P perto de N-terminal e âncoras fora da a-hélice}

A proteína Cyclin dependent kinase 1 (CDK1) (código UNIPROT P13863) apresenta um sítio de fosforilação no resíduo Ser-277 perto do início da N-terminal (KREK; NIGG, 1991). Este sítio de fosforilação contém dentro da sequência de aminoácidos duas possíveis âncoras lineares na posição Arg-275 (P-2) e Lys-274 (P-3), as quais se encontram em um loop entre duas hélices (Fig. 21). Assim como PLM, CDK1 foi alinhada pelos aminoácidos menos variáveis com a função core.find de Bio3d, e a distância entre o $\mathrm{C} \alpha$ do sítio-P e os $\mathrm{C} \alpha$ das possíveis âncoras foram medidas. Os resultados das medições permitem observar que as distâncias entre estes aminoácidos são quase constantes durante a dinâmica toda, com valores médios de distâncias de $6.22 \AA$ e $8.48 \AA$ para P0_P-2 e P0_P-3, e valores máximos que se aproximam das distâncias entre os $\mathrm{C} \alpha$ do sítio-P de PKI e suas âncoras já conhecidas (Fig. 22).

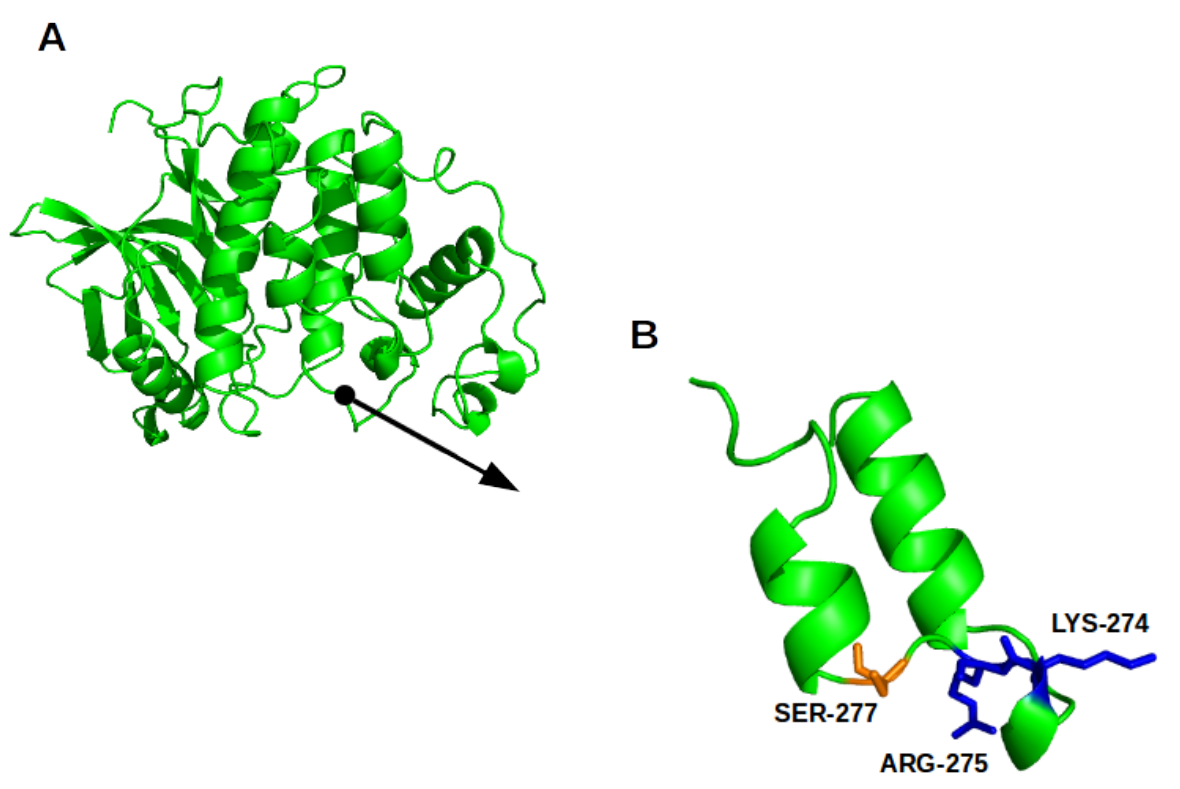

Figura 21. A) Proteína CDK1, B) mostrando em "sticks" o aminoácido Ser 277, sítio de fosforilação na região N-terminal, e as possíveis âncoras na posição Lys-274 e Arg-275 (P-3 e P-2 respectivamente). 


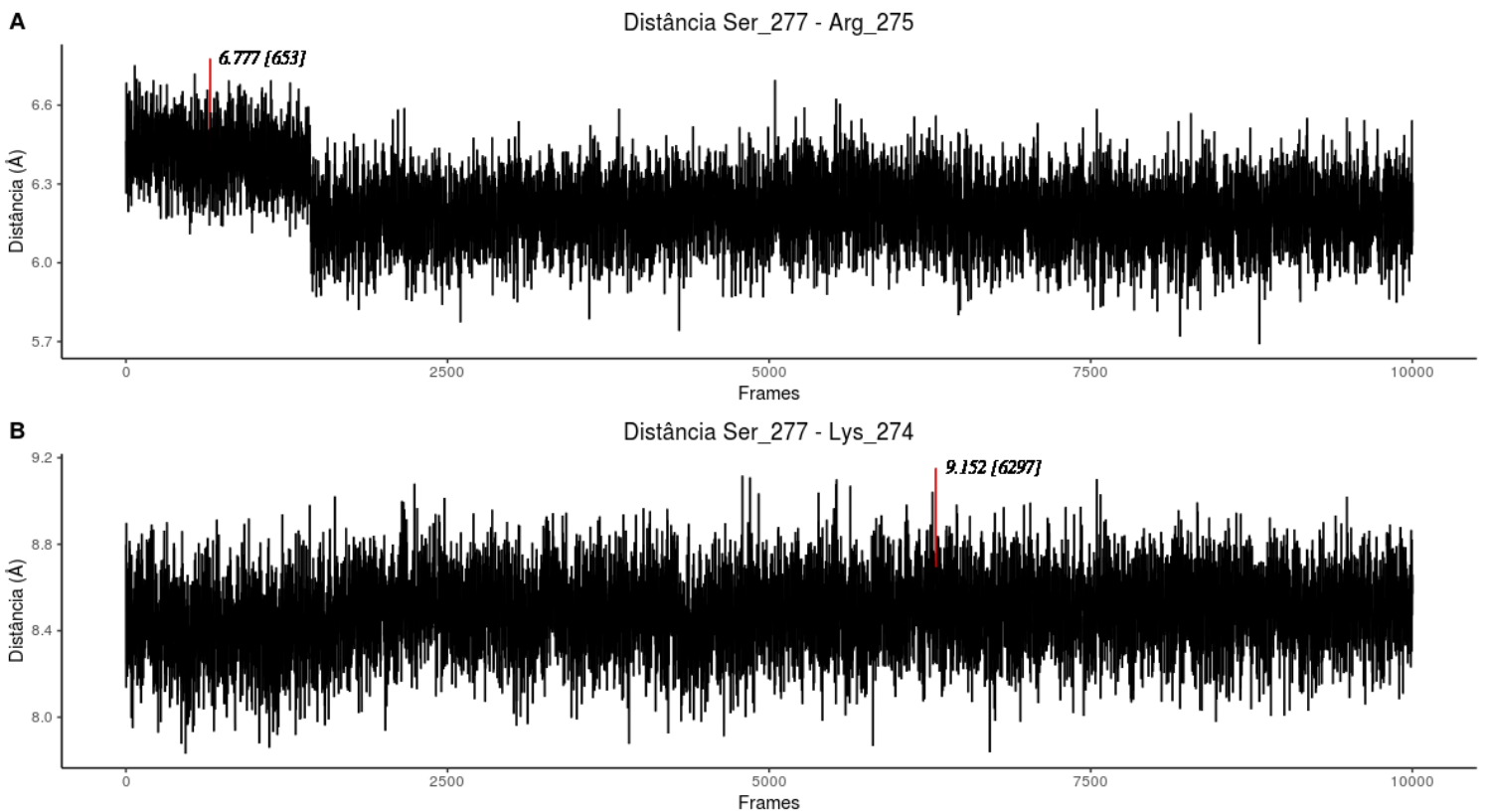

Figura 22. Distribuição de distâncias ao longo dos frames da dinâmica. Notar que as distâncias são quase constantes durante a dinâmica toda, e que os valores máximos de elas (linha vermelha), são próximos das distâncias entre os $\mathrm{C} \alpha$ do sítio P de PKI e suas âncoras.

A seleção do frame mais próximo com relação a seu RMSD dos átomos fixados das âncoras de PKI e as possíveis âncoras de CDK1 revela que o frame 540 da dinâmica é aquele que apresenta maior semelhança dos átomos selecionados, enquanto na predisposição $3 \mathrm{D}$ de seus átomos com um valor RMSD de $1.042 \AA$ (Fig. 23).

A

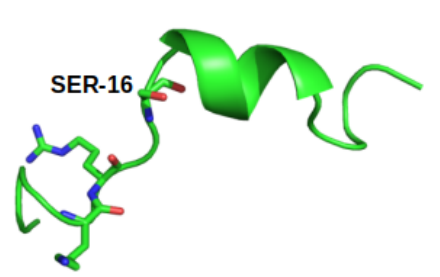

B

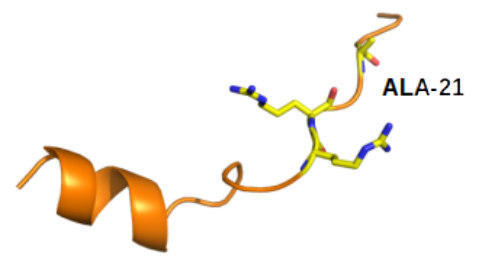

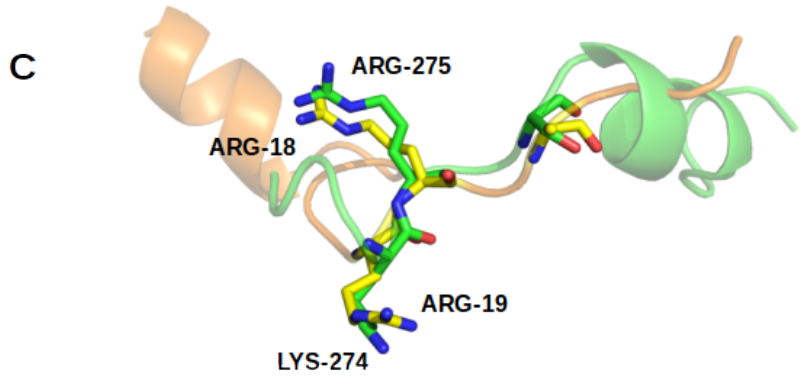

Figura 23. A) Sítio $\mathrm{P}$ do frame 504, mostrando o aminoácido Ser-277 perto de N-terminal e as âncoras Lys275, Arg-274. B) Em amarelo os aminoácidos Ala-21 e as âncoras deste Arg-18 Arg-19 de PKI. C) Sobreposição das possíveis âncoras de CDK1 (verde) com as âncoras de PKI (amarelo). 


\subsubsection{Sítio-P em C-terminal e âncoras dentro da $\alpha$-hélice}

Fosfolanbam (PLN) (código UNIPROT P26678, Fig. 24) é uma proteína integral de membrana, substrato de PKA, que regula a contração do músculo cardíaco, mantendo a homeostase de cálcio dos cardiomiócitos. PLN é composta por 52 aminoácidos contidos em duas $\alpha$-hélices, e apresenta um sítio de fosforilação no resíduo Ser-16 no final de C-terminal da primeira $\alpha$-hélice. Problemas de interação entre PLN e PKA tem sido associados com insuficiência cardíaca humana (OXENOID; RICE; CHOU, 2007; ZAMOON et al., 2003). PLN (PDB: 1fjp) foi caracterizada com a técnica de NMR, o que proporciona uma informação experimental da dinâmica molecular da proteína com 10 possíveis conformações. Por isso, os métodos de modelagem por homologia e dinâmica molecular não foram necessários para o estudo neste caso.

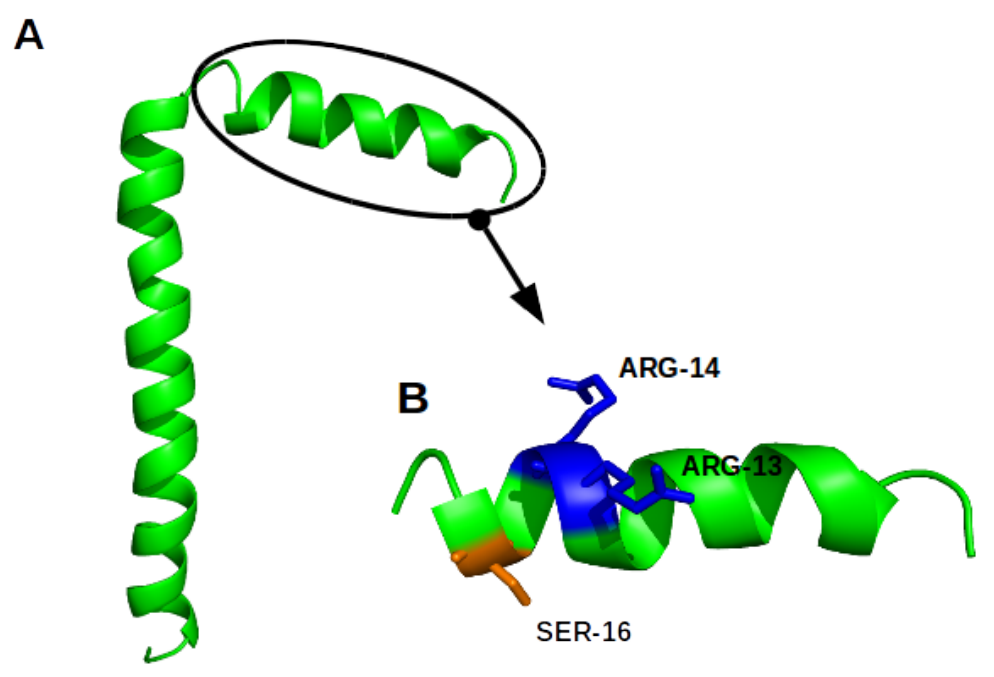

Figura 24. A) Proteína PLN, mostrando dentro do círculo a hélice que contém o sítio P e as possíveis âncoras. B) Em "sticks" o sítio P Ser-16 (laranja) e suas possíveis âncoras Arg-13 e Arg-14 (azul).

Da mesma forma que os dois casos estudados anteriormente, esta proteína foi alinhada por seus aminoácidos menos variáveis para selecionar a conformação que apresentou um RMSD de $1.417 \AA$, sendo este o menor RMSD das 10 possíveis conformações. Portanto, PLN apresenta uma disposição estrutural das âncoras parecidas com as já conhecidas em PKI (Fig. 25). 

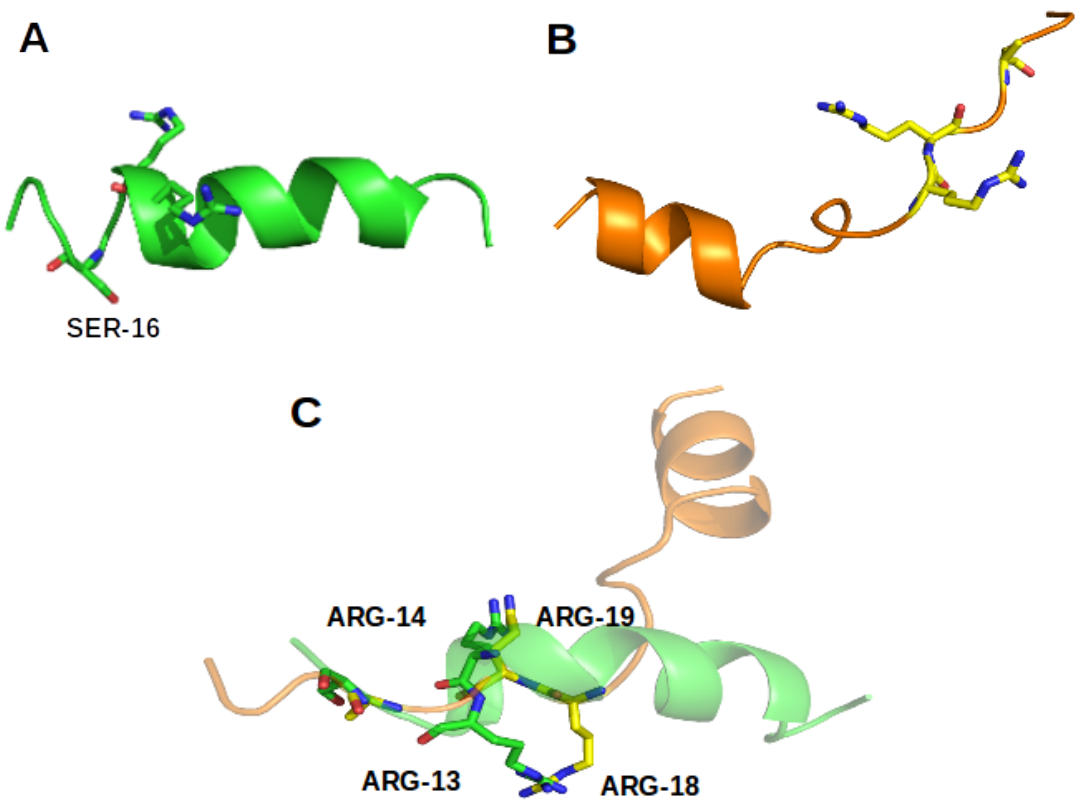

Figura 25. A) Segmento $\alpha$-hélice do primeiro frame, mostrando o aminoácido Ser-16 na região C-terminal e as âncoras Arg-13, Arg-14. B) PKI em cartoon mostrando em amarelo os aminoácidos Ala-21 e as âncoras deste Arg-18 Arg-19 de PKI. C) Sobreposição das possíveis âncoras de PLN (verde) com as âncoras de PKI (amarelo).

\subsection{Proposta de mecanismo de interação entre PKs e substratos com sítios-P em a-hélice}

Para tentar propor um mecanismo de interação entre PKs substratos com sítios-P localizados em $\alpha$-hélice, nós elegemos uma conformação de cada uma das proteínas estudadas com simulações de dinâmica molecular All Atom e realizamos experimentos de docking molecular para predizer os estados ligados.

\subsubsection{Interação PKC - Fosfolenman}

A conformação 5006 da dinâmica All Atom de Fosfolenman foi usado para o docking molecular com o programa HADDOCK, que permite fazer um docking dirigido. Neste caso, foi usada como restrição a distância de $3.5 \AA$ entre Ser-88 de PLM e Asp-148 de PKCA (informação obtida entre Ala-21 de PKI e Asp-166 de PKA, PDB: 1FMO), já que aquele Asp148 é o encarregado de desprotonar a Ser para logo ser fosforilada.

A análises com HADDOCK geraram um agrupamento mostrando os 4 melhores modelos de complexo. O modelo escolhido é aquele que não só tem o melhor "HADDOCK score", mas também aquele que apresenta a menor energia de violação de restrições (Restraints violation energy), isso é, garante que Ser-88 se encontra a uma distância que 
permite uma interação com Asp-148. O modelo HADDOCK escolhido pertence ao agrupamento 2 (Tabela 2).

\begin{tabular}{|c|c|c|c|}
\hline Parâmetros & Cluster 2 & Cluster 1 & Cluster 4 \\
\hline HADDOCK score & $-121.2+/-4.0$ & $-111.5+/-8.8$ & $-91.0+/-4.1$ \\
\hline Cluster size & 66 & 71 & 7 \\
\hline $\begin{array}{l}\text { RMSD from the overall lowest-energy } \\
\text { structure }\end{array}$ & $1.9+/-0.6$ & $18.4+/-0.1$ & $26.8+/-0.3$ \\
\hline Van der Waals energy & $-47.0+/-4.4$ & $-61.5+/-6.5$ & $-50.3+/-1.7$ \\
\hline Electrostatic energy & $-463.3+/-51.3$ & $-370.6+/-26.8$ & $-281.2+/-36.8$ \\
\hline Desolvation energy & $17.4+/-9.4$ & $10.0+/-4.1$ & $12.6+/-9.0$ \\
\hline Restraints violation energy & $10.4+/-16.59$ & $141.4+/-15.70$ & $29.6+/-16.47$ \\
\hline Buried Surface Area & $1931.8+/-100.8$ & $2025.4+/-147.6$ & $1888.8+/-79.3$ \\
\hline Z-Score & -1.5 & -1.1 & -0.1 \\
\hline
\end{tabular}

PLM é formada por 4 hélices (H1, H2, H3, H4), sendo H4 a hélice que contém P0 e as âncoras P-2, P-3 (PETER TERIETE et al., 2007). Os resultados do Docking Molecular para o modelo escolhido mostram a interação de H4 de PLM com a fenda catalítica de PKCA (Fig. 26A). Os aminoácidos Arg-86 e Arg-85, que são possíveis âncoras, se encontram dispostos no mesmo lado. Arg-86 é um aminoácido positivo que se encontra fortemente atraído por uma região composta por aminoácidos com carga negativas (Fig. 26A, superfície vermelha) e Arg85 é atraído por uma região hidrofóbica (Fig. 26A, superfície amarela). O resultado do Docking Molecular também mostra que o aminoácido Arg-81 se encontra em uma posição que permite que ele interaja com aminoácidos de carga negativa como Asp-64 e Glu-67 (Fig. 26A, superfície vermelho e 26B, seta vermelha), demonstrando que este aminoácido também pode se comportar como uma âncora. 
A

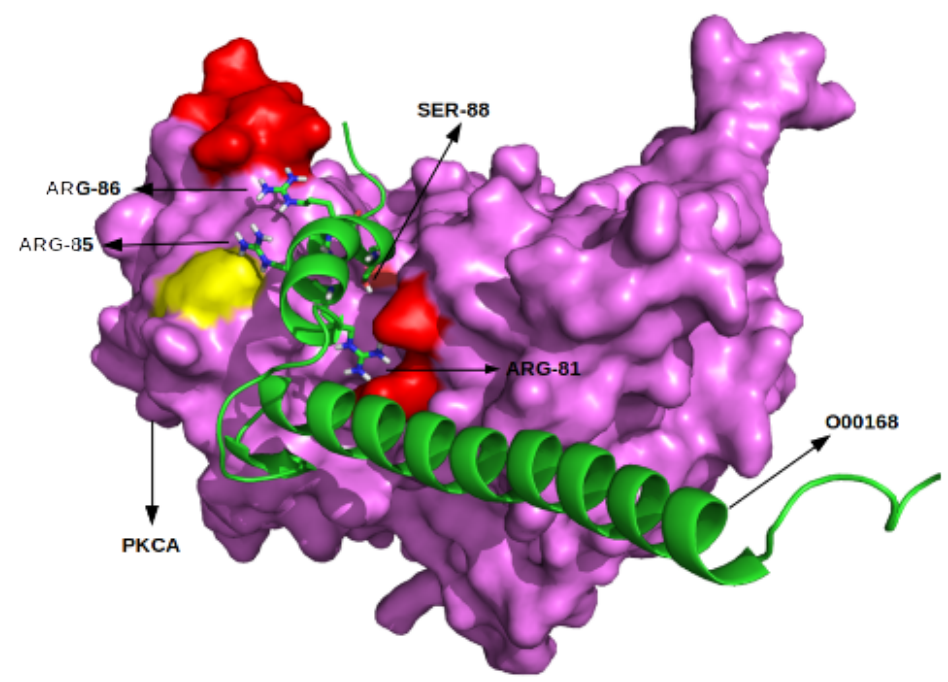

B
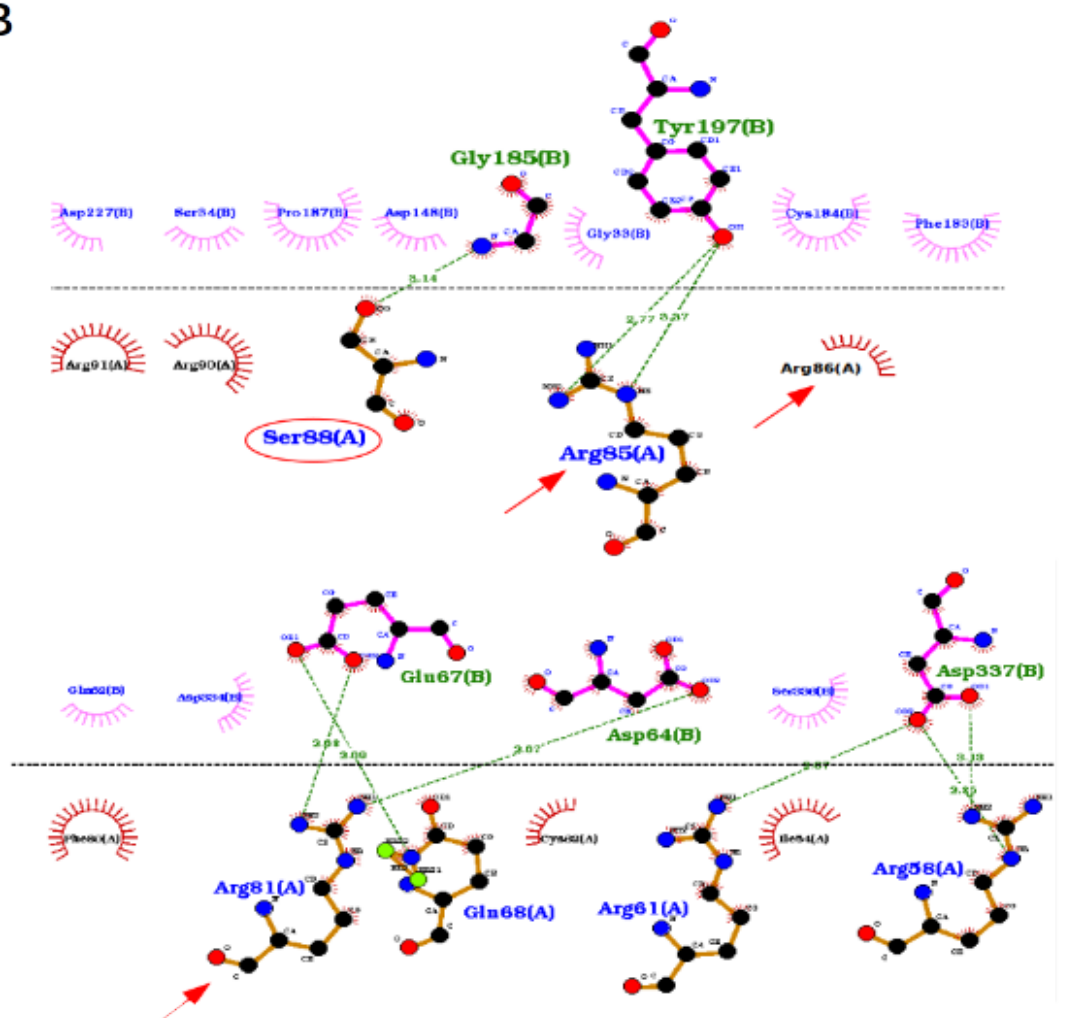

Figura 26. Resultados do Docking molecular. A) Acoplamento entre PLM, representada em cartoon verde (Cod. Uniprot O00168) e PKCA, representada em surface rosa Dentro do PLM, encontram-se os aminoácidos Ser-88(P0), Arg-86(P-2), Arg-85(P-3) e Arg-81(P-7) representados em sticks. A PKCA mostra duas regiões de aminoácidos com carga negativa que interagem com Arg-86 e Arg-81. A região hidrofóbica (amarelo) têm interação com Arg-85. B) Interações das possíveis âncoras P-2, P-3 e P-7 (marcadas com setas vermelhas) com aminoácidos ao redor delas. Dentro do círculo se encontra o sítio P, Ser-88, a uma distância de $3.8 \AA$ de Asp-148. 


\subsubsection{Interação PKC - CDK1}

O Docking Molecular entre a conformação escolhida de CDK1 e PKCA feito por HADDOCK gera como melhor modelo o agrupamento 9 que apresenta o menor "Restraints violation energy" e um HADDOCK score de -101.0 +/- 9.1. Porém, a visualização deste complexo (Fig. 27) mostra que embora seja um dos melhores modelos gerados, o sítio-P se encontra a uma distância inadequada $(\sim 8.0 \AA ̊)$ de Asp-148, e portanto, fora da fenda catalítica de PKCA. Para este caso em que o acoplamento entre PK e Substrato-Quinase deram resultados ambíguos com HADDOCK, o complexo passou por um refinamento com o programa YASARA (descrito nos Métodos), para melhorar o acoplamento, tendo em conta as mesmas restrições de distâncias dadas para HADDOCK. Este refinamento mostra o acoplamento que ocorre entre CDK1 e PKCA: o átomo OG de Ser-277 se encontra a uma distância de $4.2 \AA$ em relação ao átomo OD2 de Asp 148 (Fig. 28), e as possíveis âncoras interagem com aminoácidos negativos dos bolsões presentes na fenda catalítica, atuando como possíveis âncoras lineares para a fosforilação de Ser-277 (Fig. 29).

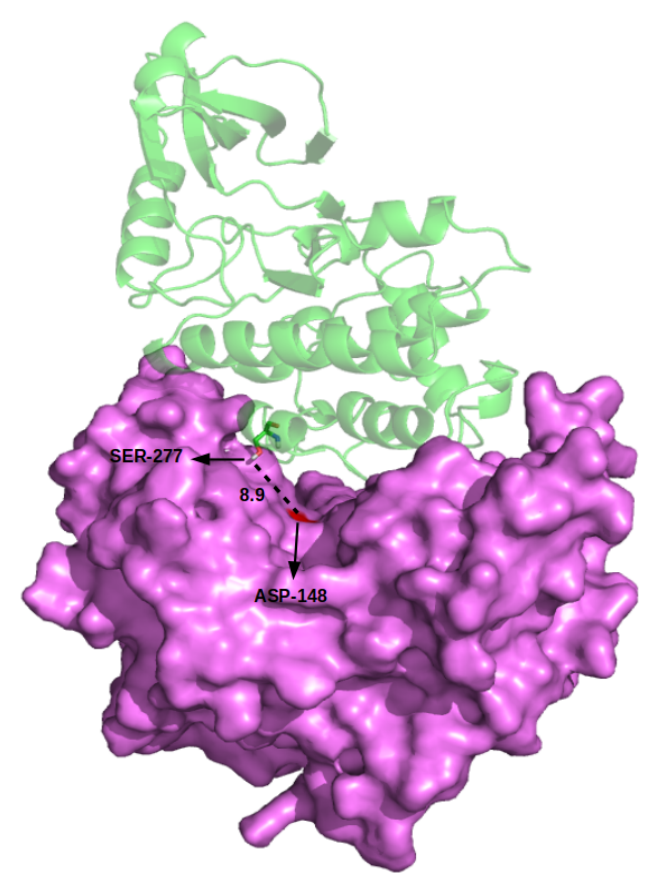

Figura 27. Resultado do Docking molecular realizado em HADDOCK, mostrando em stick o aminoácido Ser277 de CDK1 que se encontrar a uma distância de 8.9 ̊ em relação a Asp-148 (surface vermelho) na fenda catalítica de PKCA. 
A

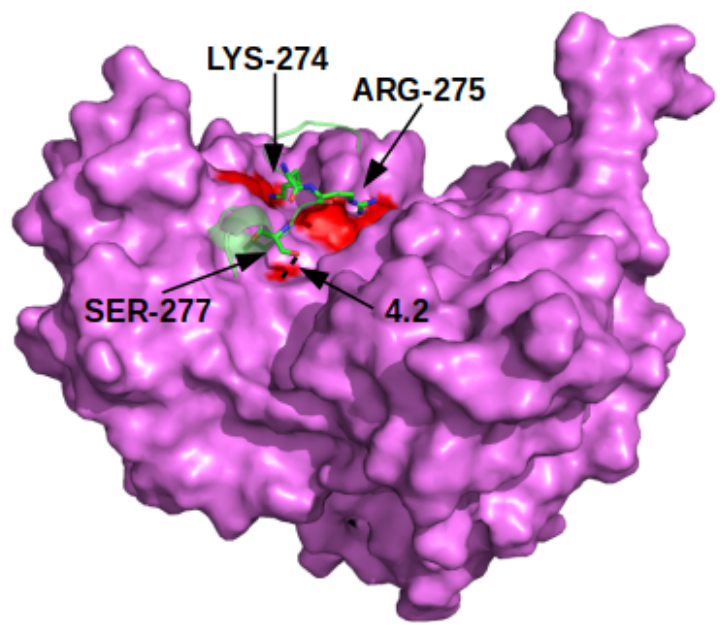

B

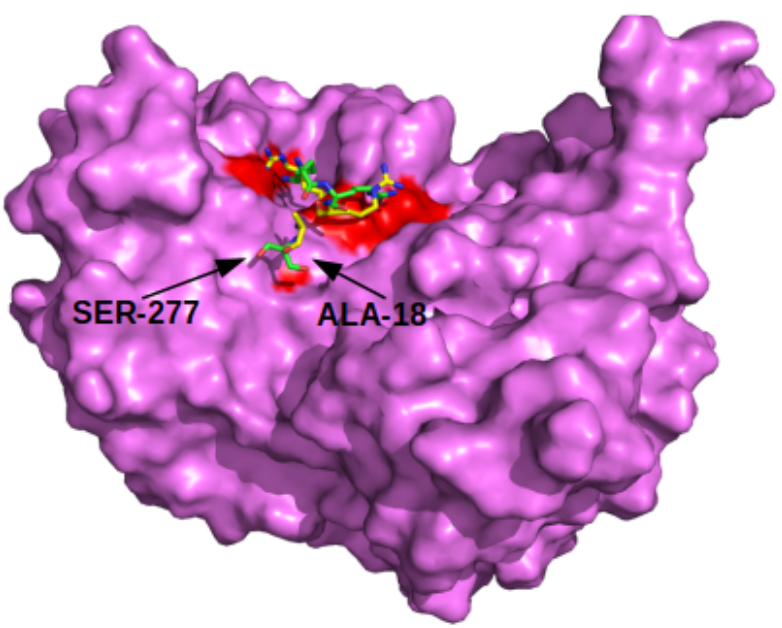

Figura 28. Resultados do refinamento do Docking molecular feito com YASARA, em complexo CDK1PKCA. A) Sítio P em stick Ser-277 de CDK1 que se encontra a uma distância de 4.2 com relação a Asp-148 de PKCA (surface vermelho), além mostra as possíveis âncoras em sticks Lys-274 e Arg-275 nos bolsões da fenda catalítica de PKCA interagindo com aminoácidos de carga negativa (surface vermelho), B) Sobreposição de Ser-277 (verde) de CDK1 com Ala-21 (amarelo) de PKI (1FMO), além de suas respectivas âncoras lineares.

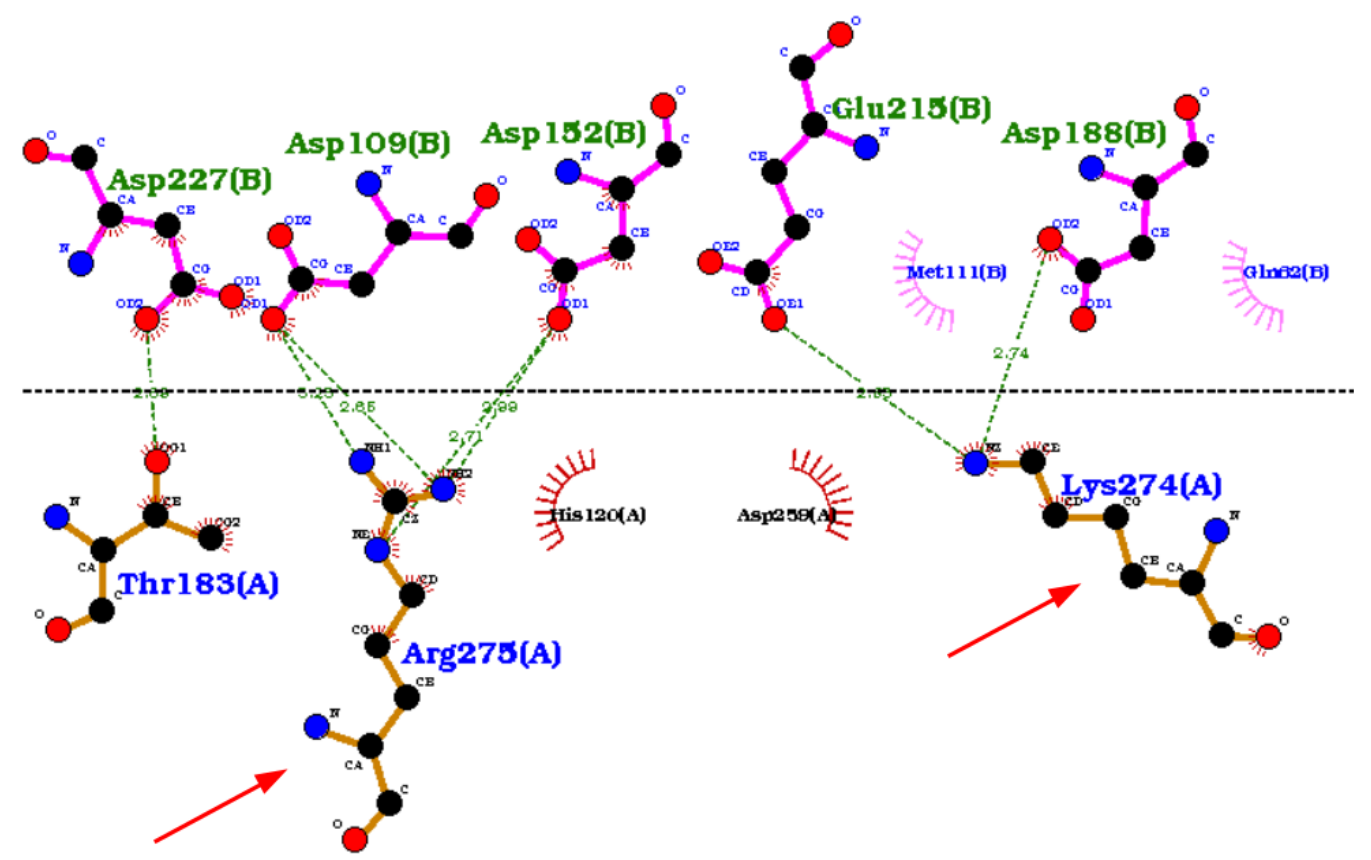

Figura 29. Interações das possíveis âncoras (setas vermelhas) com aminoácidos de carga negativa Asp-109 e Asp- 152 (Arg-275) e Glu-215 e Asp-188 (Lys-274). 


\subsubsection{Interação PKA - Fosfolanbam}

O docking molecular revela um acoplamento entre PLN e PKA (Fig. 30A) do tipo canônico, com um score de -165.5 +/- 4.2 e uma violação de restrições de 0.4 +/- 0.19. O Cterminal da $\alpha$-hélice de PLN que contém o sítio-P sofre um desenovelamento, permitindo que os aminoácidos Arg-13 (P-3) e Arg-14 (P-2) de PLN se encaixem nos bolsões da fenda catalítica de PKA, igual às âncoras P-2 e P-3 de PKI (Fig. 30 B). P-2 e P-3 de PLN interagem com aminoácidos de carga negativa dos bolsões da fenda de PKA como Glu-170, Glu-203 e Glu-230 para Arg-13, e Glu-127 para Arg-14 (surface cor vermelho em Fig. 30 B). Neste acoplamento, o átomo OG do sítio-P (Ser 16, surface cor laranja na Fig. 30 B) se encontra a uma distância de $2.95 \AA ̊$ do átomo OD2 de Asp 166, aminoácido encarregado de desprotonar P0 para ser fosforilado pela quinase (Fig. 30 C). Para Haghighi, a deleção de Arg-13 ou Arg14 interrompe a estabilidade parcial da estrutura de PLN, não permitindo o desenovelamento local da $\alpha$-hélice que implica na fosforilação (HAGHIGHI et al., 2006). Estudos em relação ao aminoácido Arg-14 revelam a importância deste na fosforilação de PLN, pois a mutação do aminoácido diminui a fosforilação de Ser-16, resultando na doença cardiomiopatia dilatada (DCM) (DEWITT et al., 2006). As pesquisas sobre os aminoácidos Arg-13 e Arg-14 de PLN revelam a relevância da posição destes dentro do consenso linear de fosforilação, ou seja, que o comportamento destes aminoácidos é crucial para a fosforilação de Ser-16, e para que isto ocorra, um rearranjo conformacional na região C-terminal da $\alpha$-hélice é necessário. 
A

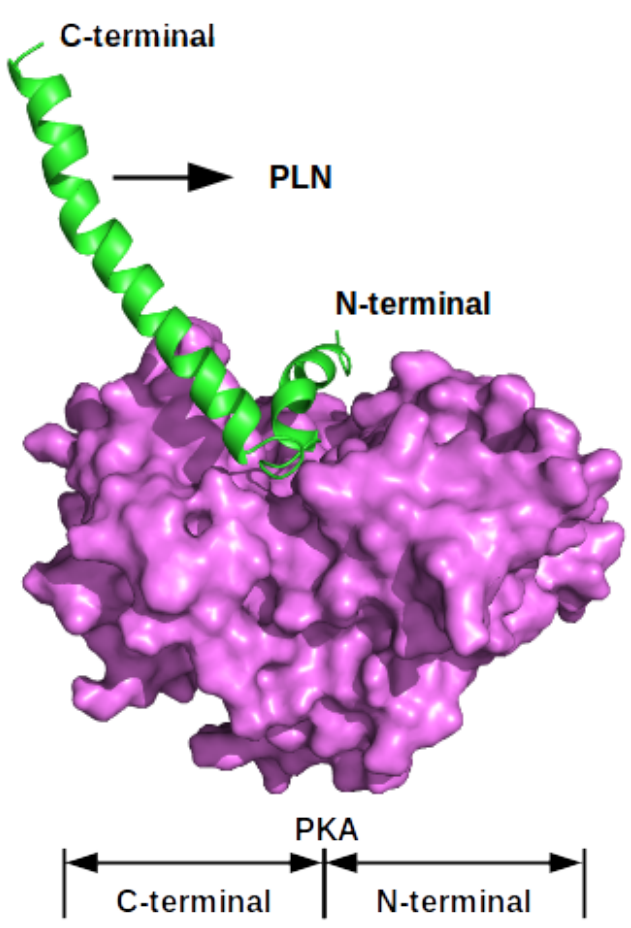

B
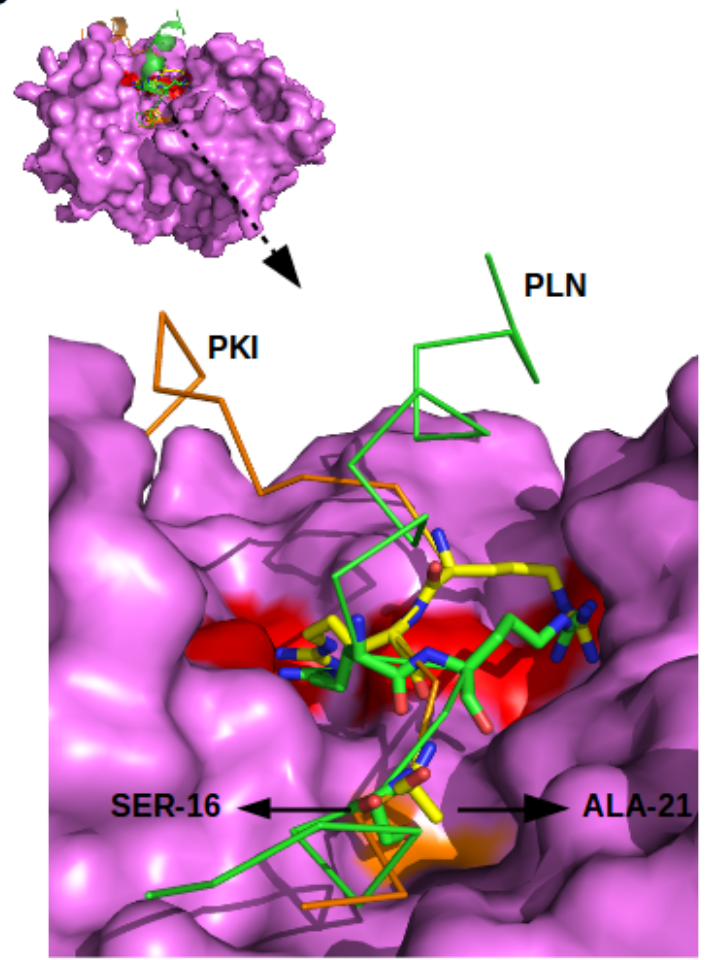

C

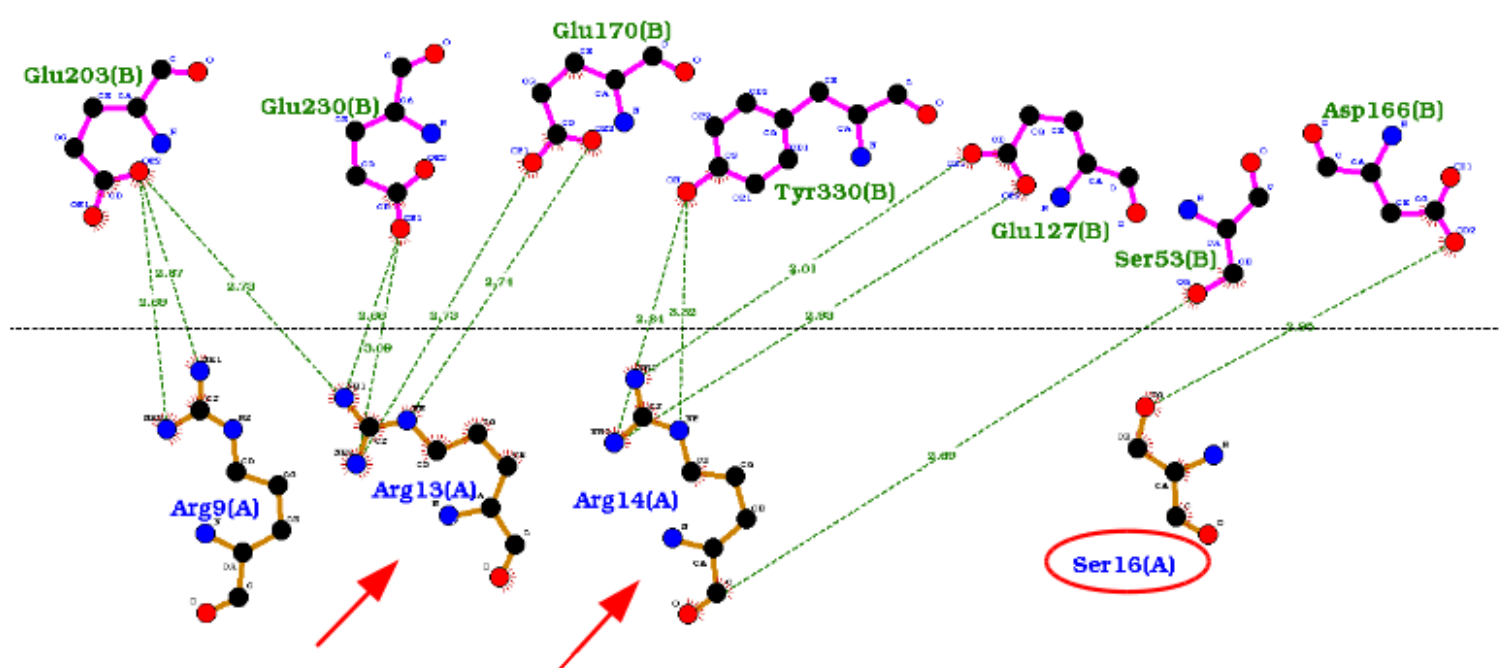

Figura 30. A) Acoplamento de PLN (verde) com PKA (roxo). B) Segmento $\alpha$-hélice de PLN (verde, ribbon), mostrando em sticks o sítio P (Ser-16) e suas âncoras interagindo nos bolsões de PKA (surface vermelho), PLN e sobreposto com PKI (laranja, ribbon) e as âncoras deste em sticks (amarelo). C) Interações das possíveis âncoras (marcadas com setas vermelhas) com aminoácidos negativos ao redor delas; dentro do círculo se encontra o sítio P, Ser-16, que interage com Asp-166.

No caso em que as duas possíveis âncoras P-2 e P-3 não tenham uma interação com a fenda catalítica da quinase, e só um dos aminoácidos (P-2 ou P-3) seja âncora, é muito 
provável que exista um aminoácido positivo $(\mathrm{R} / \mathrm{K})$ perto do sítio-P que pode suprir a condição de âncora, como é mostrado no caso estudo de Fosfolenmam. Esta proteína apresenta 2 sítiosP nas posições Ser-83 e Ser-88, e possíveis âncoras na posições lineares Arg-81 (P-2 de Ser83), Arg-85 (P-3 de Ser-88) e Arg-86 (P-2 de Ser-88), sendo que Arg-81 se encontra também na posição P-7 referente a Ser-88 e a uma distância média entre $\mathrm{C} \alpha$ de $8.5 \AA$. A $\alpha$-hélice $\mathrm{H} 4$ de PLM apresenta uma deformação no meio desta que possibilita um rearranjo conformacional local da estrutura secundária, permitindo que as distâncias entre os $\mathrm{C} \alpha$ de Ser- 88 com Arg-86 e Arg-81 sejam muito próximas às conhecidas em PKI. Segundo os resultados de HADDOCK, o acoplamento de PLM na fenda catalítica de PKCA não é do tipo canônico se comparado com o acoplamento entre PKI e PKA (N-terminal $\rightarrow$ C-terminal) porque as cadeias laterais das possíveis âncoras de PLM não interagem com os bolsões da fenda catalítica de PKCA (superfície vermelho; Fig. 18A). Ao invés disso, elas se encontram no lado oposto dos bolsões, sendo fortemente atraídas por regiões compostas por aminoácidos com cargas negativas. Esta interação não-canônica entre PLM e PKCA pode ser explicada pela baixa estereoespecificidade que a fenda catalítica desta enzima apresenta, fazendo com que a união da proteína-substrato possa ocorrer em qualquer direção (N-terminal $\rightarrow \mathrm{C}$ terminal ou C-terminal $\rightarrow$ N-terminal) (KWON; MENDELOW; LAWRENCE, 1994; NEWTON, 1995).

Este caso, assim como o anterior, suporta a hipótese proposta de que se a fosforilação ocorre dentro da $\alpha$-hélice, e não no $\mathrm{N}$-terminal (2 primeiras voltas) ou perto dela, a estrutura secundária $\alpha$-hélice requer rearranjos conformacionais que permitam aos aminoácidos positivos das posições P-2 e P-3 interagir com os bolsões da fenda catalítica da quinase. A esta hipótese, pode-se adicionar que se a deformação na $\alpha$-hélice não for suficiente para que P-2 ou P-3 sejam âncoras viáveis por se encontrarem inacessíveis para a fenda na quinase, podem existir aminoácido positivo $(\mathrm{R} / \mathrm{K})$ em posições ótimas por se encontrar a uma distância semelhante à encontrada entre sítio-P e P-3 de PKI, não necessariamente lineares na sequência (DUARTE et al., 2014), como é demonstrado no caso de PLM e PKCA. Este tipo de interação foi também descrito de maneira extensa por Nunes Ferraz, que fala que as proteínas substratos de quinases nem sempre vão conter o consenso linear de fosforilação, ou se tiverem, isso não é suficiente para que as possíveis âncoras lineares se ajustem espacialmente de forma semelhante a PKI-PKA, e portanto os consensos conformacionais são factíveis (FERRAZ, 2017). 
Quando o sítio-P se encontrar no N-terminal ou perto deste, as âncoras lineares P-2 e P-3 estarão dispostas fora da $\alpha$-hélice e esta não requer rearranjos conformacionais substanciais para interagir com PK. Isso ocorre porque a flexibilidade do loop permitirá que P-2 e P-3 se posicionem de tal forma que sirvam de âncoras para a fosforilação da proteína pela quinase respectiva, como é o caso de CDK1, em que Lys-274 e Arg-275 interagem com os bolsões presentes na fenda catalítica permitindo que Ser-277 se posicione na fenda catalítica para logo ser fosforilada por PKCA. Como mostra este caso, o rearranjo conformacional não altera a estrutura de $\alpha$-hélice em sua totalidade (Fig. 28 A). Pesquisas relacionadas ao comportamento pré-fosforilação das $\alpha$-hélice que apresentam um sítio-P não foram encontradas, mas alguns trabalhos relacionados ao comportamento de $\alpha$-hélice de acordo com o posicionamento de fosfo-Ser revelam que a presença desta fosfo-Ser no Nterminal torna a estrutura mais estável em comparação quando nesta se encontra no meio ou C-terminal, onde a estrutura conformacional da $\alpha$-hélice é destruída (ANDREW et al., 2002).

Finalmente, foi mencionado que o modelo ideal de referência em relação às distâncias que devem existir entre o sítio-P e suas possíveis âncoras lineares P-2 e P-3 se baseou nas distâncias conhecidas de PKI, um peptídeo inibidor de PKA de aproximadamente 20 aminoácidos, que contêm o consenso linear de fosforilação, o que favorece na organização local da estrutura e a interação dos resíduos nas posições P-3 e P-2, Arg-18 e Arg-19, respectivamente (NARENDRA NARAYANA et al., 1997). Recentemente, um novo complexo resolvido por difração de raios $\mathrm{X}$ foi depositado no RCSB PDB. Trata-se da interação do receptor Rianodine RyR2 com PKA (PDB 6MM8). Uma sobreposição entre os aminoácidos âncoras de Rianodine e PKI, confirma que as distâncias tomadas em conta de PKI como referência são as mesmas e, portanto, aceitas em outros modelos proteicos cristalizados (Fig. 31) (https://www.resb.org/structure/6mm8). 


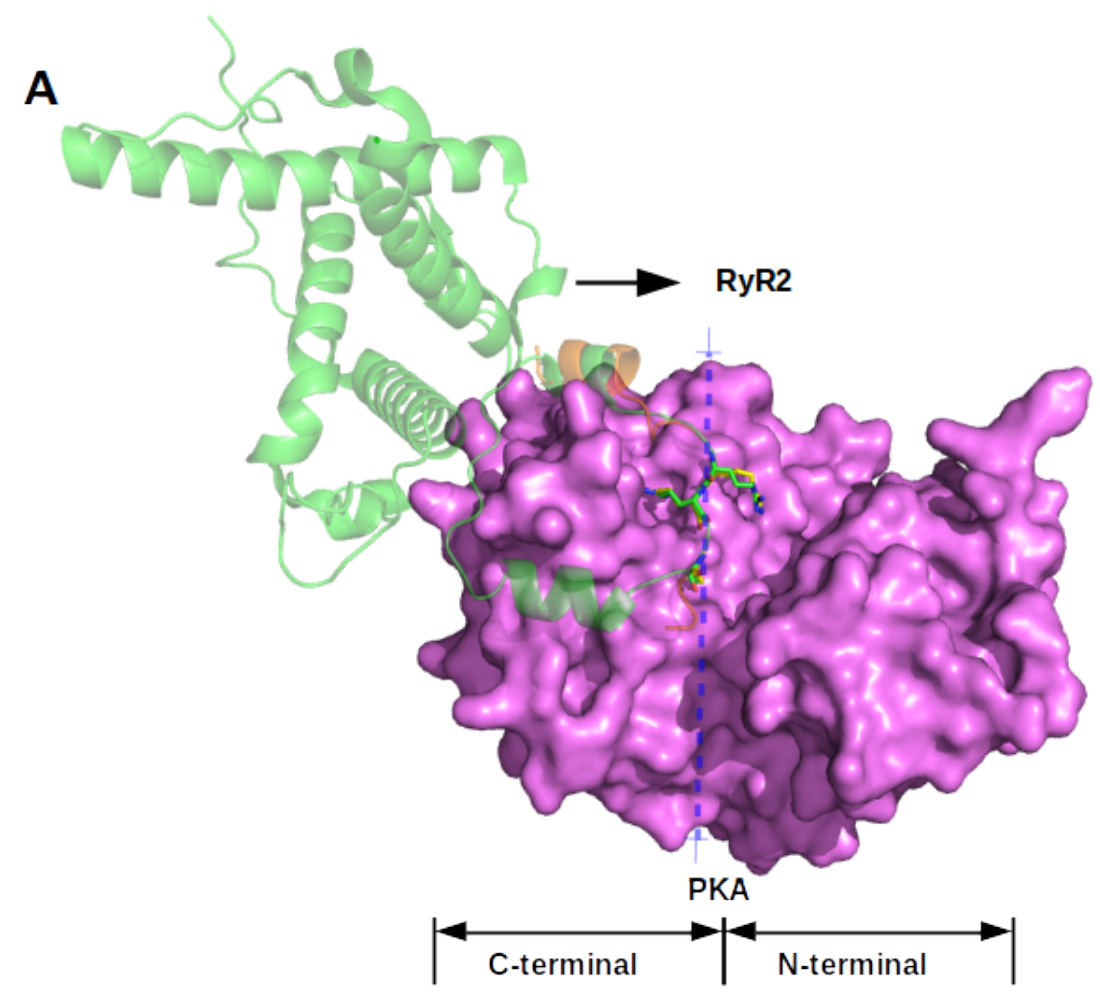

B

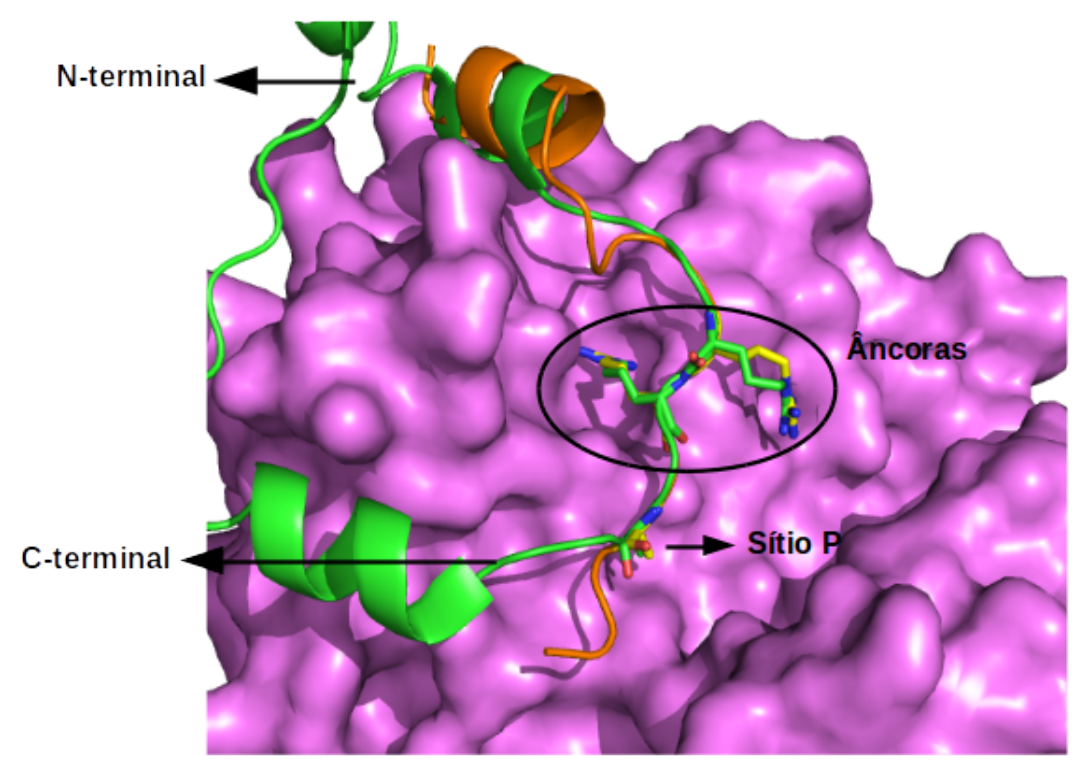

Figura 31. A) Rianodine RyR2 (verde, cartoon) acoplado a PKA (roxo, surface) e sobreposto a PKI (laranja, cartoon); a linha em azul representa a fenda catalítica onde se encontra o sítio $\mathrm{P}$ e as âncoras. B) Fenda catalítica onde se encontrar sobreposto o sítio P e as âncoras de RyR2 (verde, sticks) com Ala-21 e as âncoras de PKI (amarelo, sticks). 


\section{CONCLUSÕES}

O presente estudo visou obter uma aproximação dos eventos que coordenam processos de fosforilação de proteínas, com ênfase na etapa de pré-fosforilação. É um evento muito pouco estudado, havendo, portanto, uma quantidade exígua de trabalhos escritos sobre o tema na literatura. $\mathrm{O}$ banco de dados usado sobre sítios-P verdadeiros revela um padrão topológico bem conservado entre os diferentes substratos-quinases, o que de alguma forma cria regras estruturais de interação quinase-substrato.

Existem posições específicas em torno do sítio-P (P-2 e P-3), onde os aminoácidos são carregados positivamente (Arg ou Lys) e que constitui a região conhecida como consenso linear de fosforilação. Usando técnicas computacionais, foi confirmado que a estrutura secundária do tipo $\alpha$-hélice (relativamente rígida, com uma estrutura 3D bem definida) é um alvo de fosforilação bem comum, não apresentando, a priori, os parâmetros adequados para se ajustar na fenda catalítica das PKs. Isso nos levou a hipotetizar que existe uma predisposição dos sítios-P deste tipo de estrutura secundária a sofrer desenovelamento de sua estrutura local.

O estudo dos substratos-quinases escolhidos revela que, dependendo de onde o sítio-P está localizado, a estrutura da $\alpha$-hélice sofrerá mudanças conformacionais mais ou menos substanciais em sua estrutura local que permitirão que os aminoácidos nas posições P-2 e P-3 possam cumprir a função de âncoras, deixando o sítio-P na posição correta para ser posteriormente fosforilado.

Os casos de estudo também revelam que, mesmo que a $\alpha$-hélice possa ter uma alteração estrutural, às vezes isso não é suficiente para que os aminoácidos na posição P-2 ou P-3 possam servir como âncoras do sítio-P, e o consenso de fosforilação estrutural é aceito.

A compreensão dos processos de reconhecimento de substratos-quinases por quinases visando as duas possibilidades, consenso linear e consenso estrutural, pode ajudar a entender um pouco mais o processo de fosforilação e como os processos de modificação póstraducional são dependentes da estrutura local de proteína, bem como o modo com que esses processos podem levar a alterações temporárias nessas estruturas. 


\section{REFERÊNCIAS}

ANDREW, C. D. et al. Effect of Phosphorylation on $\alpha$-Helix Stability as a Function of Position ${ }^{\dagger}$. Biochemistry, v. 41, n. 6, p. 1897-1905, fev. 2002.

APPLEQUIST, J.; CARL, J. R.; FUNG, K.-K. Atom dipole interaction model for molecular polarizability. Application to polyatomic molecules and determination of atom polarizabilities. Journal of the American Chemical Society, v. 94, n. 9, p. 2952-2960, maio 1972.

APWEILER, R. et al. UniProt: the Universal Protein knowledgebase. Nucleic Acids Research, v. 32, n. 90001, p. 115D - 119, 1 jan. 2004.

BACHMAN, A. B. et al. Phosphorylation induced cochaperone unfolding promotes kinase recruitment and client class-specific Hsp90 phosphorylation. Nature Communications, v. 9, n. 1, p. 265, 17 dez. 2018.

BAKER, C. M. Polarizable force fields for molecular dynamics simulations of biomolecules. Wiley Interdisciplinary Reviews: Computational Molecular Science, v. 5, n. 2, p. 241254, 1 mar. 2015.

BALlesteros, J. A. et al. Serine and Threonine Residues Bend $\alpha$-Helices in the $\chi 1=\mathrm{g}-$ Conformation. Biophysical Journal, v. 79, n. 5, p. 2754-2760, 1 nov. 2000.

BERG, J. M. (JEREMY M. et al. Biochemistry. [s.1.] W.H. Freeman, 2002.

BIONDI, R. M.; NEBREDA, A. R. Signalling specificity of Ser/Thr protein kinases through docking-site-mediated interactions. Biochemical Journal, v. 372, n. 1, p. 1-13, 15 maio 2003.

BRINKWORTH, R. I.; BREINL, R. A.; KOBE, B. Structural basis and prediction of substrate specificity in protein serine/threonine kinases. Proceedings of the National Academy of Sciences, v. 100, n. 1, p. 74-79, 7 jan. 2003.

BROWN, N. R. et al. The structural basis for specificity of substrate and recruitment peptides for cyclin-dependent kinases. Nature Cell Biology, v. 1, n. 7, p. 438-443, 14 nov. 1999.

BURNETT, G.; KENNEDY, E. P. The enzymatic phosphorylation of proteins. The Journal of biological chemistry, v. 211, n. 2, p. 969-80, 1 dez. 1954.

COHEN, P. Protein kinases - the major drug targets of the twenty-first century? Nature Reviews Drug Discovery, v. 1, n. 4, p. 309-315, abr. 2002.

DE VRIES, S. J.; VAN DIJK, M.; BONVIN, A. M. J. J. The HADDOCK web server for datadriven biomolecular docking. Nature Protocols, v. 5, n. 5, p. 883-897, 15 maio 2010.

DEWITT, M. M. et al. Phospholamban R14 Deletion Results in Late-Onset, Mild, Hereditary Dilated Cardiomyopathy. Journal of the American College of Cardiology, v. 48, n. 7, p. 1396-1398, 3 out. 2006. 
DINKEL, H. et al. Phospho.ELM: a database of phosphorylation sites--update 2011. Nucleic Acids Research, v. 39, n. Database, p. D261-D267, 1 jan. 2011.

DOBRANSKY, T. et al. Protein Kinase C Isoforms Differentially Phosphorylate Human Choline Acetyltransferase Regulating Its Catalytic Activity. Journal of Biological Chemistry, v. 279, n. 50, p. 52059-52068, 10 dez. 2004.

DUARTE, M. L. et al. Protein folding creates structure-based, noncontiguous consensus phosphorylation motifs recognized by kinases. Science signaling, v. 7, n. 350, p. ra105, 4 nov. 2014.

ELBAUM, M. B.; ZONDLO, N. J. OGlcNAcylation and phosphorylation have similar structural effects in $\alpha$-helices: post-translational modifications as inducible start and stop signals in $\alpha$-helices, with greater structural effects on threonine modification. Biochemistry, v. 53, n. 14 , p. $2242-60,15$ abr. 2014.

ENDICOTT, J. A.; NOBLE, M. E. M.; JOHNSON, L. N. The Structural Basis for Control of Eukaryotic Protein Kinases. Annual Review of Biochemistry, v. 81, n. 1, p. 587-613, 7 jul. 2012.

FAHMY, A.; WAGNER, G. TreeDock: a tool for protein docking based on minimizing van der Waals energies. Journal of the American Chemical Society, v. 124, n. 7, p. 1241-50, 20 fev. 2002.

FERRAZ, F. A. N. Caracterização de sítios conformacionais de fosforilação em proteínas. São Paulo: Biblioteca Digital de Teses e Dissertações da Universidade de São Paulo, 23 jan. 2017.

FISCHER, E. H.; KREBS, E. G. Conversion of phosphorylase $b$ to phosphorylase a in muscle extracts. The Journal of biological chemistry, v. 216, n. 1, p. 121-32, set. 1955.

FISER, A.; ŠALI, A. Modeller: Generation and Refinement of Homology-Based Protein Structure Models. In: Methods in enzymology. [s.1: s.n.]. v. 374p. 461-491.

GNAD, F. et al. PHOSIDA (phosphorylation site database): management, structural and evolutionary investigation, and prediction of phosphosites. Genome Biology, v. 8, n. 11, p. R250, 2007.

GONZÁLEZ, M. A. Force fields and molecular dynamics simulations. École thématique de la Société Française de la Neutronique, v. 12, p. 169-200, 9 jun. 2011.

GROBAN, E. S.; NARAYANAN, A.; JACOBSON, M. P. Conformational Changes in Protein Loops and Helices Induced by Post-Translational Phosphorylation. PLoS Computational Biology, v. 2, n. 4, p. e32, 2006.

HAGHIGHI, K. et al. A mutation in the human phospholamban gene, deleting arginine 14, results in lethal, hereditary cardiomyopathy. Proceedings of the National Academy of Sciences, v. 103, n. 5, p. 1388-1393, 31 jan. 2006. 
HAIMOV, B.; SREBNIK, S. A closer look into the $\alpha$-helix basin. Scientific Reports, v. 6, n. 1, p. 38341,5 dez. 2016.

HE, E. et al. Effects of phosphorylation on the intrinsic propensity of backbone conformations of serine/threonine. Journal of biological physics, v. 42, n. 2, p. 247-58, mar. 2016.

HOLMES, J. K.; SOLOMON, M. J. The role of Thr160 phosphorylation of Cdk2 in substrate recognition. European Journal of Biochemistry, v. 268, n. 17, p. 4647-4653, 1 set. 2001.

HOOFT, R. W. W. et al. Errors in protein structures. Nature, v. 381, n. 6580, p. 272-272, 23 maio 1996.

HORNBECK, P. V. et al. PhosphoSite: A bioinformatics resource dedicated to physiological protein phosphorylation. PROTEOMICS, v. 4, n. 6, p. 1551-1561, 1 jun. 2004.

HORNBECK, P. V. et al. PhosphoSitePlus, 2014: mutations, PTMs and recalibrations. Nucleic Acids Research, v. 43, n. D1, p. D512-D520, 28 jan. 2015.

HOUSE, C.; KEMP, B. E. Protein kinase C contains a pseudosubstrate prototope in its regulatory domain. Science (New York, N.Y.), v. 238, n. 4834, p. 1726-8, 18 dez. 1987.

HUNTER, T. Protein kinases and phosphatases: The Yin and Yang of protein phosphorylation and signaling. Cell, v. 80, n. 2, p. 225-236, 1995.

HUNTER, T.; SEFTON, B. M. Transforming gene product of Rous sarcoma virus phosphorylates tyrosine. Proceedings of the National Academy of Sciences, v. 77, n. 3, p. 1311-1315, mar. 1980.

HUSE, M.; KURIYAN, J. The conformational plasticity of protein kinases. Cell, v. 109, n. 3, p. 275-82, 3 maio 2002.

JIMÉNEZ, J. L. et al. A systematic comparative and structural analysis of protein phosphorylation sites based on the mtcPTM database. Genome Biology, v. 8, n. 5, p. R90, 2007.

JIN, Y.-J. et al. CD4 Phosphorylation Partially Reverses Nef Down-Regulation of CD4. The Journal of Immunology, v. 173, n. 9, p. 5495-5500, 1 nov. 2004.

JUNG, J.; LEE, B. Protein structure alignment using environmental profiles. Protein Engineering, Design and Selection, v. 13, n. 8, p. 535-543, 1 ago. 2000.

KANG, D. et al. Properties of single two-pore domain TREK-2 channels expressed in mammalian cells. The Journal of physiology, v. 583, n. Pt 1, p. 57-69, 15 ago. 2007.

KANG, D.; HAN, J.; KIM, D. Mechanism of inhibition of TREK-2 ( $\left.\mathrm{K}_{2 \mathrm{P}} 10.1\right)$ by the $\mathrm{G}_{\mathrm{q}}$ -coupled $\mathrm{M}_{3}$ muscarinic receptor. American Journal of Physiology-Cell Physiology, v. 291, n. 4, p. C649-C656, out. 2006.

KARACA, E.; BONVIN, A. M. J. J. Advances in integrative modeling of biomolecular complexes. Methods, v. 59, n. 3, p. 372-381, mar. 2013. 
KARPLUS, M.; MCCAMMON, J. A. Molecular dynamics simulations of biomolecules. Nature Structural Biology, v. 9, n. 9, p. 646-652, set. 2002.

KEMP, B. E. et al. Substrate specificity of the cyclic AMP-dependent protein kinase. Proceedings of the National Academy of Sciences of the United States of America, v. 72, n. 9 , p. $3448-52$, set. 1975.

KENZAKI, H. et al. CafeMol: A Coarse-Grained Biomolecular Simulator for Simulating Proteins at Work. Journal of Chemical Theory and Computation, v. 7, n. 6, p. 1979-1989, 14 jun. 2011.

KMIECIK, S. et al. Protein Dynamics Simulations Using Coarse-Grained Models. In: [s.1.] Springer, Cham, 2019. p. 61-87.

KNIGHTON, D. R. et al. Crystal structure of the catalytic subunit of cyclic adenosine monophosphate-dependent protein kinase. Science (New York, N.Y.), v. 253, n. 5018, p. 40714, 26 jul. 1991a.

KNIGHTON, D. R. et al. Structure of a peptide inhibitor bound to the catalytic subunit of cyclic adenosine monophosphate-dependent protein kinase. Science (New York, N.Y.), v. 253, n. 5018, p. 414-20, 26 jul. 1991 b.

KOBE, B. et al. Substrate specificity of protein kinases and computational prediction of substrates. Biochimica et Biophysica Acta (BBA) - Proteins and Proteomics, v. 1754, n. 12, p. 200-209, 30 dez. 2005.

KOLINSKI, A. Protein modeling and structure prediction with a reduced representation. Acta biochimica Polonica, v. 51, n. 2, p. 349-71, 2004.

KREBS, E. G.; BEAVO, J. A. Phosphorylation-Dephosphorylation of Enzymes. Annual Review of Biochemistry, v. 48, n. 1, p. 923-959, 28 jun. 1979.

KREBS, E. G.; FISCHER, E. H. Phosphorylase activity of skeletal muscle extracts. The Journal of biological chemistry, v. 216, n. 1, p. 113-20, set. 1955.

KREK, W.; NIGG, E. A. Differential phosphorylation of vertebrate p34cdc2 kinase at the G1/S and G2/M transitions of the cell cycle: identification of major phosphorylation sites. The EMBO journal, v. 10, n. 2, p. 305-16, fev. 1991.

KRIEGER, E. et al. Making optimal use of empirical energy functions: Force-field parameterization in crystal space. Proteins: Structure, Function, and Bioinformatics, v. 57, n. 4, p. 678-683, 1 dez. 2004.

KRIEGER, E. et al. Improving physical realism, stereochemistry, and side-chain accuracy in homology modeling: Four approaches that performed well in CASP8. Proteins: Structure, Function, and Bioinformatics, v. 77, n. S9, p. 114-122, 2009. 
KUMAR, A. et al. Phosphorylation-induced unfolding regulates p19INK4d during the human cell cycle. Proceedings of the National Academy of Sciences of the United States of America, v. 115, n. 13, p. 3344-3349, 27 mar. 2018.

KWON, Y. G.; MENDELOW, M.; LAWRENCE, D. S. The active site substrate specificity of protein kinase C. The Journal of biological chemistry, v. 269, n. 14, p. 4839-44, 8 abr. 1994.

LAHIRY, P. et al. Kinase mutations in human disease: interpreting genotype-phenotype relationships. Nature Reviews Genetics, v. 11, n. 1, p. 60-74, 1 jan. 2010.

LEE, M. R. et al. Molecular dynamics in the endgame of protein structure prediction. Journal of Molecular Biology, v. 313, n. 2, p. 417-430, 19 out. 2001.

LI, W. et al. Energy landscape and multiroute folding of topologically complex proteins adenylate kinase and 2ouf-knot. Proceedings of the National Academy of Sciences of the United States of America, v. 109, n. 44, p. 17789-94, 30 out. 2012.

LU, Y.; SALSBURY, F. R. Recapturing the Correlated Motions of Protein Using CoarseGrained Models. Protein and peptide letters, v. 22, n. 7, p. 654-9, 2015.

MACKERELL, A. D. Empirical force fields for biological macromolecules: Overview and issues. Journal of Computational Chemistry, v. 25, n. 13, p. 1584-1604, out. 2004.

MANNING, G. et al. The protein kinase complement of the human genome. Science (New York, N.Y.), v. 298, n. 5600, p. 1912-34, 6 dez. 2002.

MCCAMMON, J. A.; GELIN, B. R.; KARPLUS, M. Dynamics of folded proteins. Nature, v. 267, n. 5612, p. 585-590, jun. 1977.

MCGUFFIN, L. J.; BRYSON, K.; JONES, D. T. The PSIPRED protein structure prediction server. Bioinformatics, v. 16, n. 4, p. 404-405, 1 abr. 2000.

MELQUIOND, A. S. J.; BONVIN, A. M. J. J. Data-driven Docking: Using External Information to Spark the Biomolecular Rendez-vous. In: Protein-Protein Complexes. [s.1.] IMPERIAL COLLEGE PRESS, 2010. p. 182-208.

MILLER, C. J.; TURK, B. E. Homing in: Mechanisms of Substrate Targeting by Protein Kinases. Trends in Biochemical Sciences, v. 43, n. 5, p. 380-394, maio 2018.

MONNÉ, M.; HERMANSSON, M.; VON HEIJNE, G. A turn propensity scale for transmembrane helices. Journal of Molecular Biology, v. 288, n. 1, p. 141-145, 23 abr. 1999.

MONTICELLI, L. et al. The MARTINI Coarse-Grained Force Field: Extension to Proteins. Journal of Chemical Theory and Computation, v. 4, n. 5, p. 819-834, 16 maio 2008.

NARENDRA NARAYANA, $\$$ et al. Crystal Structure of a Polyhistidine-Tagged Recombinant Catalytic Subunit of cAMP-Dependent Protein Kinase Complexed with the Peptide Inhibitor PKI(5-24) and Adenosine†. 1997. 
NEWTON, A. C. Protein kinase C: structure, function, and regulation. The Journal of biological chemistry, v. 270, n. 48, p. 28495-8, 1 dez. 1995.

OHEIX, E.; PEACOCK, A. F. A. De Novo Design of Metallocoiled Coils. In: Reference Module in Chemistry, Molecular Sciences and Chemical Engineering. [s.1.] Elsevier, 2015.

OXENOID, K.; RICE, A. J.; CHOU, J. J. Comparing the structure and dynamics of phospholamban pentamer in its unphosphorylated and pseudo-phosphorylated states. Protein science : a publication of the Protein Society, v. 16, n. 9, p. 1977-83, set. 2007.

PAGADALA, N. S.; SYED, K.; TUSZYNSKI, J. Software for molecular docking: a review. Biophysical Reviews, v. 9, n. 2, p. 91-102, 16 abr. 2017.

PAULING, L.; COREY, R. B.; BRANSON, H. R. The structure of proteins; two hydrogenbonded helical configurations of the polypeptide chain. Proceedings of the National Academy of Sciences of the United States of America, v. 37, n. 4, p. 205-11, 1 abr. 1951.

PEARCE, L. R.; KOMANDER, D.; ALESSI, D. R. The nuts and bolts of AGC protein kinases. Nature Reviews Molecular Cell Biology, v. 11, n. 1, p. 9-22, 1 jan. 2010.

PETER TERIETE et al. Structure of the Na,K-ATPase Regulatory Protein FXYD1 in Micelles†. 2007.

PULLEN, K. et al. Phosphorylation of serine-46 in HPr, a key regulatory protein in bacteria, results in stabilization of its solution structure. Protein Science, v. 4, n. 12, p. 2478-2486, 1 dez. 1995.

QIU, J.; ELBER, R. SSALN: An alignment algorithm using structure-dependent substitution matrices and gap penalties learned from structurally aligned protein pairs. Proteins: Structure, Function, and Bioinformatics, v. 62, n. 4, p. 881-891, 29 dez. 2005.

ROBERTS, R. J. PubMed Central: The GenBank of the published literature. Proceedings of the National Academy of Sciences of the United States of America, v. 98, n. 2, p. 381-2, 16 jan. 2001.

RODRIGUES, J. P. G. L. M. et al. Clustering biomolecular complexes by residue contacts similarity. Proteins: Structure, Function, and Bioinformatics, v. 80, n. 7, p. n/a-n/a, jul. 2012 .

RODRIGUES, J. P. G. L. M.; KARACA, E.; BONVIN, A. M. J. J. Information-Driven Structural Modelling of Protein-Protein Interactions. In: Methods in molecular biology (Clifton, N.J.). [s.l: s.n.]. v. 1215p. 399-424.

ROSKOSKI, R. Enzyme Structure and Function. Reference Module in Biomedical Sciences, 1 jan. 2014.

ROSKOSKI, R. A historical overview of protein kinases and their targeted small molecule inhibitors. Pharmacological Research, v. 100, p. 1-23, 1 out. 2015. 
SCHECHTER, I.; BERGER, A. On the size of the active site in proteases. I. Papain. Biochemical and Biophysical Research Communications, v. 27, n. 2, p. 157-162, abr. 1967.

SHABB*, J. B. Physiological Substrates of cAMP-Dependent Protein Kinase. 2001.

SHINDYALOV, I. N.; BOURNE, P. E. Protein structure alignment by incremental combinatorial extension (CE) of the optimal path. Protein engineering, v. 11, n. 9, p. 739-47, set. 1998.

SIGNARVIC, R. S.; DEGRADO, W. F. De novo design of a molecular switch: phosphorylation-dependent association of designed peptides. Journal of molecular biology, v. 334, n. 1, p. 1-12, 14 nov. 2003.

SMART, J. L.; MCCAMMON, J. A. Phosphorylation stabilizes the N-termini of ?-helices. Biopolymers, v. 49, n. 3, p. 225-233, mar. 1999.

STARK, C. et al. PhosphoGRID: a database of experimentally verified in vivo protein phosphorylation sites from the budding yeast Saccharomyces cerevisiae. Database, v. 2010, n. 0, p. bap026-bap026, 30 jul. 2010.

SUTHERLAND, E. W.; WOSILAIT, W. D. Inactivation and Activation of Liver Phosphorylase. Nature, v. 175, n. 4447, p. 169-170, jan. 1955.

SZILÁK, L. et al. Phosphorylation destabilizes $\alpha$-helices. Nature Structural Biology, v. 4, n. 2, p. 112-114, fev. 1997.

TAKADA, S. Coarse-grained molecular simulations of large biomolecules. Current Opinion in Structural Biology, v. 22, n. 2, p. 130-137, 1 abr. 2012.

TAKAHASHI, K.; ODA, T.; NARUSE, K. Coarse-grained molecular dynamics simulations of biomolecules. AIMS Biophysics, v. 1, n. 1, p. 1-15, 2014.

UBERSAX, J. A.; FERRELL, J. E. Mechanisms of specificity in protein phosphorylationNature Reviews Molecular Cell Biology, jul. 2007.

VETTER, S. W.; LECLERC, E. Phosphorylation of serine residues affects the conformation of the calmodulin binding domain of human protein 4.1. European Journal of Biochemistry, v. 268, n. 15, p. 4292-4299, 1 ago. 2001.

WARSHEL, A.; KATO, M.; PISLIAKOV, A. V. Polarizable Force Fields: History, Test Cases, and Prospects. Journal of Chemical Theory and Computation, v. 3, n. 6, p. 2034-2045, 25 nov. 2007.

WILLIAMS, R. W. et al. Secondary structure predictions and medium range interactions. Biochimica et Biophysica Acta (BBA) - Protein Structure and Molecular Enzymology, v. 916, n. 2, p. 200-204, 26 nov. 1987.

WOODGETT, J. R.; GOULD, K. L.; HUNTER, T. Substrate specificity of protein kinase C. Use of synthetic peptides corresponding to physiological sites as probes for substrate 
recognition requirements. European Journal of Biochemistry, v. 161, n. 1, p. 177-184, 17 nov. 1986.

YE, Y.; GODZIK, A. Flexible structure alignment by chaining aligned fragment pairs allowing twists. Bioinformatics, v. 19, n. Suppl 2, p. ii246-ii255, 27 set. 2003.

ZAMOON, J. et al. NMR solution structure and topological orientation of monomeric phospholamban in dodecylphosphocholine micelles. Biophysical journal, v. 85, n. 4, p. 2589-98, out. 2003. 


\section{ANEXO 1 :Exemplo de um arquivo .inp de CafeMol}

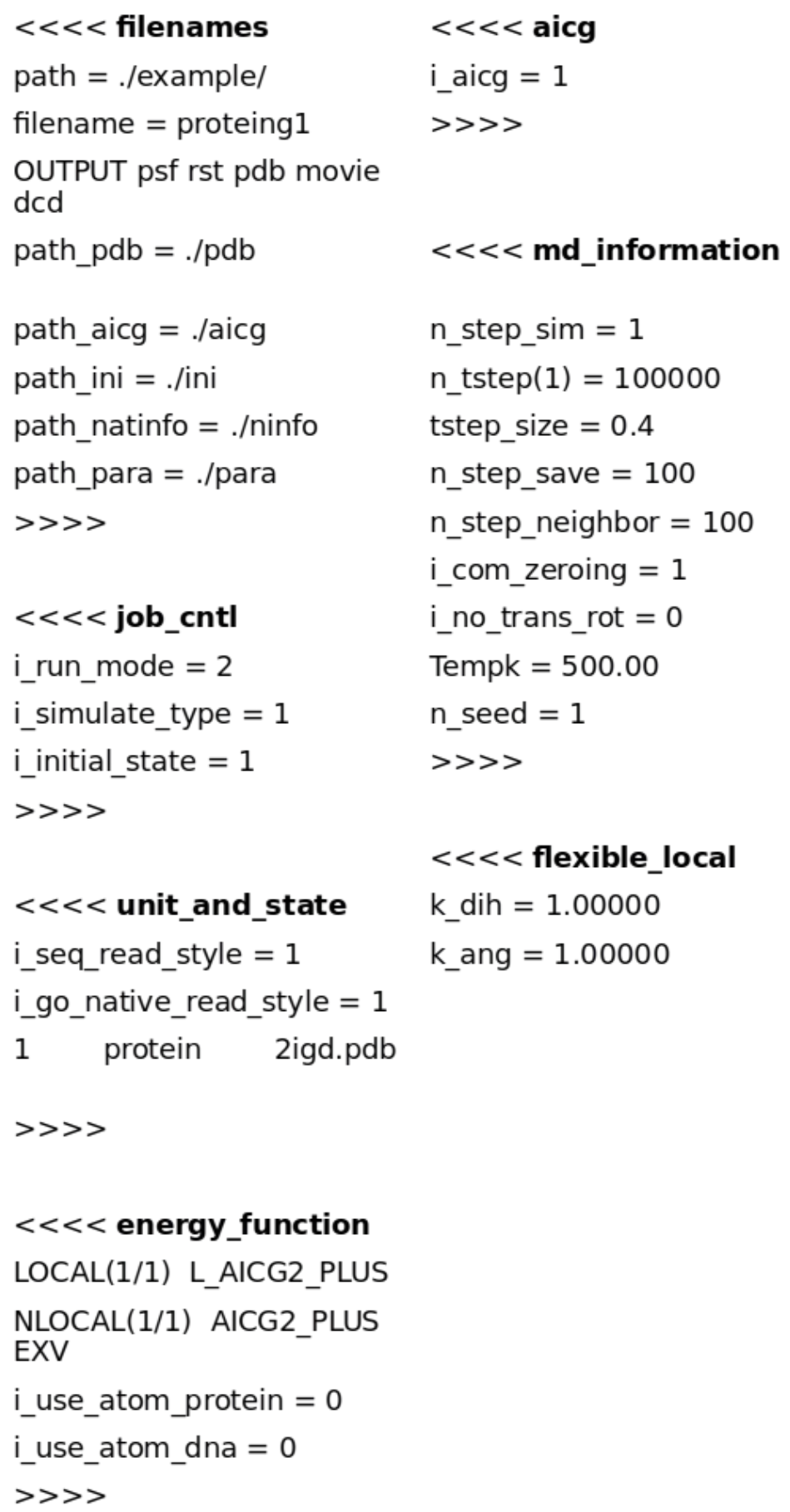


ANEXO 2: Proteínas selecionadas.

\begin{tabular}{|c|c|c|c|c|}
\hline Proteina-Quinase & Cod. UNIPROT & Nome da proteina & Sequencia $+/-7$ & Pos. P0 \\
\hline \multicolumn{5}{|l|}{ PKA } \\
\hline & P63104 & $14-3-3$ eta & VVGARRSsWRVISSI & 58 \\
\hline & P48729 & CK1 & KISEKKMsTPVEVLC & 242 \\
\hline & P24385 & CCND1 & NYLDRFLsLEPVKKS & 90 \\
\hline & P24385 & CCND1 & ATDVKFIsNPPSMVA & 197 \\
\hline & $\mathrm{P} 24385$ & CCND1 & YRLTRFLsRVIKCDP & 234 \\
\hline & P19429 & TNNI3 & EPHAKKKsKISASRK & 39 \\
\hline & P11831 & SRF & DNKLRRYtTFSKRKT & 159 \\
\hline & P26678 & PLN & RSAIRRAstIEMPQQ & 16 \\
\hline \multicolumn{5}{|l|}{ PKCB } \\
\hline & P04083 & ANXA1 & yVQtVksskGGPGsA & 28 \\
\hline & P15336 & ATF-2 & tPQtQSTsGRRRRAA & 340 \\
\hline & P15336 & ATF-2 & ERNRAAAsRCRQKRk & 367 \\
\hline & P28329-3 & CHAT iso 3 & TVLVKDStNRDSLDM & 255 \\
\hline & P28329-3 & CHAT iso 3 & LLKHVTQssRKLIRA & 346 \\
\hline & P28329-3 & CHAT iso 3 & LKHVTQssRKLIRAD & 347 \\
\hline & P28329-3 & CHAT iso 3 & VPTYESAsIRRFQEG & 440 \\
\hline & P28329-3 & CHAT iso 3 & HKAAVPAsEKLLLLK & 476 \\
\hline & P11167 & GLUT1 & NEENRAKsVLKKLRG & 226 \\
\hline & P22449 & HNF4 alpha & CKGFFRRsVRKNHMY & 87 \\
\hline & Q16625 & occludin & RLKQVKGsADYKSKK & 490 \\
\hline & P48736 & PIK3CG & LWHFRYEsLKHPKAY & 582 \\
\hline & P31044 & RKIP & RGkFkVEsFRKKYHL & 153 \\
\hline & P29353 & SHC 1 & EEWTRHGsFVNKPtR & 139 \\
\hline & P29353 & SHC 1 & VPGAkGAtRRRKPCs & 206 \\
\hline & P29353 & SHC 1 & tRRRKPCsRPLSSIL & 213 \\
\hline & P60881 & SNAP-25 & RIMEkADsNkTRIDE & 187 \\
\hline & P11473 & VDR & CKGFFRRsMKRKALF & 51 \\
\hline \multicolumn{5}{|l|}{ PKCA } \\
\hline & Q62622 & 4E-BP1 & FLMECRNsPVAKtPP & 64 \\
\hline & Q9WVE0 & AID & MDsLLMKQKK & 3 \\
\hline & Q9WVE0 & AID & GVQIGIMtFKDYFYC & 140 \\
\hline & P04083 & ANX1 & EyVQtVksskGGPGs & 27 \\
\hline
\end{tabular}




$\begin{array}{cc}\text { P04083 } & \text { ANX1 } \\ \text { P46193 } & \text { ANXA1 } \\ \text { P46193 } & \text { ANXA1 } \\ \text { P07355 } & \text { ANXA2 } \\ \text { P07355 } & \text { ANXA2 } \\ \text { AAB24204 } & \text { ANXA5 iso2 } \\ \text { AAB24205 } & \text { ANXA5 iso3 } \\ \text { P29972 } & \text { AQP1 } \\ \text { P55087 } & \text { AQP4 } \\ \text { P55088 } & \text { AQP4 } \\ \text { P10275 } & \text { AR } \\ \text { P14568 } & \text { ASS1 } \\ \text { P53004 } & \text { BVR } \\ \text { P53004 } & \text { BVR } \\ \text { P11275 } & \text { CAMK2A } \\ \text { P01730 } & \text { CD4 } \\ \text { P01730 } & \text { CD4 } \\ \text { P13863 } & \text { CDK1 } \\ \text { O75689 } & \text { CENTA1 } \\ \text { O75689 } & \text { CENTA1 } \\ \text { P28329-3 } & \text { CHAT iso 3 } \\ \text { P28329-3 } & \text { CHAT iso 3 } \\ \text { P28329-3 } & \text { CHAT iso 3 } \\ \text { P28329-3 } & \text { CHAT iso 3 } \\ \text { P28329-3 } & \text { CHAT iso 3 } \\ \text { P23528 } & \text { Cofilin-1 } \\ \text { P23528 } & \text { Cofilin-1 } \\ \text { P17812 } & \text { CTPS } \\ \text { P17812 } & \text { CTPS } \\ \text { P08684 } & \text { CYP3A4 } \\ \text { P08684 } & \text { CYP3A4 } \\ \text { P08684 } & \text { CYP3A4 } \\ \text { P08684 } & \text { CYP3A4 } \\ \text { P08684 } & \text { CYP3A4 } \\ \text { P08684 } & \text { CYP3A4 }\end{array}$

yVQtVksskGGPGsA

EEQEYIKtVKGsKGG

YIKtVKGsKGGPGSA

HEILCkLsLEGDHs

tPPsAyGsVkAytNF

DERADAEtLRKAMKG

DERADAEtLRKAMKG

VLCVLATtDRRRRDL

TIFASCDsKRTDVTG

TIFASCDSKRTDVTG

YGALTCGsCKVFFKR

VYTGFWHsPECEFVR

GKDLLkGsLLFTAGP

LKRNRyLsFHFksGs

sCMHRQEtVDCLkkF

RRQAERMsQIkRLLs

sQIkRLLsEKKTCQC

YDPAKRIsGKMALNH

AARARFESKVPSFYY

GFRkRWFtMDDRRLM

TVLVKDStNRDSLDM

LLKHVTQssRKLIRA

LKHVTQssRKLIRAD

VPTYESAsIRRFQEG

HKAAVPAsEKLLLLK

NDMkVRksstPEEVk

DMkVRksstPEEVkk

MRLGKRRtLFQTkNs

tLFQTkNsVMRkLYG

TDPDMIKtVLVKECY

VLVKECYsVFtNRRP

KECYsVFtNRRPFGP

GPVGFMksAIsIAED

GFMksAIsIAEDEEW

EEWkRLRsLLsPtFT
24

12

26

22

157

180

180

579

149

224 


CYP3A4
CYP3A4
CYP3A4
CYP3A4
CYP3A4
CYP3A4
CYP3A4
CYP3A4
DDX58
DDX58
EAR-2
EGFR
ER-alpha
EZR
GIRK1
GIRK4
GluR2
GluR2
GSTA4
GSTP1
HES1
HES1
HNF4 alpha
HuR
INSR
INSR
IREB1
IREB1
IREB1
IREB1
KCNE1
KCNE3
Kv-beta2
NR1I3
p47phox

kRLRsLLsPtFTsGK LrsLLsPtFTsGKLK

LLsPtFTsGKLKEMV

SVKRMKESRLEDtQK

KEsRLEDtQKHRVDF

DSQNSkEtESHKALS

GVVVMIPSYALHRDP

kFLPERFsKKNKDNI

MTTEQRRsLQAFQDY

DkENWPktLkLALEK

CKSFFKRsIRRNLsY

RHIVRKRtLRRLLQE

CKAFFKRsIQGHNDY

QGRDKyKtLRQIRQG

GCMFIKMsQPKKRAE

GCMFVKIsQPKKRAE

IESAEDLsKQTEIAY

KMWTYMRSAEPSVFV

VKLsNIPtIKRFLEP

SAYVGRLsARPkLkA

TAsEHRKssKPIMEK

AsEHRKssKPIMEKR

CKGFFRRsVRKNHMY

FIRFDKRsEAEEAIT

AVkTVNEsAsLRERI

kTVNEsAsLRERIEF

DFNRRADsLQkNQDL

REFNSYGsRrGNDAV

HFNRRADsLQkNQDL

REFNSYGSRRGNDAI

FQARVLEsFRACYVI

LILGYTRsRKVDKRS

IPPYSRAsLkGYQWL

CKGFFRRtVSKSIGP

RGAPPRRssIRNAHs
134

136

259

264

284

398

420

8

170

83

30

216

567

185

191

661

697

193

185

38

87

158

103

105

138

711

138

711

103

82

266

38 
P14598

P14598

P14598

P14598

P14598

P14598

P14598

O15350

P53811

P53811

P53812

O00168

O00168

O08589

O08589

O08589

P56513

P56513

P56513

P06766

P06766

Q07869

P37230

P37230

P37230

Q15139

Q15139

Q62101

Q9BZL6

Q9BZL6

O94806

P02584

Q05209

O75469

Q15311 p47phox

p47phox

p47phox

p47phox

p47phox

p47phox

p47phox

p73

PITPNB

PITPNB

PITPNB

PLM

PLM

PLM

PLM

PLM

PLM

PLM

PLM

POLB

POLB

PPAR-alpha

PPAR-alpha

PPAR-alpha

PPAR-alpha

PRKD1

PRKD

PRKD1

PRKD2

PRKD2

PRKD

Profilin 1

PTP-PEST

PXR

RALBP1
GAPPRRssIRNAHsI

AHsIHQRsRKRLsQD

QRsRKRLsQDAYRRN

QDAYRRNsVRFLQQR

EERQtQRsKPQPAVP

PAVPPRPsADLILNR

DLILNRCsEstKRKL

VPQPLVDsYRQQQQL

EDPALFHsVKTKRGP

ETMRKKGsVRGTsAA

ETMRKKGsVRGTSAA

EEGtFRssIRRLstR

RssIRRLstRRR

EEGtFRSsIRRLstR

RSsIRRLstRR

SsIRRLstRRR

EEGTFRSsIRRLstR

RSsIRRLstRR

SsIRRLstRRR

NAYRKAAsVIAKyPH

KyPHKIKsGAEAKKL

VKARVILsGKASNNP

CKGFFRRtIRLKLAY

AYDKCDRsCKIQKKN

RFGRMPRsEKAKLKA

ARIIGEksFRRsVVG

GEksFRRsVVGtPAy

ARIIGEksFRRsVVG

ARIIGEksFRRsVVG

GEksFRRsVVGtPAy

ARIIGEksFRRsVVG

FMRLRRL stKYRTEK

RSINAQHtQRLLRIQ

VFKKPsFsKKKEKD
304

379

388

262 
Q15311

Q15311

O15539

O15539

P02699

P02699

P02699

P02699

P02699

P52565

Q99PT1

P52566

P30086

P31044

P31645

P31645

P31645

P11831

P11831

P61765

P61765

P36897

P19429

P19429

P19429

P19429

P19429

P48787

P23693

P08057

P08057

P39429

Q9JIS4

O35433

O35433
RALBP1

RALBP1

RGS5

RGS5

Rhodopsin

Rhodopsin

Rhodopsin

Rhodopsin

Rhodopsin

RhoGDI alpha

RhoGDI alpha

RhoGDI beta

RKIP

RKIP

SERT

SERT

SERT

SRF

STXBP1

STXBP2

TGFBR1

TNNI3

TNNI3

TNNI

TNNI3

TNNI3

TNNI

TNNI3

TNNI3

TNNI3

TRAF2

TREK-2

TRPV1

TRPV
ACGRTTEtEKVQEFQ 297

LSPTVQISNRVLYVF 353

SFKSFLKsEFSEENL

HALMEKDSLPRFVRS 166

PLGDDEAsttVsKtE $\quad 334$

LGDDEAsttVsKtEt $\quad 335$

GDDEAsttVsKtEts $\quad 336$

DEAsttVsKtEtsQV 338

tVsKtEtsQVAPA

DLTGDLEsFKkQsFV 96

DLTGDLEsFKkQsFV 96

ykPPPQksLkELQEM

RGKFKVAsFRKKYEL 153

RGkFkVEsFRKKYHL 153

yHRNGCIsIWRKICP

IWKGVKtsGKVVWVT 277

RLIITPGtFKERIIK 603

DNKLRRYtTFsKRKT

LRRYtTFsKRKTGIM $\quad 162$

VSQEVTRsLkDFSSs 306

sLkDFSSsKRMNTGE $\quad 313$

LPLLVQRTIARtIVL 200

PAPIRRRssNyRAyA

APIRRRssNyRAyAt

AKKKskIsAsRKLQL 42

KKskIsAsRKLQLKt 44

RGKFKRPtLRRVRIs 143

AkKKSKIsAsRKLQL 43

AKKKSKIsAsRKLQL

AKKKSKIsAsRKLQL $\quad 44$

KKSKIsAsRKLQLKT $\quad 46$

DGCTWKGtLKEYESC

GDWLRVLSKKTKEEV 326

QRSKKRLtDSEFKDP 144

YFLQRRPSLKSLFVD 502 
O35433

Q9BQE3

Q9BQE3

P10599

P12003

P12003
TRPV

TUBA1C

TUBA1C

TXN

Vincuin

Vincuin
WKLQRAItILDTEKS

sLLMERLsVDyGkks

sVDyGkkskLEFSIy

NkEkLEAtINELV

NAQNLMQSVKETVRE

VREAEAAsIKIRTDA
704

158

100

1102

1114 